INEEL/EXT-99-00095

January 1999

\title{
DIII-D Dust Particulate Characterization (June 1998 Vent)
}

William J. Carmack

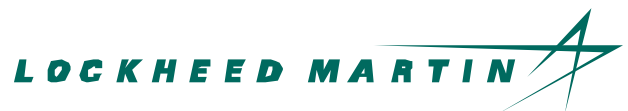




\title{
DIII-D Dust Particulate Characterization
}

\section{(June 1998 Vent)}

\author{
William J. Carmack
}

Published January 1999

Idaho National Engineering and Environmental Laboratory

Nuclear Engineering Technologies Department

Fusion Safety Program

Lockheed Martin Idaho Technologies Company

Idaho Falls, Idaho 83415

Prepared for the

U.S. Department of Energy

Office of Energy Research Office of Fusion Energy Sciences

Under DOE Idaho Operations Office

Contract DE-AC07-94ID13223 


\section{Signatures and Approvals}

\begin{tabular}{c} 
Author: \\
\hline William J. Carmack \\
Review: \\
\hline
\end{tabular}

David A. Petti 


\section{SUMMARY}

Dust is a key component of fusion power device accident source term. Understanding the amount of dust expected in fusion power devices and its physical and chemical characteristics is needed to verify assumptions currently used in safety analyses. An important part of this safety research and development work is to characterize dust from existing experimental tokamaks. In this report, we present the collection, data analysis methods used, and the characterization of dust particulate collected from various locations inside the General Atomics DIII-D vacuum vessel following the June 1998 vent. DIII-D is located in San Diego, California. The collected particulate was analyzed at the Idaho National Engineering and Environmental Laboratory (INEEL).

Two methods were used to collect particulate with the goal of preserving the particle size distribution and physical characteristics of the particulate. Choice of collection technique is important because the sampling method used can bias the particle size distribution collected. Vacuum collection on substrates and adhesion removal with metallurgical replicating tape were chosen as non-intrusive sampling methods. Sampling was completed in four areas of the machine; 0 to $90^{\circ}$ area, the $90^{\circ}$ to $180^{\circ}$ area, the $180^{\circ}$ to $270^{\circ}$ area, and the $270^{\circ}$ to $360^{\circ}$ area. The $0^{\circ}$ direction designates the north side of the DIII-D machine. Seventeen samples were collected including plasma facing surfaces in lower, upper, and horizontal locations, surfaces behind floor tiles, surfaces behind divertor tiles, and surfaces behind ceiling tiles. The results of the analysis are listed below.

- Our Brunauer, Emmett, and Teller (BET) specific surface area analysis results are based upon three measurements of a sample combined from approximately $75 \%$ of the filter housing samples. The samples were combined to yield a detectable surface area of dust. The combined sample had an average specific surface area of $3.18 \mathrm{~m}^{2} / \mathrm{gram}$ from a total sample weight of 0.11 grams. This value is very similar to the value obtained in the 1996 DIII-D dust campaign and is a factor of 2 greater than that for theoretically dense graphite spheres. This indicates that as previously observed, the particulate is not spherical and is composed of agglomerates of smaller particles.

- The particle size distribution analysis results of dust taken from inside the vacuum vessel show a range of count median diameter (CMD) values ranging between $0.81 \mu \mathrm{m}$ and 2.89 $\mu \mathrm{m}$ with a range of geometric standard deviation (GSD) values between 1.33 and $3.43 . \mathrm{D}_{\mathrm{MVs}}$ values ranged between 1.1 and $13.3 \mu \mathrm{m}$. The mass median diameter (MMD) of the particulate was determined from the cascade impactor data. The MMD's were $7.25 \mu \mathrm{m}$ with a GSD of 1.4 and $5.44 \mu \mathrm{m}$ with a GSD of 2.2. The observed particles appeared in the form of both flakes and spheres. Compositional analysis by scanning electron microscopy/energy dispersive spectroscopy (SEM/EDS) showed individual dust composed of molybdenum, iron, boron, and aluminum. Overall chemical analysis by inductively coupled mass spectroscopy (ICP-MS) of the cascade impactor samples and the combined filter housing sample used for BET analysis resulted in a wide variety of material.

- Elemental analysis of the dust indicates that the dust is primarily carbon (30 wt $\%)$ with significant quantities of metal (45 wt\%) (primarily iron/nickel based alloys). Insulator materials were found in the dust throughout the machine as well as smaller quantities of various elements that are contained in instrumentation and diagnostic components.

- The bulk of the material analyzed was found in lower protected regions of the vacuum vessel. Most of the dust was found under the floor tiles and inside the access ports. Dust 
concentrations in these locations were between 10 and $100 \mu \mathrm{g} / \mathrm{cm}^{2}$. The smallest quantities of dust were found in the upper vertical locations of the vacuum vessel and on plasma facing surfaces. Dust concentrations in these locations were between 0.01 to $1 \mu \mathrm{g} / \mathrm{cm}^{2}$. Using these dust concentrations and integrating around the vacuum vessel in the general areas sampled, the total quantity of dust that may be present in the vacuum vessel could be as low as 30 grams and as high as 90 to 120 grams. 


\section{Acknowledgment}

Prepared for the U.S. Department of Energy, Office of Fusion Energy, DOE Idaho Operations Office, under Contract DE-AC07-76ID01570 by Lockheed Martin Idaho

Technologies Co. at the Idaho National Engineering and Environmental Laboratory.

This work would not have been possible without the help and cooperation of many General Atomics DIII-D personnel especially, Arnold Kellman and Clement Wong.

The following individuals provided analyses in support of this work: Byron White, John Jolley, John Wey, Robert Pawelko, and Mike Hankins. 


\section{Table of Contents}

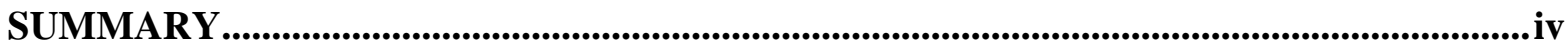

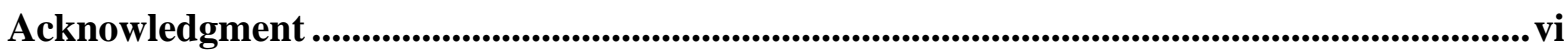

Table of Contents.........................................................................................................................................................vii

Table of Figures .............................................................................................................................................viii

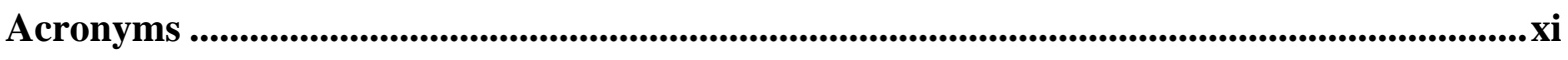

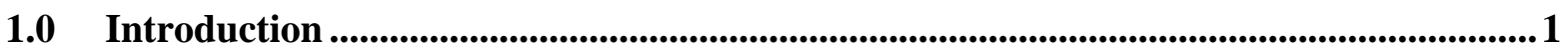

2.0 Particle Collection Description and Methods ..........................................................................2

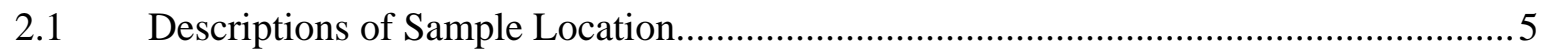

2.1.1 Beneath Lower Horizontal Surfaces ................................................................... 5

2.1.2 Beneath Upper Horizontal Surfaces............................................................. 8

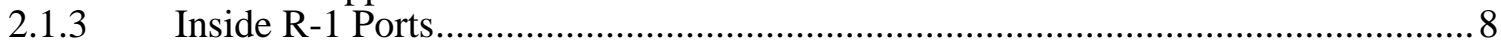

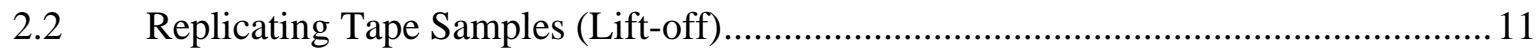

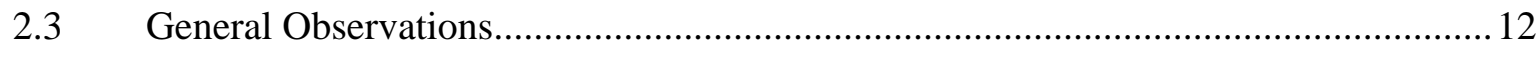

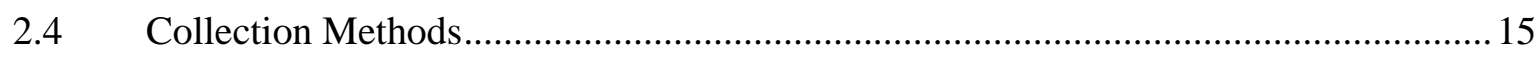

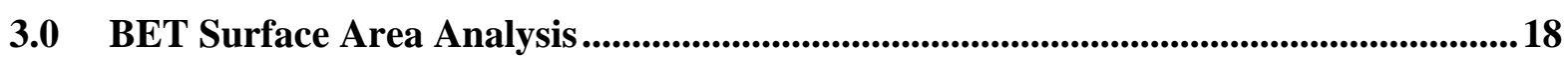

4.0 CP-MS and ESEM/EDS Composition Analysis.................................................................20

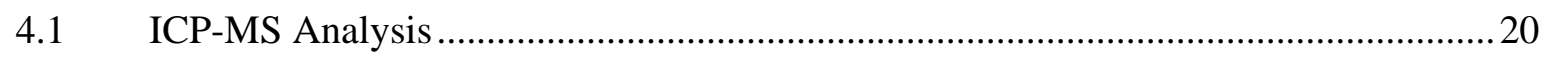

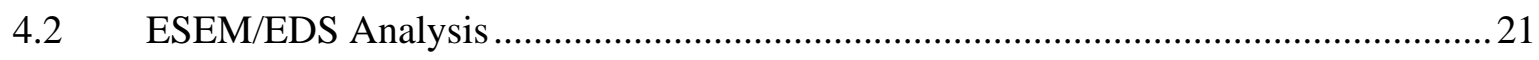

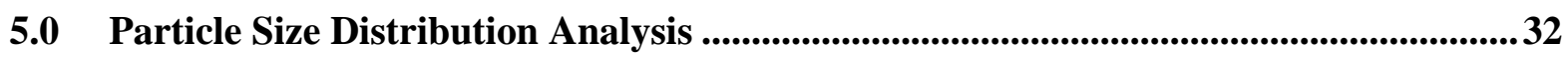

$5.1 \quad$ Optical Particle Size Analysis Methodology …....................................................... 32

5.2 Particle Size Distribution Measurement Results from Vacuum Total Filter Samples.33

5.3 Particle Size Analysis using a Coulter LS130 Laser Particle Sizer...........................51

5.4 Particle Size Distribution Measurement Results from Cascade Impactor Measurements 52

5.4.1 Method of Cascade Impactor Sampling ........................................................53

5.4.2 Results of Cascade Impactor Sampling …......................................................5

5.5 Spherical Particle Size Distribution Analysis Results ............................................56

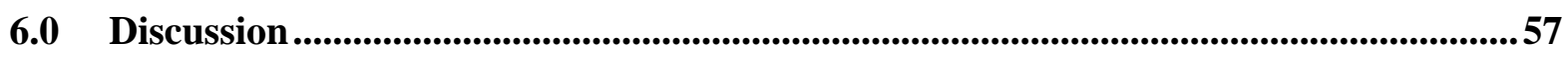

6.1 Comparison with Previous DIII-D Collection (1996 Vent) ......................................57

6.2 Comparison with other Tokamak Dusts ...............................................................5 57

6.3 Comparison with Simulated Disruption Dust (SIRENS) ..........................................58

6.4 Estimate of Total Dust Content of the DIII-D Vacuum Vessel.................................60

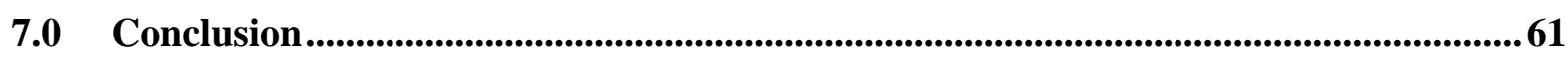

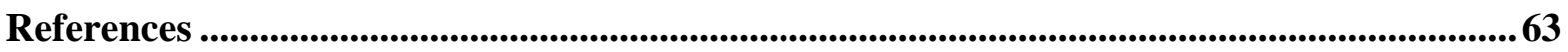




\section{Table of Figures}

Figure 2.1. Photograph of DIII-D showing the general areas of tile removal. Note that this photo does not show the new upper divertor structure that is now in place. (Actually we removed the Lower $45^{\circ}$ and Row 1, 2, and 3 tiles (as shown in

Figure 2.4.)....

Figure 2.2. Cross-sectional schematic of the upper divertor section of DIII-D. This shows the new upper divertor structure. Only the $45^{\circ}$ and Row 1 tiles will be removed (As Marked). (4 tiles) 3

Figure 2.3. Lower Baffle Plate. The entire assembly is removable. (8 tiles)........................... 4

Figure 2.4. Photograph of the DIII-D floor showing key items of interest including the

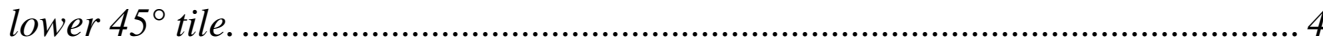

Figure 2.5. Photograph of the lower baffle with the $337-345^{\circ}$ tiles removed. ...................... 6

Figure 2.6. Close-up photograph of area behind the lower $45^{\circ}$ and Row $145-55^{\circ}$ floor

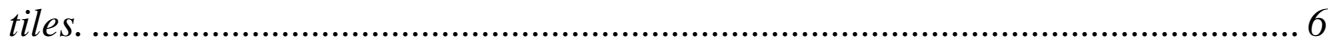

Figure 2.7. Close-up photograph of area behind the lower $45^{\circ}$ and Row $1135-145^{\circ}$ floor

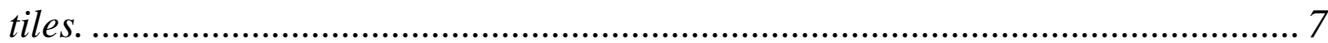

Figure 2.8. Close-up photograph of area behind the lower $45^{\circ}$ and Row $1,225-235^{\circ}$ floor

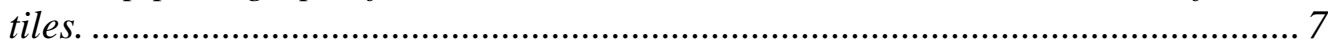

Figure 2.9. Photograph of area behind the Lower $45^{\circ}$ and Row 1 and 2, 337 $-345^{\circ}$ floor

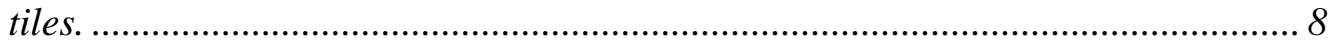

Figure 2.10. Photograph of area behind the $337-345^{\circ}$ Upper $45^{\circ}$ and Row 1 ceiling tiles...... 9

Figure 2.11. Photograph of the $0-90^{\circ} \mathrm{R}-1$ access ports................................................... 9

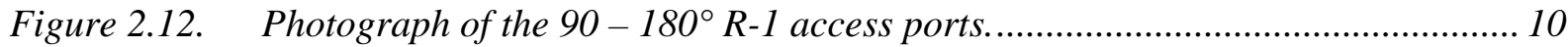

Figure 2.13. Broken glass found in the a $90-180^{\circ}$ port...................................................... 10

Figure 2.14. Photograph of the replicating tape samples on the $95^{\circ}$ Lower $45^{\circ}$ tile............... 11

Figure 2.15. Photograph of the replicating tape samples inside the $135^{\circ} \mathrm{R}-1$ port.................. 12

Figure 2.16. Photograph of DIII-D floor tiles. (Photograph courtesy of DIII-D personnel).... 13

Figure 2.17. Photograph of DIII-D ceiling tiles. (Photograph courtesy of DIII-D personnel) 14

Figure 2.18. Photograph showing dust collected on the surfaces of a penetration port.......... 14

Figure 2.19. Graph of the toroidal mass distribution of dust around the DIII-D machine...... 17

Figure 4.1. Photomicrograph showing the porosity of the FH5 filter substrate.................... 22

Figure 4.2. Photomicrograph of FH5 sample at 1000X showing a variety of materials........ 23

Figure 4.3. Photomicrograph of FH5 sample showing a high magnification image of a sub-

micron spherical particle ............................................................................... 23

Figure 4.4. Photomicrograph of a sub-micron spherical particle found in the FH5 sample... 24

Figure 4.5. Photomicrograph of an aluminum and oxygen particle found in the FH7

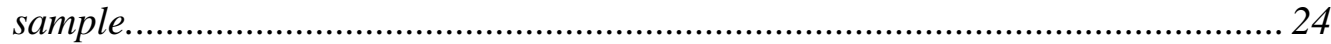

Figure 4.6. Photomicrograph of particulate found in the FH7 sample ................................ 25

Figure 4.7. Photomicrograph of particulate found in the FH7 sample including spherical

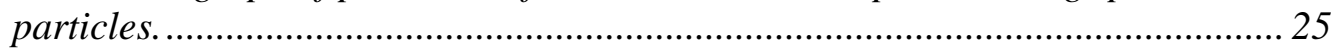

Figure 4.8. Photomicrograph of particulate found in the FH7 sample including a larger

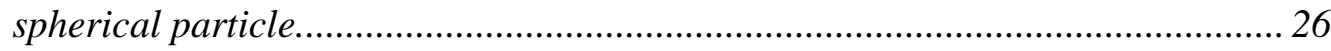

Figure 4.9. Photomicrograph of particulate found in the FH7 sample including a submicron spherical particle. 
Figure 4.10. Photomicrograph of particulate found in the FH9 sample including a spherical particle.

Figure 4.11. Photomicrograph of carbon, steel, and spherical carbon particles in sample

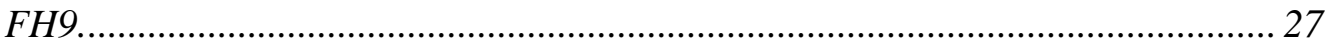

Figure 4.12. High magnification photomicrograph of the $\mathrm{Fe}, \mathrm{Ni}$, Cr particle shown in

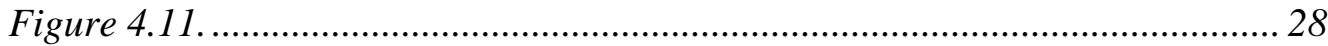

Figure 4.13. Photomicrograph of a spherical carbon particle found in sample FH9............. 28

Figure 4.14. Photomicrograph of a 2 micron particle found in sample FH9........................ 29

Figure 4.15. Photomicrograph showing compositions of particles found in FH12................ 29

Figure 4.16. Photomicrograph of particles found in FH12 at 5000 X................................. 30

Figure 4.17. Photomicrograph of particles found in FH12 at 10000 X magnification............. 30

Figure 4.18. Photomicrograph of particles found in FH12 at 12000 X magnification............. 31

Figure 4.19. Photomicrograph of particles found in FH12 at 20000 X magnification............ 31

Figure 5.1. Flow chart schematic of particle size distribution construction........................... 32

Figure 5.2. $\quad$ Photograph of DIII-D filter housing sample FH7 at 1000x magnification........... 36

Figure 5.3. Photograph of DIII-D sample 14 at 500x magnification...................................... 36

Figure 5.4. Photograph of DIII-D filter housing sample 15 at 200x magnification................ 37

Figure 5.5. Photograph of DIII-D sample FH7 at 100x magnification. .................................. 37

Figure 5.6. Photograph of DIII-D filter housing sample 5 at 50x magnification.................... 38

Figure 5.7. Cumulative log probability distribution generated with $95 \%$ confidence intervals for DIII-D FHI............................................................................. 39

Figure 5.8. Cumulative log probability distribution generated with $95 \%$ confidence intervals for DIII-D FH2................................................................................ 39

Figure 5.9. Cumulative log probability distribution generated with $95 \%$ confidence intervals for DIII-D FH3............................................................................... 40

Figure 5.10. Cumulative log probability distribution generated with $95 \%$ confidence intervals for DIII-D FH4............................................................................ 40

Figure 5.11. Cumulative log probability distribution generated with $95 \%$ confidence intervals for DIII-D FH5............................................................................. 41

Figure 5.12. Cumulative log probability distribution generated with $95 \%$ confidence intervals for DIII-D FH6..................................................................................... 41

Figure 5.13. Cumulative log probability distribution generated with $95 \%$ confidence intervals for DIII-D FH7......................................................................... 42

Figure 5.14. Cumulative log probability distribution generated with $95 \%$ confidence intervals for DIII-D FH8.......................................................................... 42

Figure 5.15. Cumulative log probability distribution generated with $95 \%$ confidence intervals for DIII-D FH9. 43

Figure 5.16. Cumulative log probability distribution generated with $95 \%$ confidence intervals for DIII-D FH10................................................................................. 43

Figure 5.17. Cumulative log probability distribution generated with $95 \%$ confidence intervals for DIII-D FHI1.................................................................................. 44

Figure 5.18. Cumulative log probability distribution generated with $95 \%$ confidence intervals for DIII-D FH12................................................................................. 44

Figure 5.19. Cumulative log probability distribution generated with $95 \%$ confidence intervals for DIII-D 13. 45 
Figure 5.20. Cumulative log probability distribution generated with $95 \%$ confidence intervals for DIII-D 14................................................................................. 45

Figure 5.21. Cumulative log probability distribution generated with $95 \%$ confidence intervals for DIII-D 15.............................................................................. 46

Figure 5.22. Cumulative log probability distribution generated with $95 \%$ confidence intervals for DIII-D 16. ............................................................................... 46

Figure 5.23. Cumulative log probability distribution generated with $95 \%$ confidence intervals for DIII-D 17.............................................................................. 47

Figure 5.24. Cumulative log probability distribution generated with $95 \%$ confidence intervals for DIII-D RT1............................................................................ 47

Figure 5.25. Cumulative log probability distribution generated with $95 \%$ confidence intervals for DIII-D RT2 .............................................................................. 48

Figure 5.26. Cumulative log probability distribution generated with $95 \%$ confidence intervals for DIII-D RT3..... 48

Figure 5.27. Plot of CMD with associated 95\% confidence intervals................................... 50

Figure 5.28. Plot of distribution GSD with associated 95\% confidence intervals................... 50

Figure 5.29. Differential volume percent verses particle size as determined by Coulter LS130 analysis................................................................................................... 51

Figure 5.30. Cumulative volume percent verses log $\left(D_{v}\right)$ on a log-normal plot for $R T 1, R T 2$,

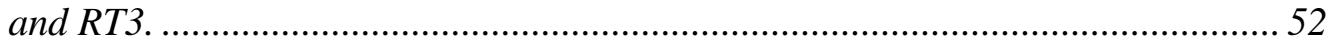

Figure 5.31. Cumulative percent distribution for the four cascade impactor samples. ............ 54

Figure 5.32. Cumulative percent size distribution for spherical particles. .............................. 56

Figure 6.1. Graph of the BET Specific Surface area plotted verses the mean surface-volume diameter for a variety of materials, previous measurements, and the current $C$ MOD measurement........................................................................................ 58

Figure 6.2. Photomicrograph of SIRENS ATJ graphite test (S764, button 3) (5000X

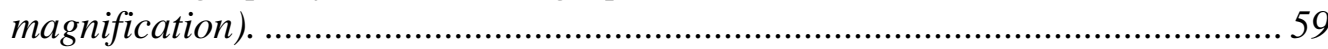

Figure 6.3. Plot of various dust characterization analyses and SIRENS tests results............ 59 


\section{Acronyms}

\begin{tabular}{|c|c|}
\hline ASAP & accelerated surface area and porosimetry system \\
\hline BET & Brunauer, Emmett, and Teller method of specific surface area measurement \\
\hline BLH & beneath lower horizontal tiles \\
\hline BUH & behind upper horizontal tiles \\
\hline $\mathrm{CDF}$ & cumulative distribution function \\
\hline CMD & count median diameter \\
\hline CMOD & tokamak experiment located at Massachusetts Institute of Technology \\
\hline DIII-D & $\begin{array}{l}\text { tokamak experiment located at and operated by General Atomics in San Diego, } \\
\text { California }\end{array}$ \\
\hline $\mathrm{D}_{\mathrm{MVS}}$ & mean volume-surface diameter \\
\hline DOE & Department of Energy \\
\hline EDF & engineering design file \\
\hline EDX & energy dispersive $\mathrm{x}$-ray spectroscopy \\
\hline ESEM & environmental scanning electron microscopy \\
\hline GSD & geometric standard deviation \\
\hline ICP-MS & inductively coupled mass spectrometry \\
\hline INEEL & Idaho National Engineering and Environmental Laboratory \\
\hline ITER & International Thermonuclear Experimental Reactor \\
\hline LPFS & lower plasma facing surface \\
\hline MMD & mass median diameter \\
\hline NCSU & North Carolina State University \\
\hline NSSR-2 & Non-Site Specific Safety Report-2 \\
\hline PPPL & Princeton Plasma Physics Laboratory \\
\hline $\mathrm{R}-1$ & inside $\mathrm{R}-1$ ports \\
\hline RT & replicating tape samples \\
\hline SEM & scanning electron microscopy \\
\hline SIRENS & surface interaction research experiments at North Carolina State University \\
\hline TFTR & Tokamak Fusion Test Reactor \\
\hline UPFS & upper plasma facing surface \\
\hline
\end{tabular}




\subsection{Introduction}

Particulate is formed during operation of fusion machines by three mechanisms: erosion of loosely attached vapor deposited material from surfaces, erosion of structural and plasma facing materials during plasma-wall interactions, and direct nucleation and growth of particles following vaporization of material during a plasma-wall interaction.

On August 3 and 4, 1998 the DIII-D vacuum vessel was accessed by the operations personnel for dust sampling and other maintenance activities inside the vessel. Prior to sampling, concern was raised by the operations personnel that a significant quantity of dust was found on the colder surfaces of the machine. Dust was visible in many of the instrument and access ports. The composition of the dust was not known and it was possible that the dust contained significant quantities of beryllium. Thus, as a precaution, respirators were required for subsequent work inside the vacuum vessel due to the potential for resuspension of the dust during the dust sampling activities.

Following the dust sampling, the vessel was cleaned prior to maintenance activities in the vacuum vessel. Subsequent analysis indicated that the dust contained no beryllium and was primarily an iron/nickel based alloy.

This sampling effort represents the second sampling of dust from the DIII-D vacuum vessel. There were three goals associated with this sample collection effort. First, comparison with the sampling effort of 1996 was desired, including tracking of sampled surface area as well as documentation of specific sample locations. Larger surface areas were also sampled. Secondly, the deposition concentration and distribution across the machine was desired and finally, the results of this analysis are used to estimate the total amount of dust present in the DIII-D vacuum vessel.

This report presents the sample descriptions and collection methods in Section 2.0. Section 3.0 details the specific surface area analysis completed on the dust and compositional analysis of the dust is presented in Section 4.0. The particle size

distribution analysis is presented in Section 5.0. Section 6.0 includes a discussion of the results of this analysis, comparison with previous DIII-D particle characterization as well as with other tokamak dusts and plasma disruption experiment results obtained from North Carolina State University's SIRENS carbon tests. Also an estimate of the total particulate mass found in the DIII-D vacuum vessel is presented. Conclusions are found in Section 7.0. 


\subsection{Particle Collection Description and Methods}

Figure 2.1 shows a photograph of the inside of the DIII-D vacuum vessel. We were able to sample a variety of locations including: upper plasma facing surfaces, upper locations protected from the plasma, lower plasma facing surfaces, lower protected locations, and inside the R-1 instrumentation ports. Upper plasma facing surfaces included the upper ceiling portions of the first wall. Upper protected surfaces are represented by surfaces located behind ceiling tiles. Lower sample positions were from the outer baffle and the floor tiles. The R-1 instrumentation ports are located on the outer wall of the vessel just below the horizontal mid-plane of the machine.

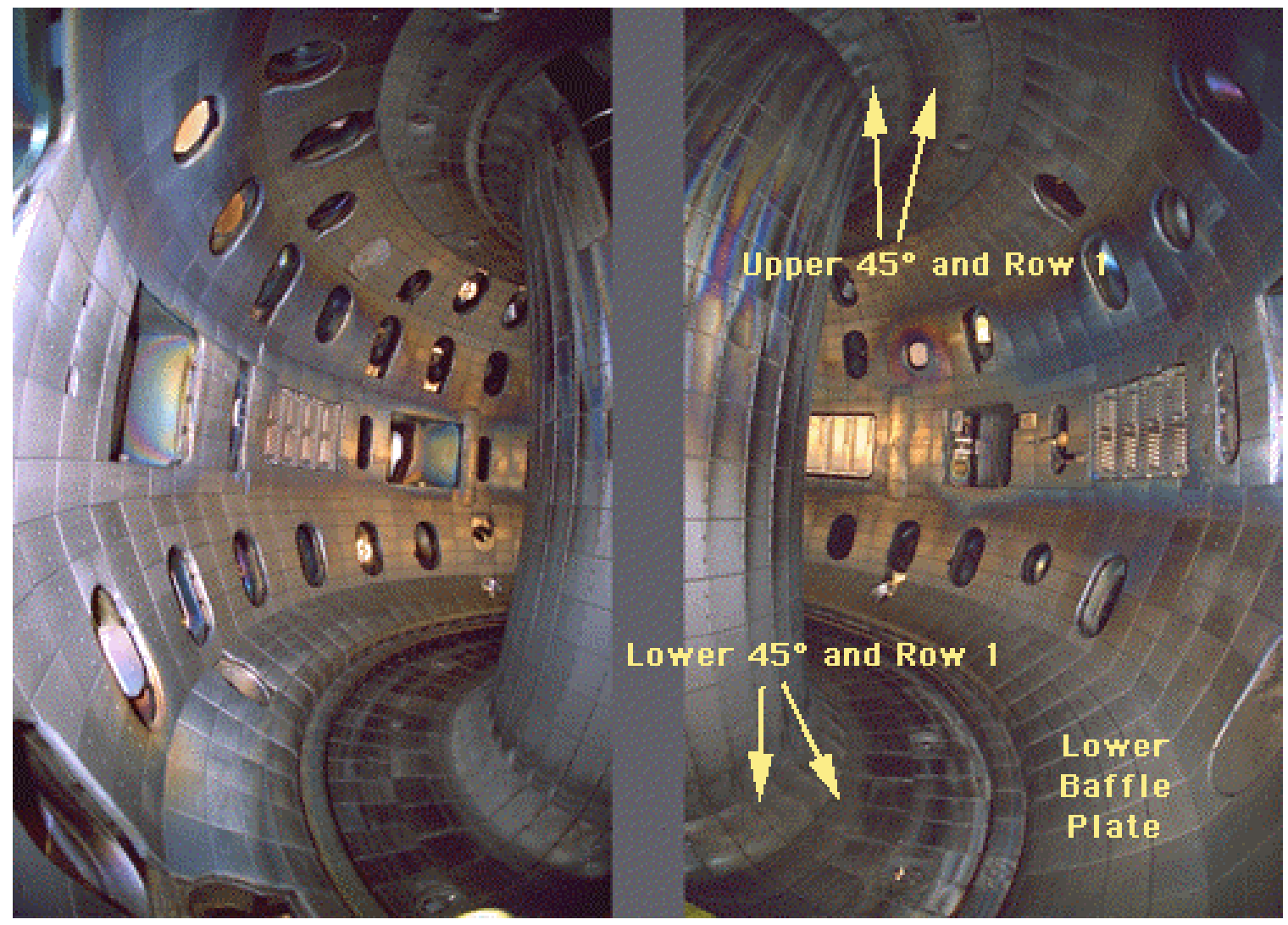

Figure 2.1. Photograph of DIII-D showing the general areas of tile removal. Note that this photo does not show the new upper divertor structure that is now in place. (Actually we removed the Lower $45^{\circ}$ and Row 1, 2, and 3 tiles (as shown in Figure 2.4.)

We were able to sample in detail in the 337 to $345^{\circ}$ poloidal direction on both the plasma facing surface tiles and underneath the tiles on the lower substructures. The tiles are configured in "banks" and are removed in these banked sections. Figure 2.2 shows a cross-sectional drawing of the upper divertor structure. The $45^{\circ}$ tile and the row 1 tile were removed in the $337-345^{\circ}$ location. Figure 2.3 shows a cross-sectional drawing of the lower baffle assembly. The tiles between 337 and $345^{\circ}$ were removed and the surface underneath vacuumed. Figure 2.4 shows a photograph of the floor of DIII-D including the lower $45^{\circ}$ tile. The tiles removed in the $337-345^{\circ}$ location are indicated in the photograph. In the $45-55^{\circ}$, the $135-145$, and the $225-235^{\circ}$ locations only the lower $45^{\circ}$ 
and the row 1 floor tiles were removed. The lower baffle and the ADP isolated ring are also shown in Figure 2.4.

During the 1996 DIII-D vent we used a system of sample identification by "Quadrants." This was primarily due to unfamiliarity with location identification within the DIII-D vacuum vessel. All references to samples during this (July 1998) vent are by DIII-D toroidal radial location designations. Table 2.1 shows how the previously used "Quadrants" correspond to actual DIII-D radial location designations.

Table 2.1. Previous 1996 vent sample designation correspondence to toroidal position.

\begin{tabular}{|c|c|}
\hline Quadrant & Toroidal Position \\
\hline 1 & $0-90^{\circ}$ \\
\hline 2 & $90-180^{\circ}$ \\
\hline 3 & $180-270^{\circ}$ \\
\hline 4 & $270-360(0)^{\circ}$ \\
\hline
\end{tabular}

For location comparisons, in 1996 lines of floor tiles at the $45^{\circ}, 135^{\circ}, 225^{\circ}$, and $315^{\circ}$ locations were the focus of the sampling effort. Results obtained during the previous 1996 vent dust collection effort will be summarized and compared in Section 6.0 of this report.

Three methods of dust collection were used during this sampling campaign. Vacuuming onto filter substrates having $0.02 \mu \mathrm{m}$ pore size was used as the primary sampling method. Four cascade impactors were used to sample from underneath four areas of the lower $45^{\circ}$ and Row 1 floor tiles. This area tends to have the largest concentration of dust and debris and makes use of cascade impactors feasible. Three liftoff tape samples were also obtained, two on lower $45^{\circ}$ tiles and one sample from inside a R-1 port.

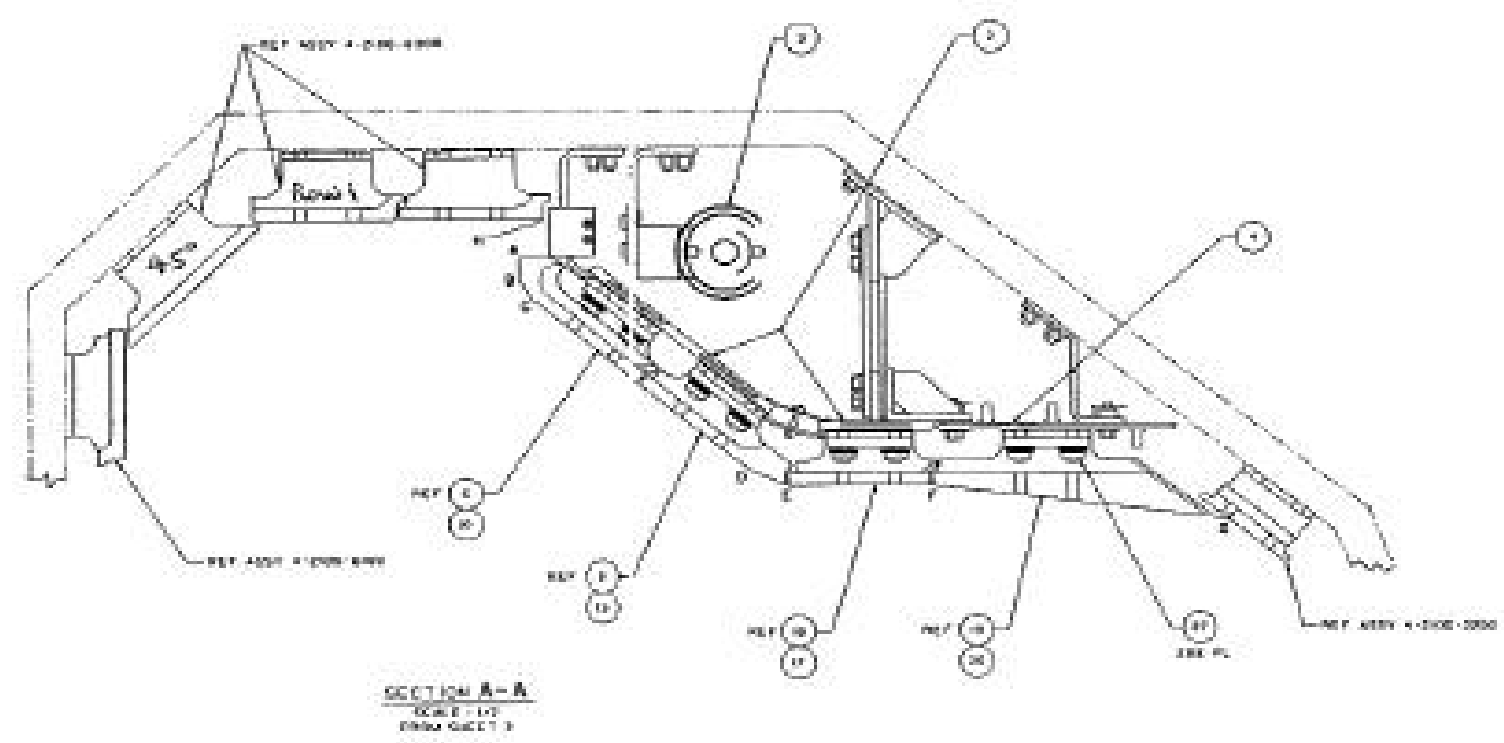

Figure 2.2. Cross-sectional schematic of the upper divertor section of DIII-D. This shows the new upper divertor structure. Only the $45^{\circ}$ and Row 1 tiles will be removed (As Marked). (4 tiles) 


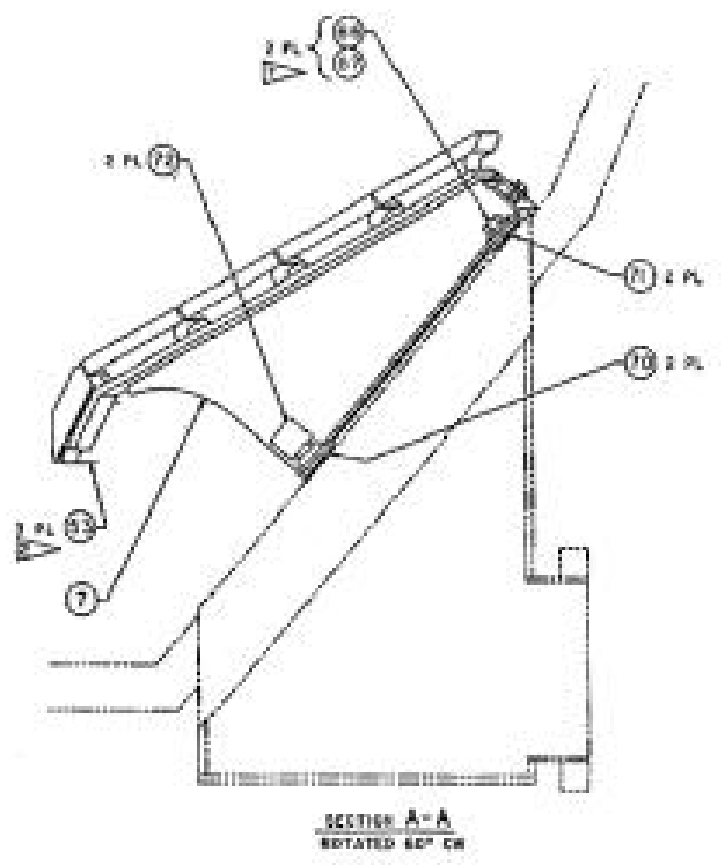

Figure 2.3. Lower Baffle Plate. The entire assembly is removable. (8 tiles).

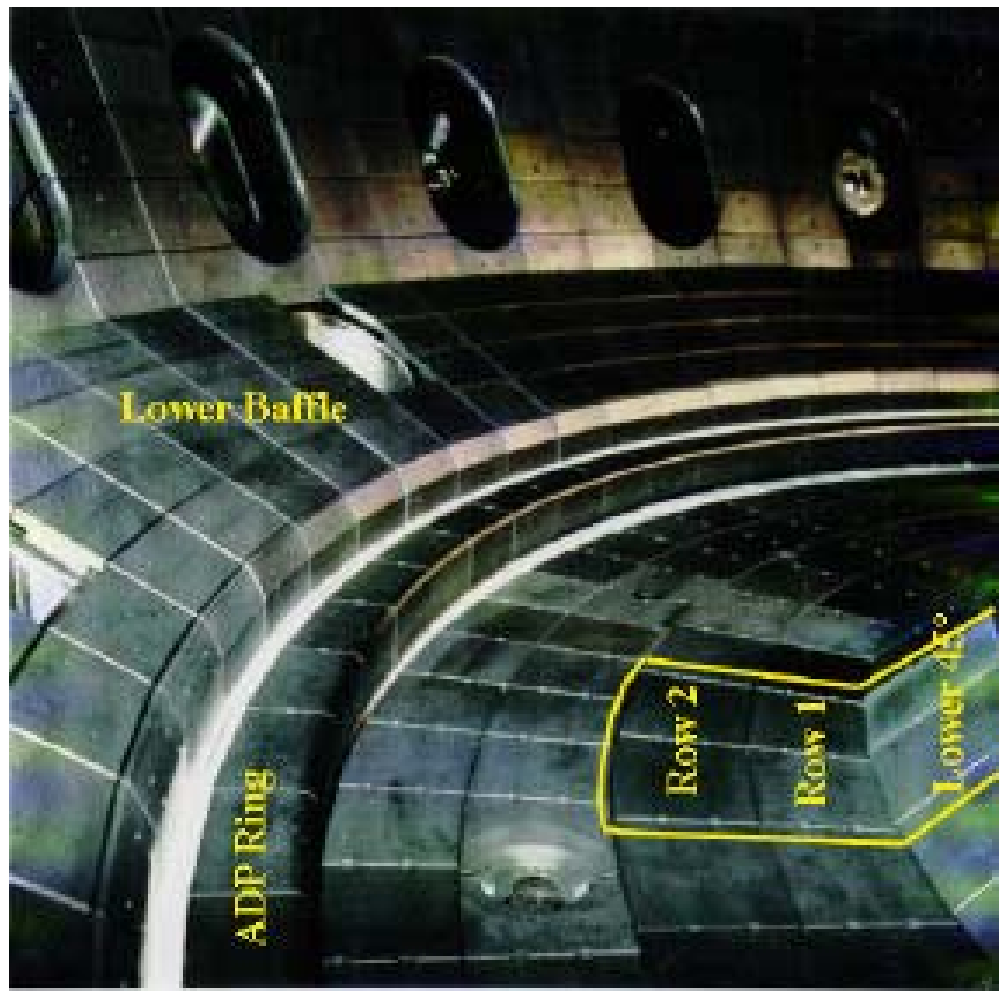

Figure 2.4. Photograph of the DIII-D floor showing key items of interest including the lower $45^{\circ}$ tile. 


\subsection{Descriptions of Sample Location}

Samples were taken from six general areas of the DIII-D vacuum vessel. Samples were taken from plasma facing surfaces in lower horizontal and upper horizontal locations. Samples were also taken from the corresponding locations underneath lower horizontal and upper horizontal surfaces. Three vacuum samples were collected from inside the R-1 access ports. Three samples were taken from inside R-1 ports. Table 2.2 shows a summary of the samples, location, description of location.

Table 2.2. Sample description and collection location.

\begin{tabular}{|c|c|c|c|}
\hline & Sample Description & $\begin{array}{l}\text { Toroidal } \\
\text { Location }\end{array}$ & $\begin{array}{l}\text { Sample } \\
\text { Identifier }\end{array}$ \\
\hline FH1 & Underneath the $337-345^{\circ}$ Lower Baffle tiles & $337-345^{\circ}$ & BLH \\
\hline FH2 & Top surface of $337-345^{\circ}$ Lower Baffle tiles & $337-345^{\circ}$ & LPFS \\
\hline FH3 & Top surface of $337-345^{\circ}$ lower $45^{\circ}$, Row $1,2, \& 3$ Floor tiles & $337-345^{\circ}$ & LPFS \\
\hline FH4 & Top surface of $337-345^{\circ}$ upper 45 and Row 1 Ceiling tiles & $337-345^{\circ}$ & UPFS \\
\hline FH5 & $\begin{array}{l}\text { Underneath and back of } 337-345^{\circ} \text { upper } 45 \text { and Row } 1 \text { Ceiling } \\
\text { tiles }\end{array}$ & $337-345^{\circ}$ & BUH \\
\hline FH6 & Top of $0-90^{\circ}$ lower baffle plate & $0-90^{\circ}$ & LPFS \\
\hline FH7 & $0-90^{\circ} \mathrm{R}-1$ ports & $0-90^{\circ}$ & $\mathrm{R}-1$ \\
\hline FH8 & Top of $90-180^{\circ}$ lower baffle plate & $90-180^{\circ}$ & LPFS \\
\hline FH9 & $90-180^{\circ} \mathrm{R}-1$ ports & $90-180^{\circ}$ & $\mathrm{R}-1$ \\
\hline FH10 & Top of $180-270^{\circ}$ lower baffle plate & $180-270^{\circ}$ & LPFS \\
\hline FH11 & $180-270^{\circ} \mathrm{R}-1$ ports & $180-270^{\circ}$ & R-1 \\
\hline FH12 & Surface of the $90-180^{\circ}$ upper $45^{\circ}$ and Row 1 Ceiling Tiles & $90-180^{\circ}$ & UPFS \\
\hline FH13 & Surface of the $180-270^{\circ}$ upper $45^{\circ}$ and Row 1 Ceiling Tiles & $180-270^{\circ}$ & UPFS \\
\hline FH14 & Surface of the $270-360^{\circ}$ upper $45^{\circ}$ and Row 1 Ceiling Tiles & $270-360^{\circ}$ & UPFS \\
\hline FH15 & Surface of the $45-55^{\circ}$ lower $45^{\circ}$, Row 1 Floor, Row 1 CP tiles & $45-55^{\circ}$ & LPFS \\
\hline FH16 & Surface of the $135-145^{\circ}$ lower $45^{\circ}$, Row 1 Floor, Row $1 \mathrm{CP}$ tiles & $135-145^{\circ}$ & LPFS \\
\hline FH17 & Surface of the $225-235^{\circ}$ lower $45^{\circ}$, Row 1 Floor, Row $1 \mathrm{CP}$ tiles & $225-235^{\circ}$ & LPFS \\
\hline RT1 & Lift-off tape from $30^{\circ}$ Lower $45^{\circ}$ Tile & $30^{\circ}$ & RT \\
\hline RT2 & Lift-off tape from $95^{\circ}$ Lower $45^{\circ}$ Tile & $95^{\circ}$ & RT \\
\hline RT3 & Lift-off tape from $105^{\circ} \mathrm{R}-1$ access port & $105^{\circ}$ & RT \\
\hline CI-MSS-01 & Underneath the Lower $45^{\circ}$ and row 1 floor tiles & $45-55^{\circ}$ & BLH \\
\hline CI-MSS-03 & Underneath the Lower $45^{\circ}$ and row 1 floor tiles & $135-145^{\circ}$ & BLH \\
\hline CI-MSS-05 & Underneath the Lower $45^{\circ}$ and row 1 floor tiles & $225-235^{\circ}$ & BLH \\
\hline $02-250 \mathrm{SS}$ & Underneath the Lower $45^{\circ}$, Row 1 , and row 2 Floor tiles & $337-345$ & BLH \\
\hline $\mathrm{CP} \quad-$ & Center post & & \\
\hline BLH & Beneath Lower Horizontal Tiles & & \\
\hline LPFS & Lower Plasma Facing Surface & & \\
\hline UPFS & Upper Plasma Facing Surface & & \\
\hline BUH & Behind Upper Horizontal Tiles & & \\
\hline $\mathrm{R}-1$ & Inside R-1 ports & & \\
\hline RT & Replicating tape samples & & \\
\hline
\end{tabular}

\subsubsection{Beneath Lower Horizontal Surfaces}

The largest quantities of dust were found in locations behind lower horizontal surfaces. Five samples were taken from behind lower horizontal surfaces. The Lower $45^{\circ}$ and Row 1 tiles in four separate areas were removed and the surfaces underneath vacuumed with cascade impactors. The area behind the $337-345^{\circ}$ lower baffle was 
vacuumed with a filter housing. Figures 2.5 through 2.9 show photographs of the areas behind the lower horizontal tiles.

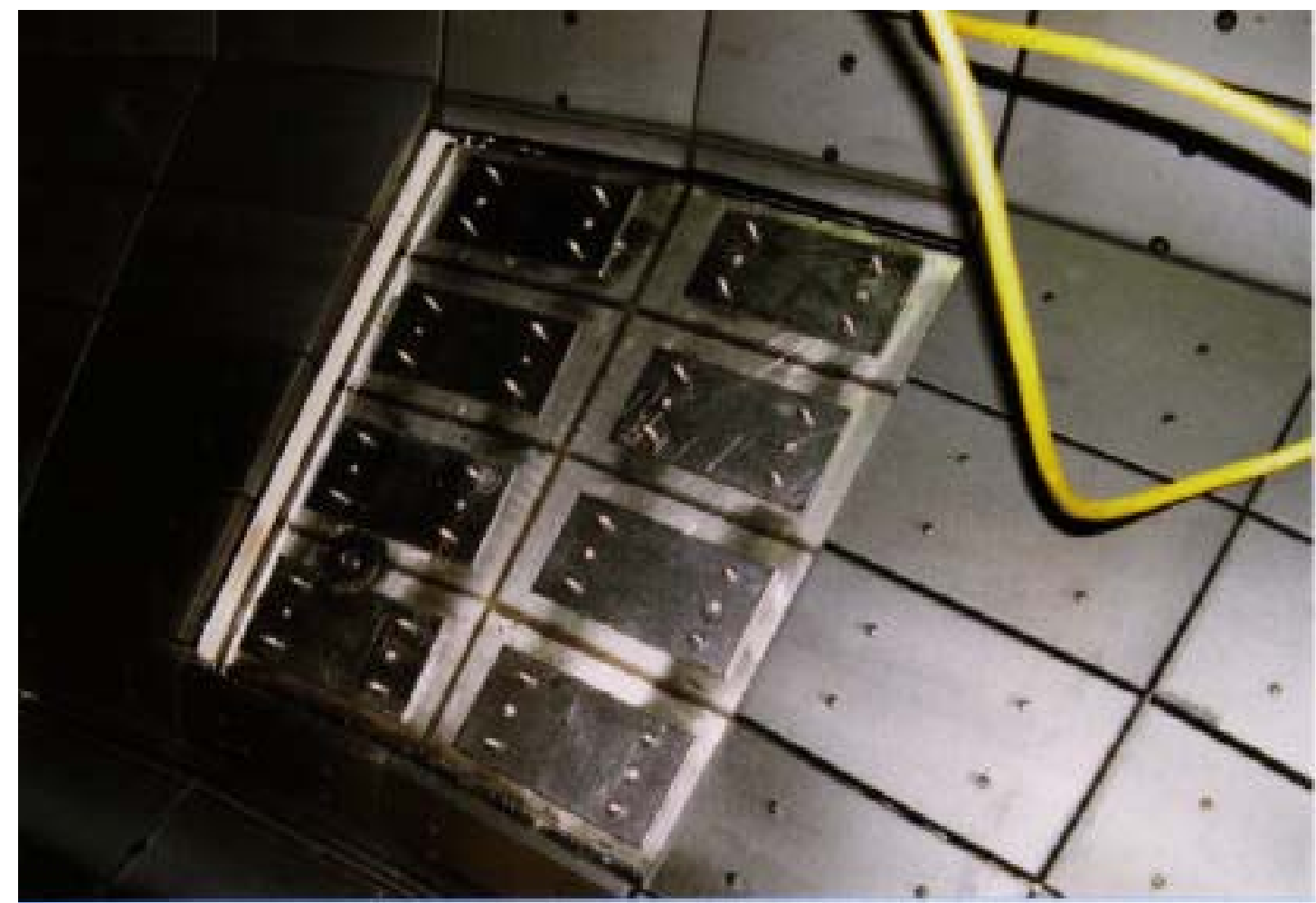

Figure 2.5. Photograph of the lower baffle with the $337-345^{\circ}$ tiles removed.

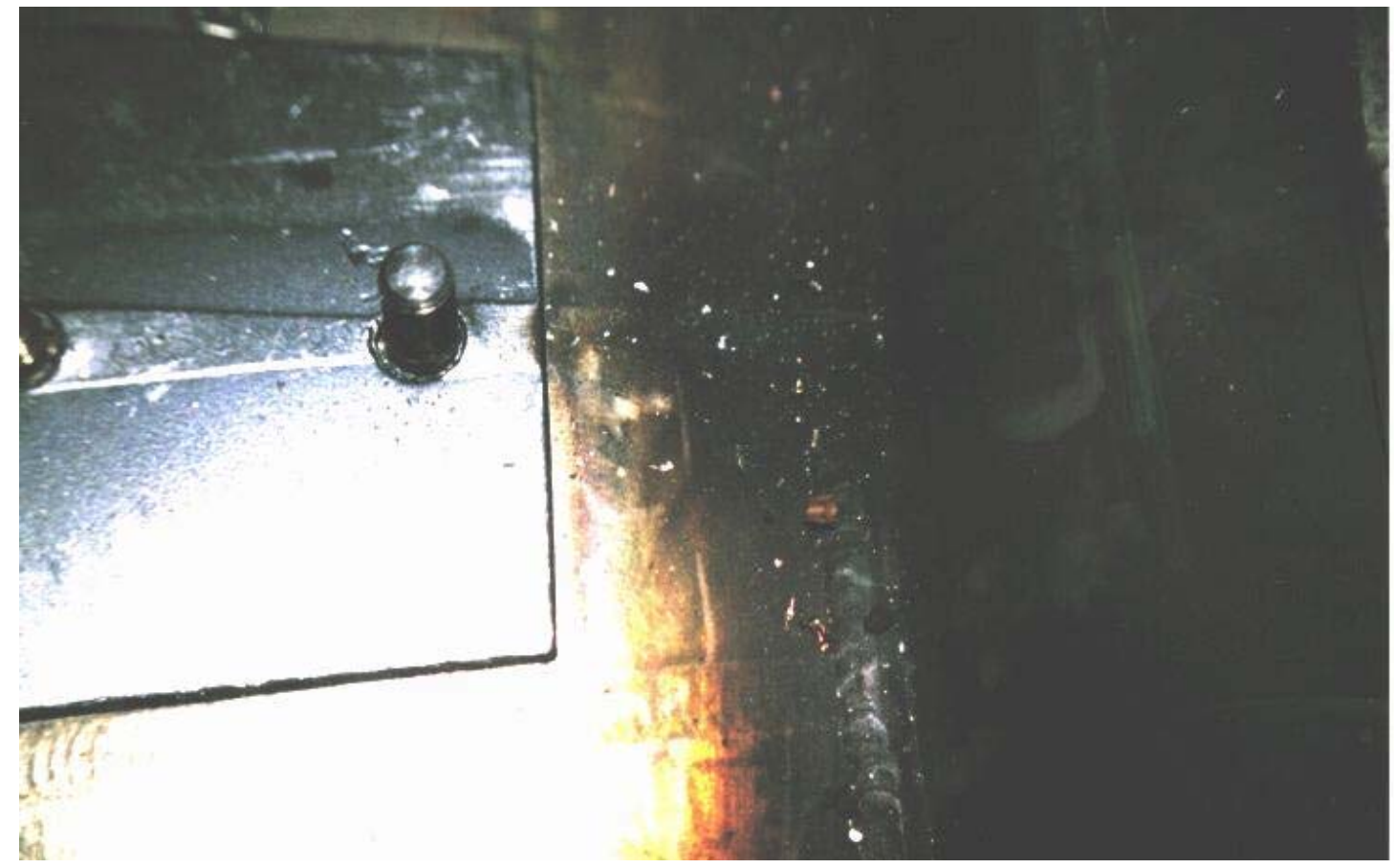

Figure 2.6. Close-up photograph of area behind the lower $45^{\circ}$ and Row $145-55^{\circ}$ floor tiles. 


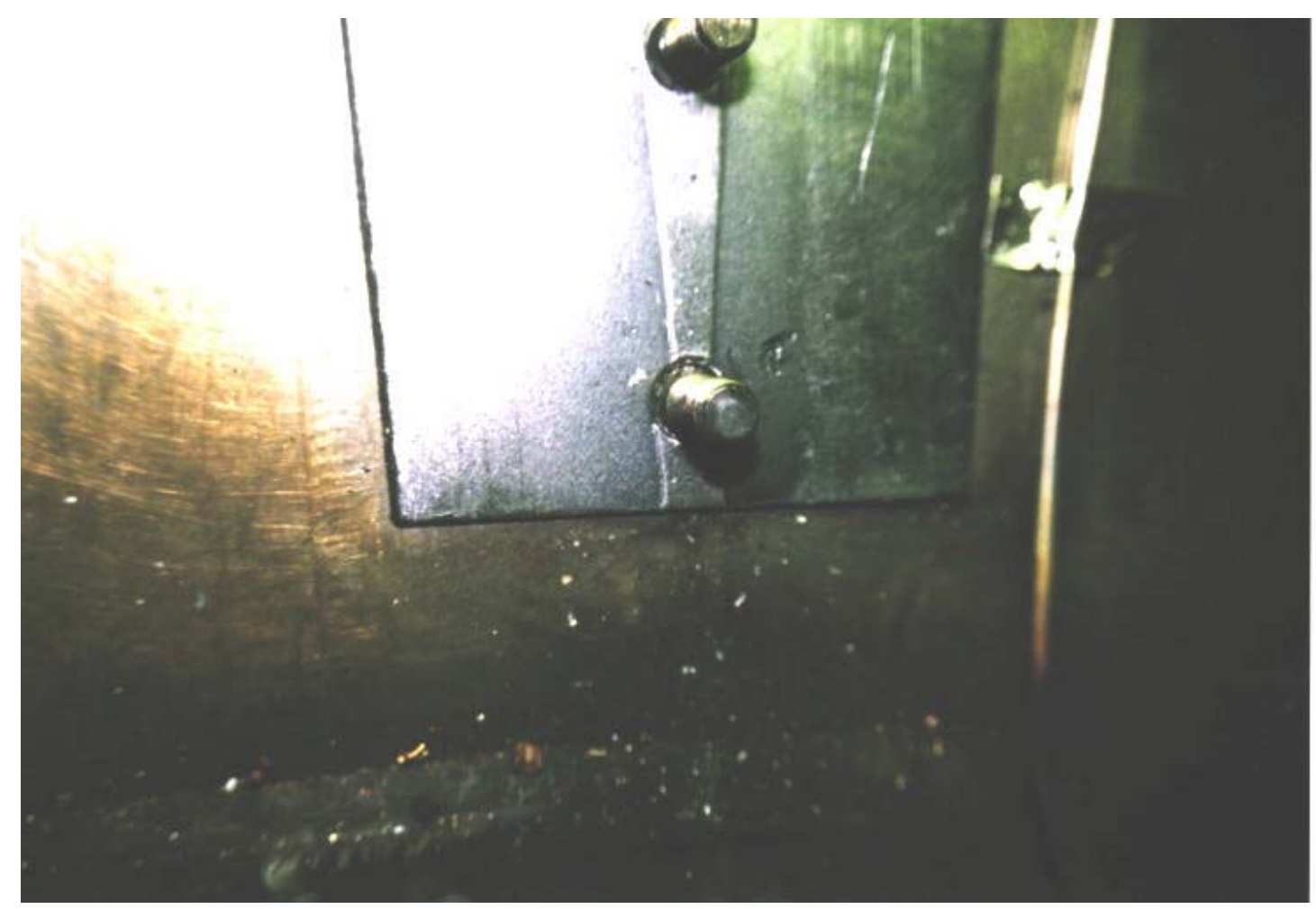

Figure 2.7. Close-up photograph of area behind the lower $45^{\circ}$ and Row $1135-145^{\circ}$ floor tiles.

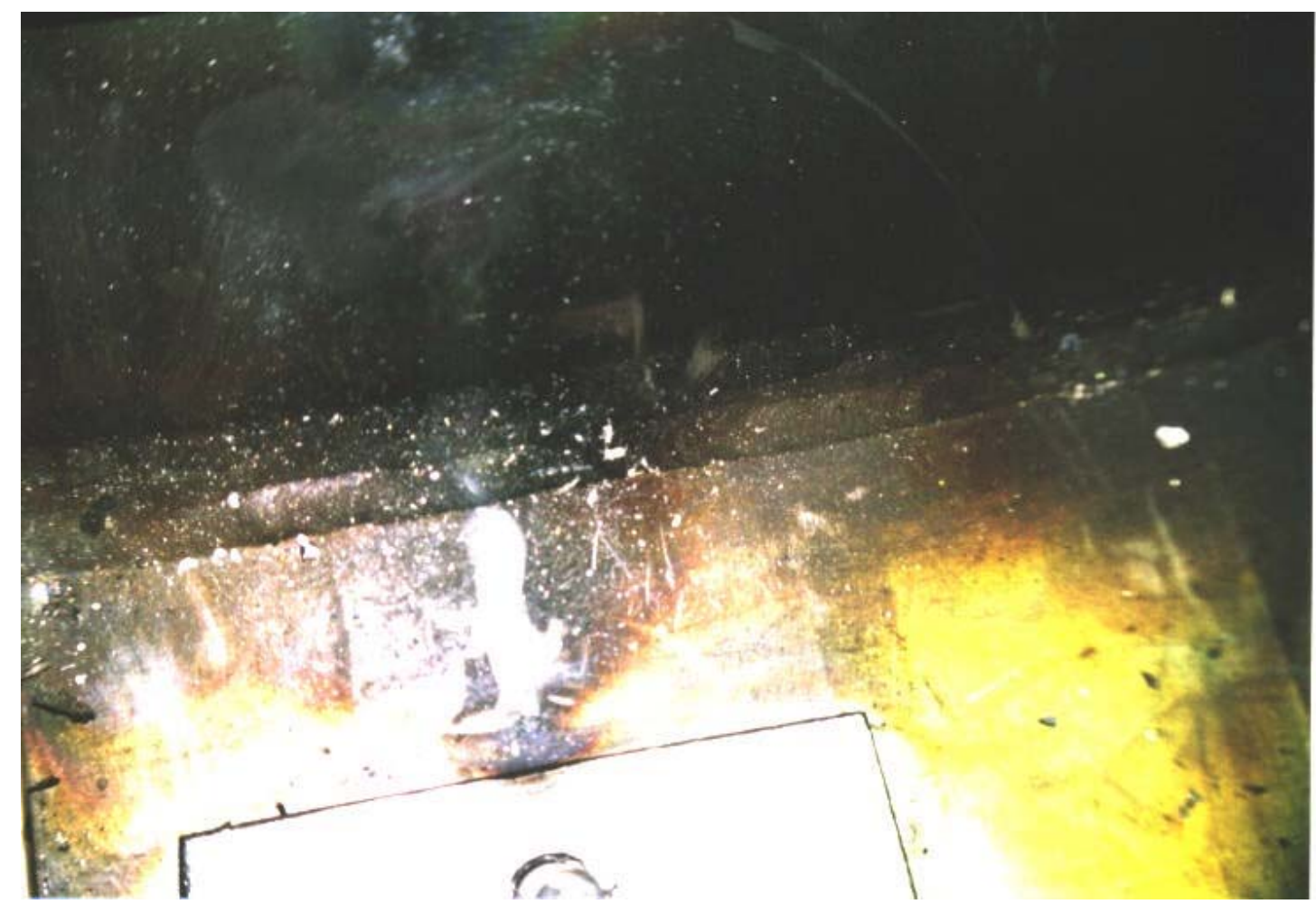

Figure 2.8. Close-up photograph of area behind the lower $45^{\circ}$ and Row $1,225-235^{\circ}$ floor tiles. 


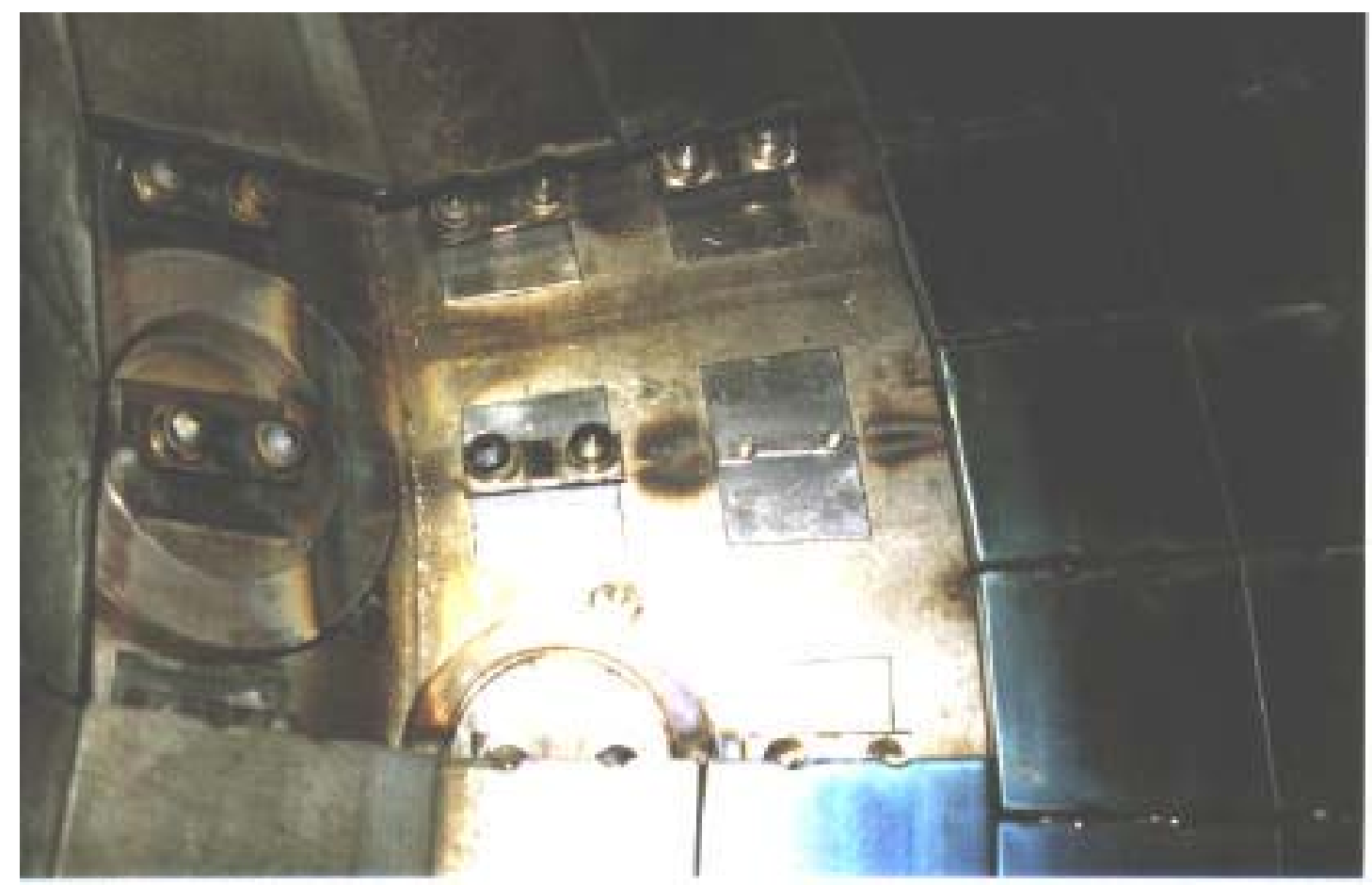

Figure 2.9. Photograph of area behind the Lower $45^{\circ}$ and Row 1 and 2, $337-345^{\circ}$ floor tiles.

\subsubsection{Beneath Upper Horizontal Surfaces}

Dust was sampled from beneath one upper horizontal surface, the Upper $45^{\circ}$ and Row 1 ceiling tiles. Figure 2.10 is a photograph of the area sampled in the $337-345^{\circ}$ toroidal location. The backs of the tiles removed from this location were also vacuumed with the same filter housing.

\subsubsection{Inside R-1 Ports}

Figure 2.11 is a photograph of the $0-90^{\circ} \mathrm{R}-1$ access ports. Figure 2.12 shows a photograph of the $90-180^{\circ} \mathrm{R}-1$ access ports. Figure 2.13 shows a photograph of one of the $90-180^{\circ} \mathrm{R}-1$ access ports. Broken and crushed glass was found in one of the $90-$ $180^{\circ}$ ports. The glass was from a broken diagnostic or window. 


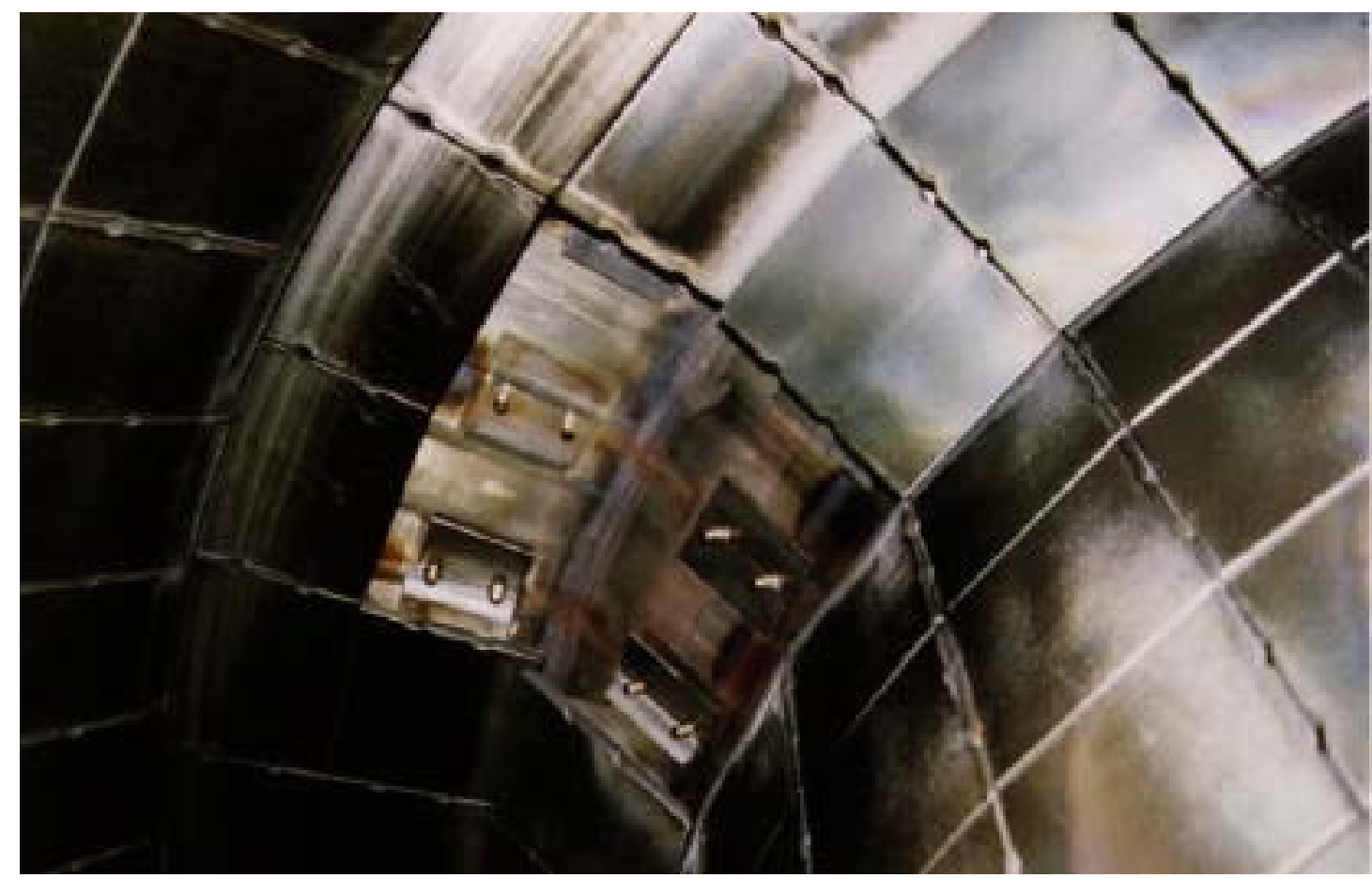

Figure 2.10. Photograph of area behind the $337-345^{\circ}$ Upper $45^{\circ}$ and Row 1 ceiling tiles.

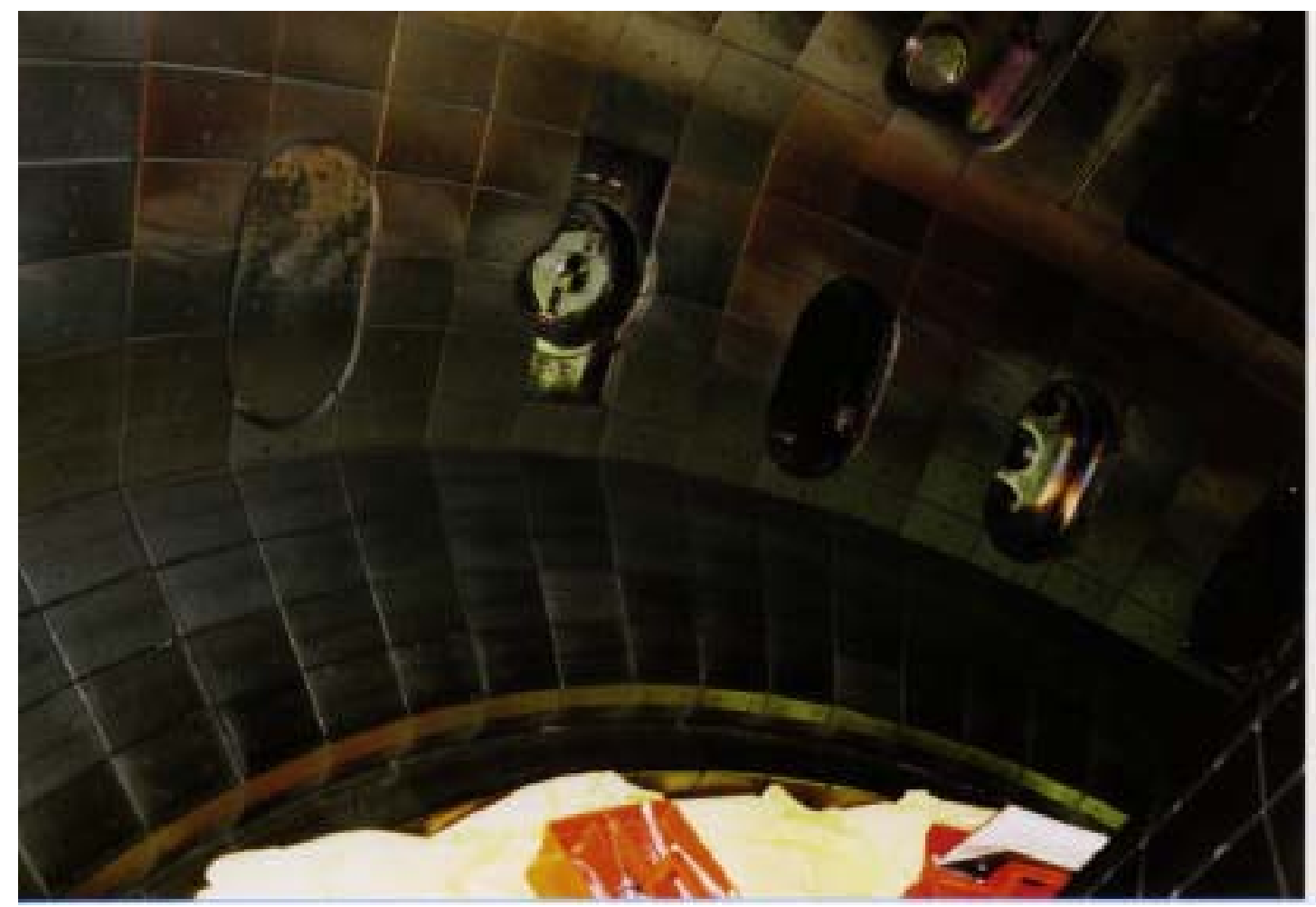

Figure 2.11. Photograph of the $0-90^{\circ} \mathrm{R}-1$ access ports. 


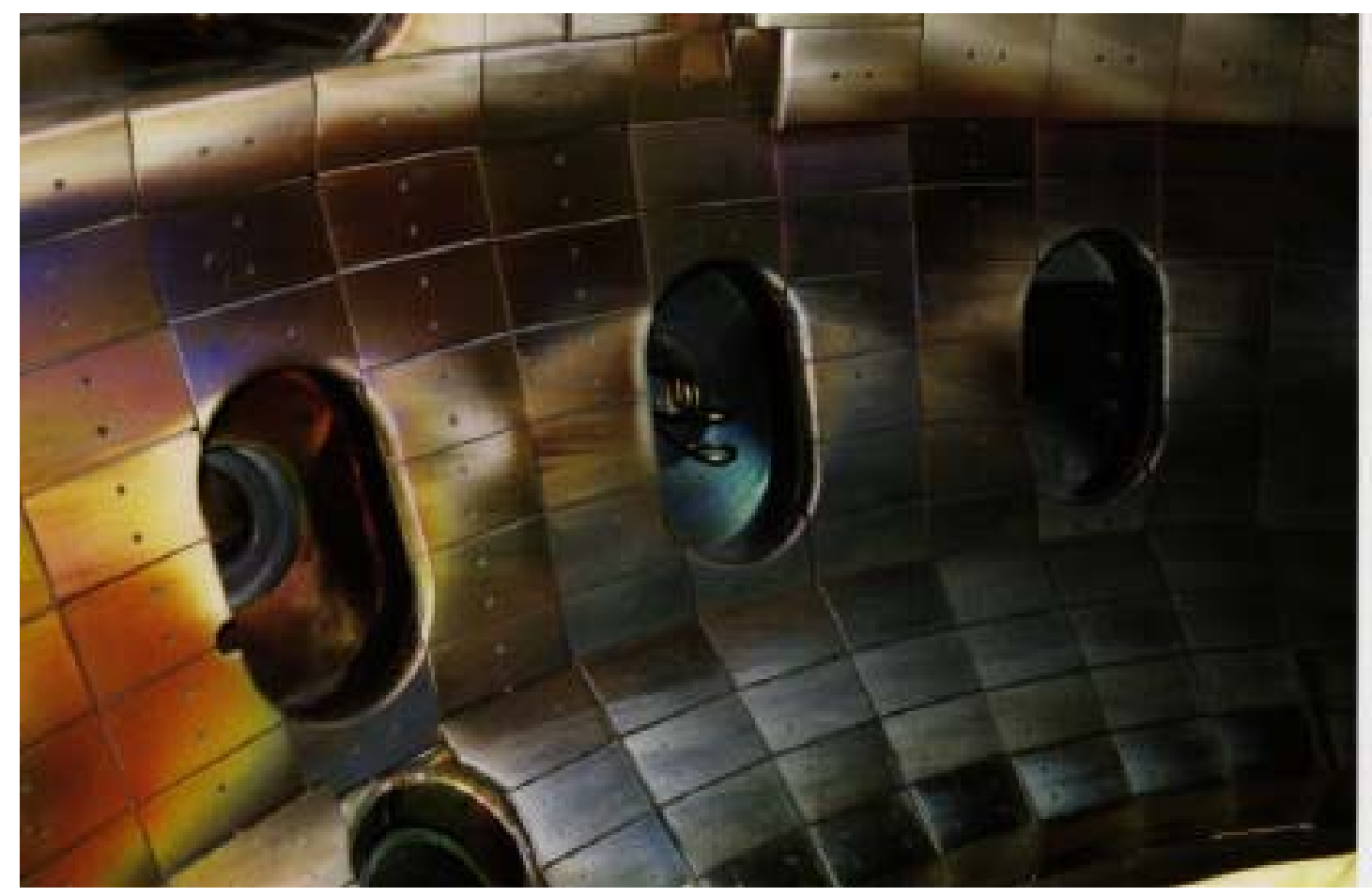

Figure 2.12. Photograph of the $90-180^{\circ} \mathrm{R}-1$ access ports.

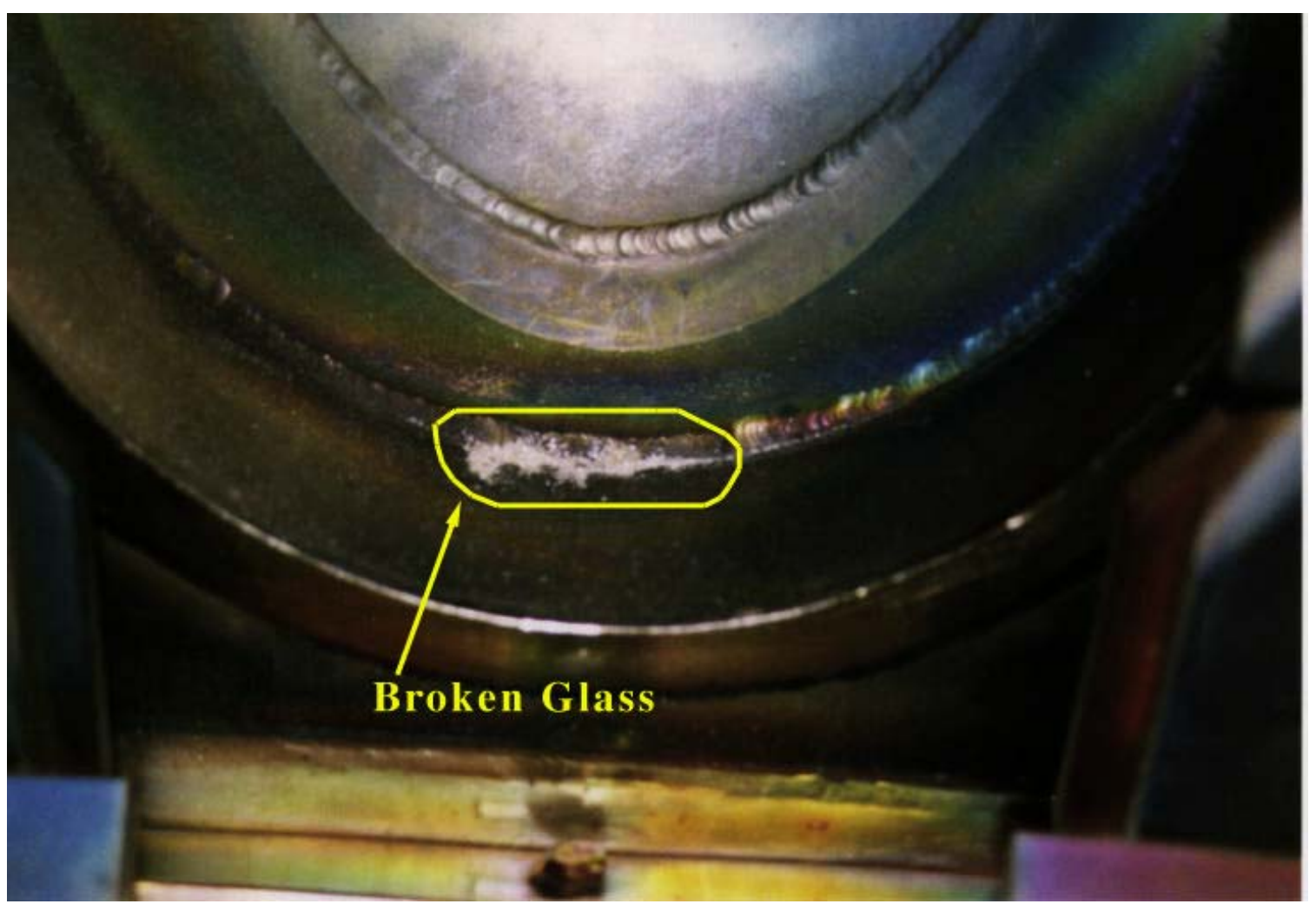

Figure 2.13. Broken glass found in the a $90-180^{\circ}$ port. 


\subsection{Replicating Tape Samples (Lift-off)}

Three sets of lift-off tape samples were collected. The first set of tapes were used on the Lower $45^{\circ}$ tiles located at the $30^{\circ}$ and the $95^{\circ}$ toroidal locations. The third set of replication tape samples were taken from inside the $105^{\circ} \mathrm{R}-1$ port. Figure 2.14 shows the replication tape samples on the Lower $45^{\circ}$ tile and Figure 2.15 shows the replicating tape samples located inside the R-1 port. Two strips were placed on each tile to be sampled. The two strips were then combined into one sample for the tile.

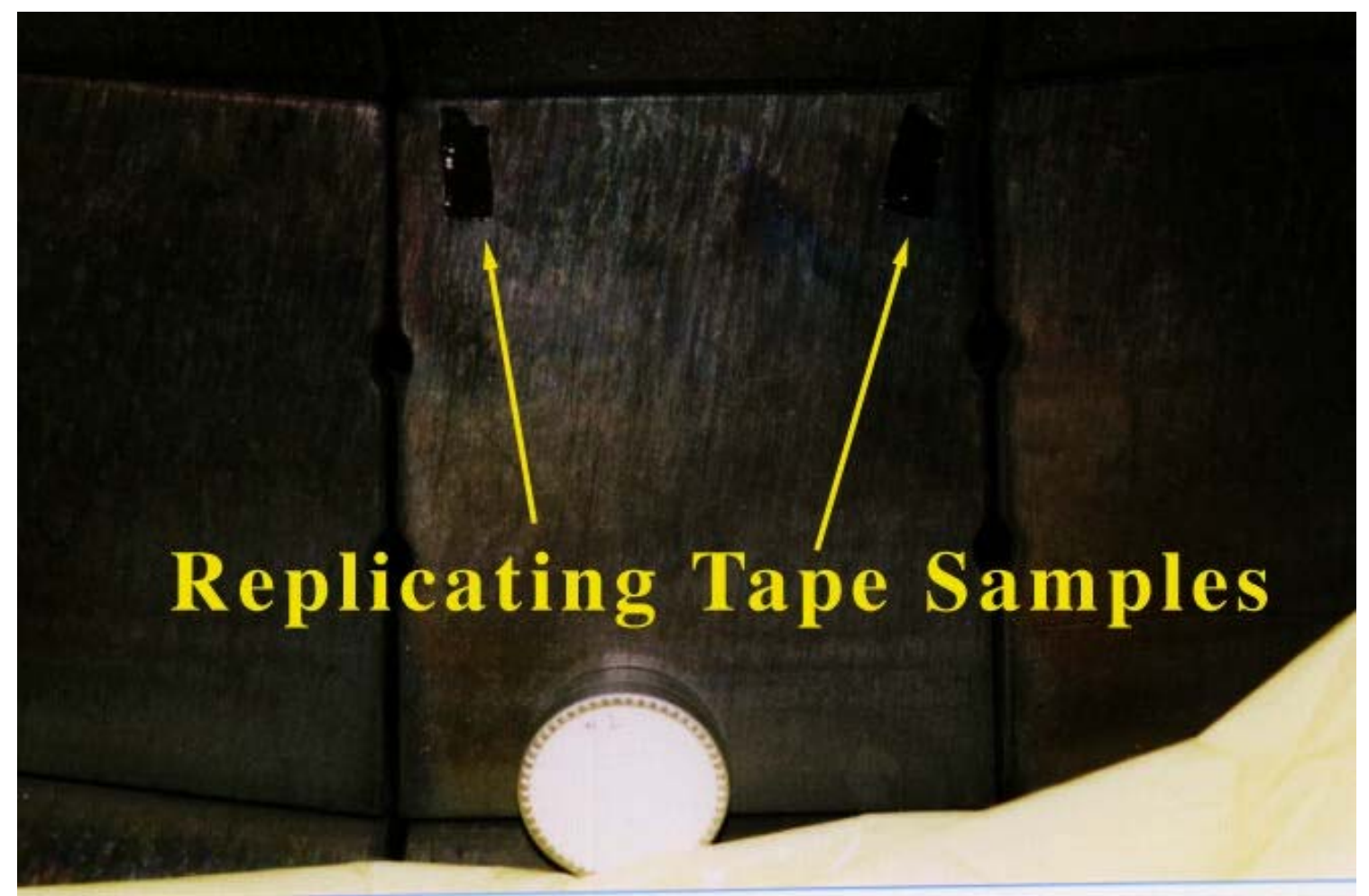

Figure 2.14. Photograph of the replicating tape samples on the $95^{\circ}$ Lower $45^{\circ}$ tile. 


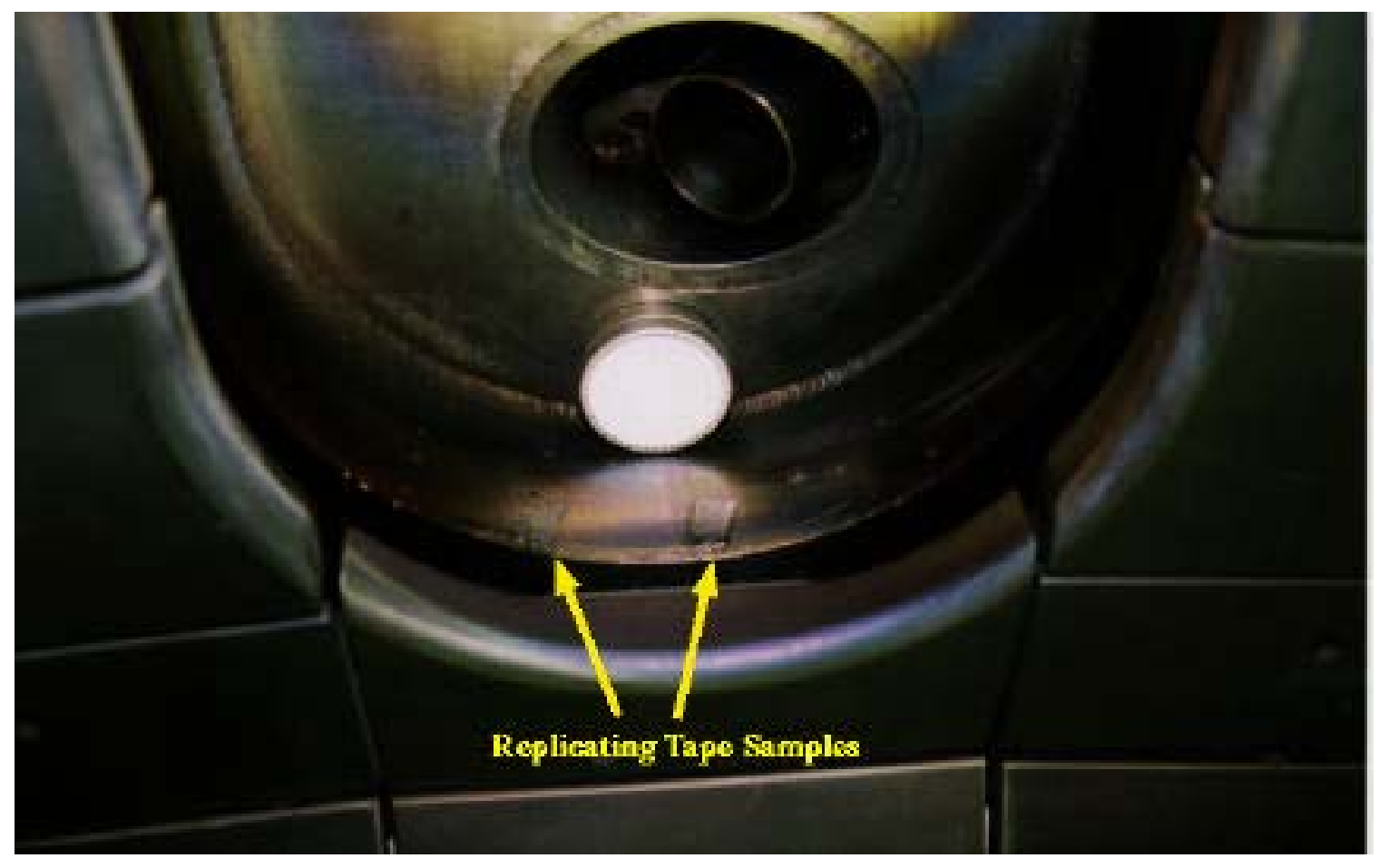

Figure 2.15. Photograph of the replicating tape samples inside the $135^{\circ} \mathrm{R}-1$ port.

\subsection{General Observations}

During the last two vents of DIII-D, a sooty particulate has been found on the lower $45^{\circ}$, Row 1 floor, and Row 1 center post tiles in visible quantities. As illustrated in Figure 2.16, the sooty region begins just inside of the inner strike point of the plasma. Outboard of this location, the tile surfaces are fairly smooth and clean. The ADP isolated ring can also be seen in the left of Figure 2.16. In contrast to the floor, the ceiling is relatively smooth and clean, including the region inside of the inner strike point of the plasma. Figure 2.17 shows a photograph of the ceiling tiles in the same toroidal location as the floor tiles shown in Figure 2.16. 


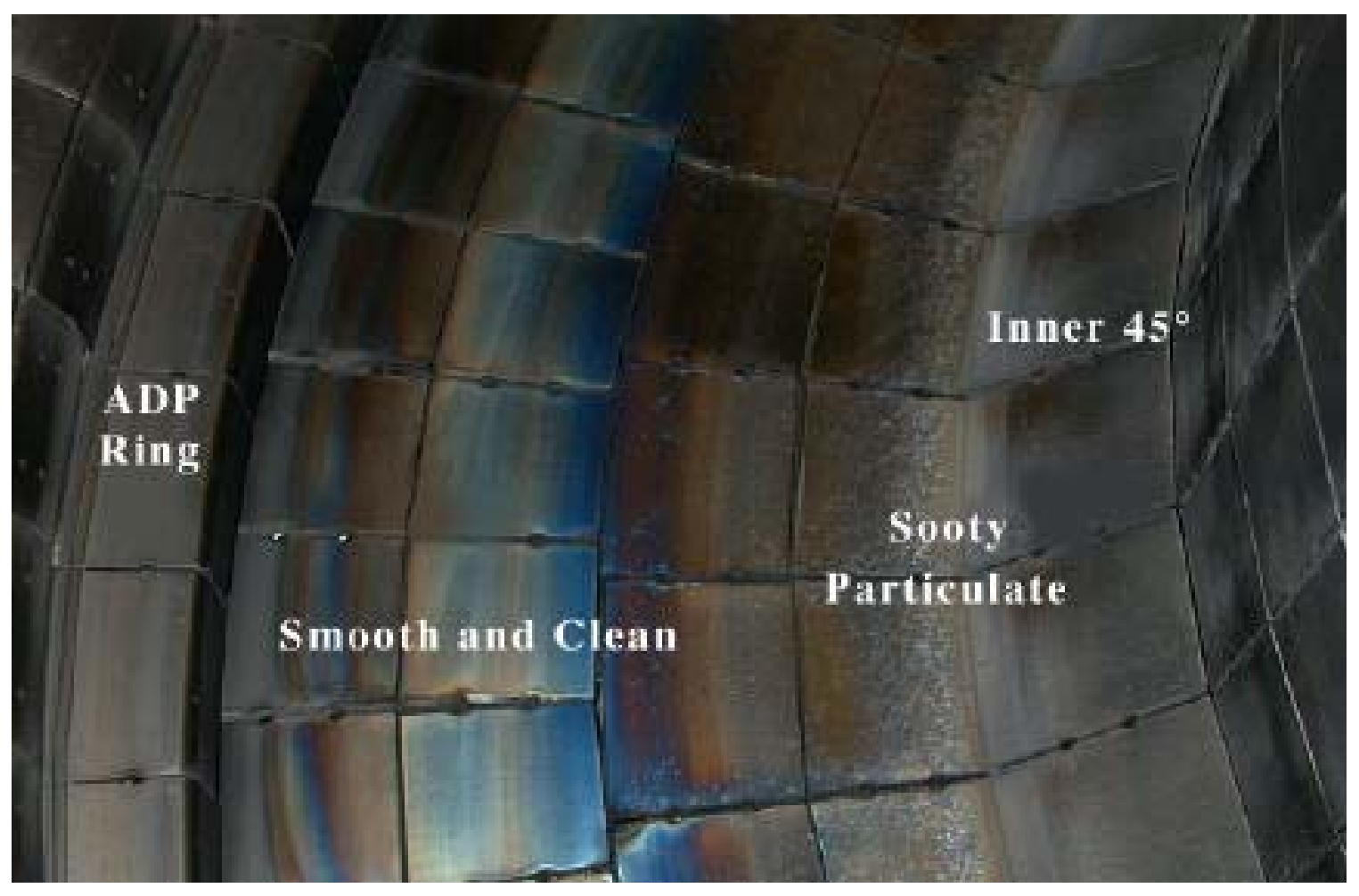

Figure 2.16. Photograph of DIII-D floor tiles. (Photograph courtesy of DIII-D personnel)

A key goal of this collection effort was to determine dust concentrations in various poloidal and toroidal locations. It is suspected that the sooty deposits on the inboard side of the plasma are actually eroded from outboard locations and then swept and deposited inboard. Although this has not been confirmed, the sooty deposit on the inboard side of the plasma is eroded from locations other than the inboard lower $45^{\circ}$ and row 1 floor tiles. Much of the dust sampling effort focuses on the areas underneath and on the surface of the Lower $45^{\circ}$ and Row 1 floor tiles where these soot deposits form. It seems that much of the dust formed by the various mechanisms in the machine is swept to the lower inboard side of the plasma and deposited either underneath the tiles or on the plasma facing surfaces of the tiles. The deposit seems to be fairly uniform toroidally around the machine. 


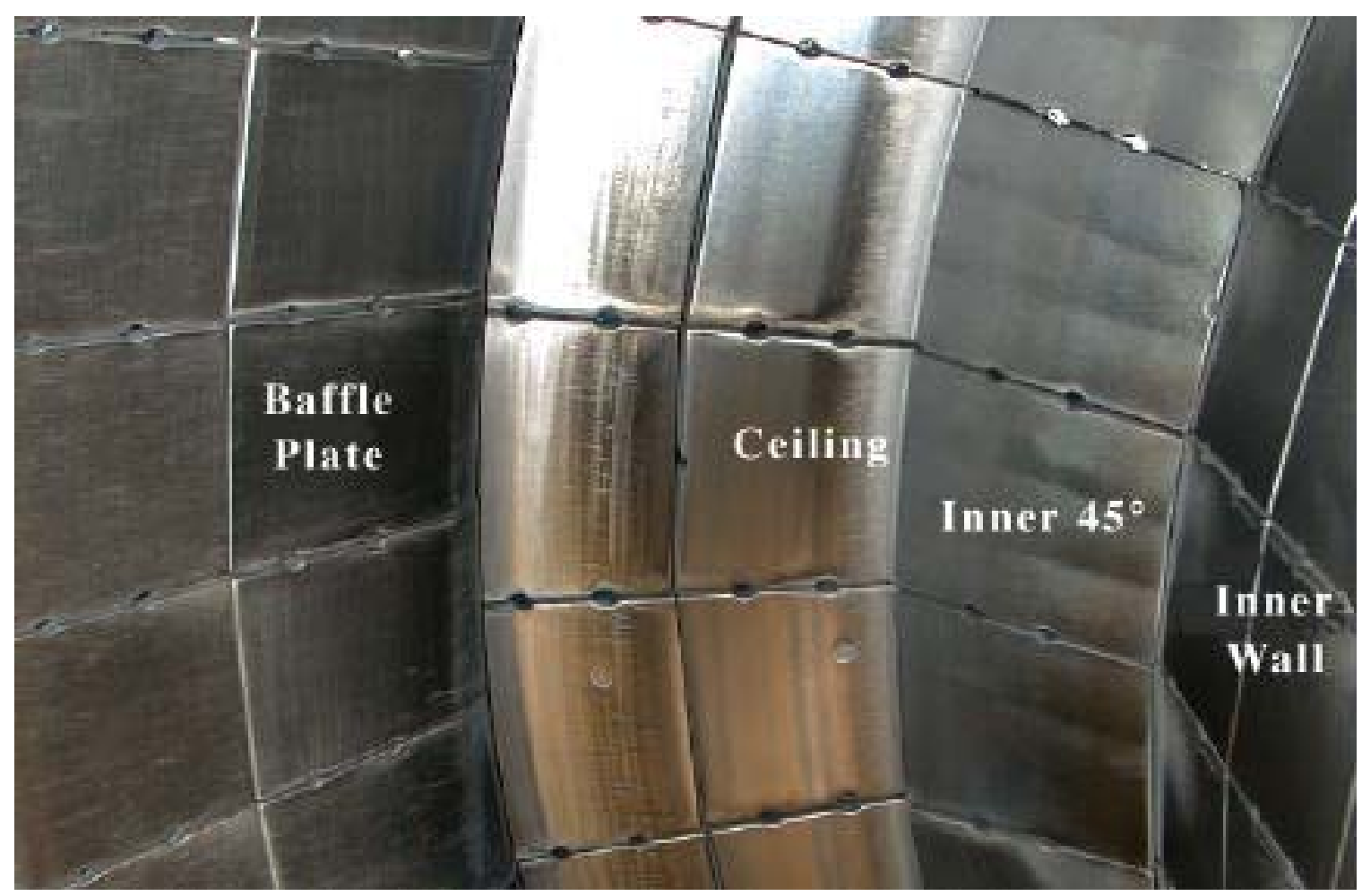

Figure 2.17. Photograph of DIII-D ceiling tiles. (Photograph courtesy of DIII-D personnel)

A dust phenomena not observed to a large extent in previous vents of DIII-D is illustrated in Figure 2.18. The word "DUST" can be seen written in the dust collected on the wall of a penetration port in the $180^{\circ} \mathrm{R}-0$ plane of the vacuum vessel. This fine collection of dust was primarily metallic and very spherical. The dust was found on most of the cold surfaces of the penetration ports around the machine. At this point in time it is believed that this dust was formed by the interaction of an Inconel component of the experiment with the plasma. The particulate is very spherical and will be discussed below.

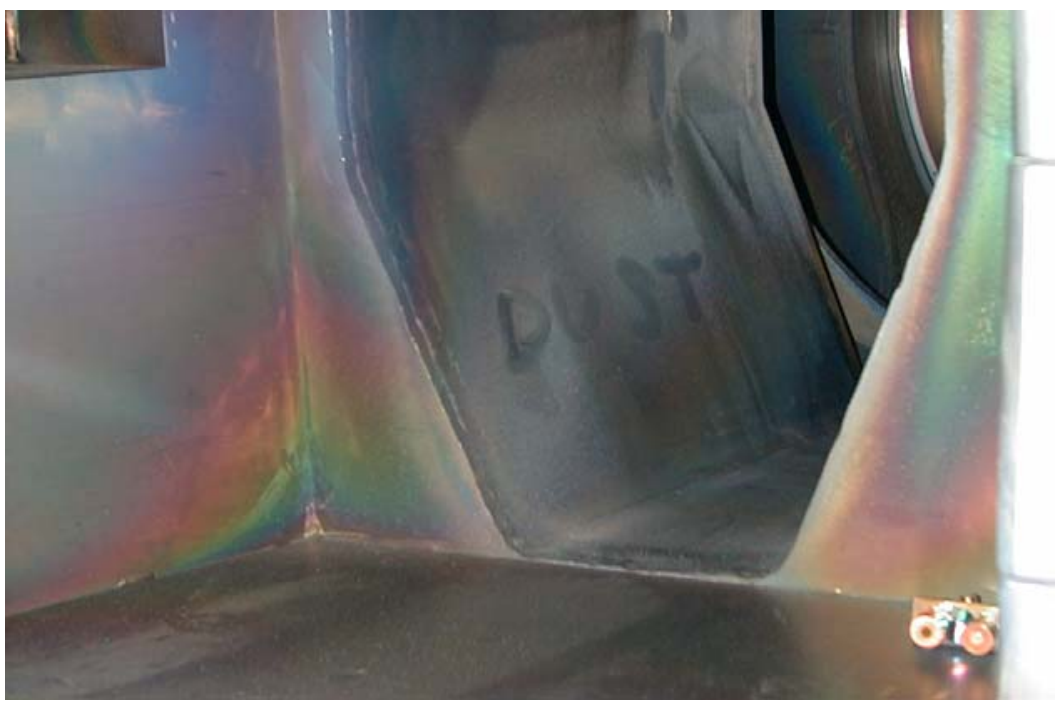

Figure 2.18. Photograph showing dust collected on the surfaces of a penetration port. 


\subsection{Collection Methods}

Three dust collection methods were used during this collection campaign. Filter housings containing $0.02 \mu \mathrm{m}$ pore size filter substrates were used in conjunction with a small vacuum pump to vacuum particulate from surfaces. This is a method that has been used extensively in the past for sampling particulate from tokamak experiments for the purpose of dust characterization ${ }^{1}$.

Seven stage total mass INTOX cascade impactors were used to obtain a mass based distribution of the dust found underneath the floor tiles. The cascade impactors were used only in this location because these areas generally contain the largest quantity (by mass) of particulate. Final filters with a $0.8 \mu \mathrm{m}$ pore size were used in the cascade impactors. Smaller pore size final filters were not used because the required flow rate through the impactor could not be maintained with the larger pressure drop associated with the finer pore size filters. Loss of particles smaller than $0.8 \mu \mathrm{m}$ are not usually significant to a mass based particle size distribution measurement since most of the mass in aerosols is generally associated with the larger particle sizes.

Finally, metallurgical replicating (lift-off) tape was used in three locations to physically remove particulate from surfaces. This method has also been used in the past for the purpose of collecting particulate for characterization.

The surface area of the walls sampled was recorded as well as the differential weight of the collected sample. Overall, 1.152 grams of dust was collected from the DIII-D vacuum vessel. A total of $1.25 \times 10^{5} \mathrm{~cm}^{2}\left(12.5 \mathrm{~m}^{2}\right)$ of surface area was sampled with the vacuum filter housings or with one of the four cascade impactors. This represents an average of $9.21 \mu \mathrm{g} / \mathrm{cm}^{2}$ surface concentration of dust. This is somewhat misleading since the largest quantity of dust is found underneath the lower horizontal surfaces on a relatively small surface area. Large quantities of dust did not collect on the plasma facing surfaces and the surface concentration of dust is much smaller than that found under floor tiles. An average across the entire machine is not representative of the actual behavior of dust in the vacuum vessel. Table 2.3 presents a summary of the surface concentration of dust for each sample collected in the DIII-D vacuum vessel. Also presented in Table 2.3 are the mass, surface area, toroidal location, and general descriptor of the sample origin.

Figure 2.19 is a plot of the data shown in Table 2.3 as a function of toroidal location and surface orientation. The graph indicates that dust is evenly distributed around the torus. Dust collected from similar positions at different toroidal locations shows little variance. Poloidally, the same is not true. Vertical or inverted surfaces in the machine, such as the ceiling tiles and the outer upper and lower divertor regions, generally hold very little dust (between 0.1 and $1 \mu \mathrm{g} / \mathrm{cm}^{2}$ ). In general, dust concentrations on plasma facing surfaces are smaller than in ports or in areas underneath tiles. Of all of the plasma facing surfaces, the greatest concentration of dust $\left(1 \mu \mathrm{g} / \mathrm{cm}^{2}\right)$ is associated with the Row 1 center post tiles, the inner Lower $45^{\circ}$ tile, and the Row 1 floor tiles because of the soot that collected there during operation (see Figure 2.16). It is suspected that the sweeping action of the plasma erodes the outer PFC regions and deposits the material on these tiles. 
Table 2.3. Summary of sample locations, surface area, and collected mass.

\begin{tabular}{|c|c|c|c|c|c|}
\hline & $\begin{array}{l}\text { Toroidal } \\
\text { Location }\end{array}$ & $\begin{array}{c}\text { Sample } \\
\text { Identifier }\end{array}$ & $\begin{array}{l}\text { Mass } \\
\text { mg }\end{array}$ & $\begin{array}{c}\text { Surface Area } \\
\mathrm{cm}^{2}\end{array}$ & $\begin{array}{c}\text { Dust Concentration } \\
\mu \mathrm{g} / \mathrm{cm}^{2}\end{array}$ \\
\hline FH1 & $337-345^{\circ}$ & BLH & 16.4 & 838 & 19.6 \\
\hline $\mathrm{FH} 2$ & $337-345^{\circ}$ & LPFS & 0.2 & 838 & 0.24 \\
\hline FH3 & $337-345^{\circ}$ & LPFS & 0.8 & 1935 & 0.41 \\
\hline FH4 & $337-345^{\circ}$ & UPFS & 0.4 & 929 & 0.43 \\
\hline FH5 & $337-345^{\circ}$ & $\mathrm{BUH}$ & 1.5 & 1858 & 0.81 \\
\hline FH6 & $0-90^{\circ}$ & LPFS & 0.3 & 14864 & 0.02 \\
\hline FH7 & $0-90^{\circ}$ & R-1 & 5.9 & 206 & 28.6 \\
\hline FH8 & $90-180^{\circ}$ & LPFS & 2.9 & 14864 & 0.20 \\
\hline FH9 & $90-180^{\circ}$ & R-1 & 13.9 & 206 & 67.3 \\
\hline FH10 & $180-270^{\circ}$ & LPFS & 3.7 & 14864 & 0.25 \\
\hline FH11 & $180-270^{\circ}$ & $\mathrm{R}-1$ & 35.7 & 206 & 172.9 \\
\hline FH12 & $90-180^{\circ}$ & UPFS & 1.7 & 8129 & 0.21 \\
\hline FH13 & $180-270^{\circ}$ & UPFS & 0.3 & 8129 & 0.04 \\
\hline FH14 & $270-360^{\circ}$ & UPFS & 0.3 & 5806 & 0.0517 \\
\hline FH15 & $45-55^{\circ}$ & LPFS & 2.5 & 14806 & 0.1688 \\
\hline FH16 & $135-145^{\circ}$ & LPFS & 1.3 & 14806 & 0.0878 \\
\hline FH17 & $225-235^{\circ}$ & LPFS & 2 & 14806 & 0.1351 \\
\hline RT1 & $30^{\circ}$ & RT & - & - & - \\
\hline RT2 & $95^{\circ}$ & RT & - & - & - \\
\hline RT3 & $105^{\circ}$ & RT & - & - & - \\
\hline CI-MSS-01 & $45-55^{\circ}$ & BLH & 170.1 & 1935 & 42.6 \\
\hline CI-MSS-03 & $135-145^{\circ}$ & BLH & 288.4 & 1535 & 114.9 \\
\hline CI-MSS-05 & $225-235^{\circ}$ & BLH & 460.3 & 1535 & 143.7 \\
\hline $02-250 \mathrm{SS}$ & $337-345$ & BLH & 143.5 & 1935 & 28.4 \\
\hline \multicolumn{6}{|c|}{ Beneath Lower Horizontal Tiles } \\
\hline LPFS & \multicolumn{5}{|c|}{ Lower Plasma Facing Surface } \\
\hline UPFS & \multicolumn{5}{|c|}{ Upper Plasma Facing Surface } \\
\hline BUH & \multicolumn{5}{|c|}{ Behind Upper Horizontal Tiles } \\
\hline R-1 & \multicolumn{5}{|c|}{ Inside $\mathrm{R}-1$ ports } \\
\hline RT & \multicolumn{5}{|c|}{ Replicating tape samples } \\
\hline
\end{tabular}




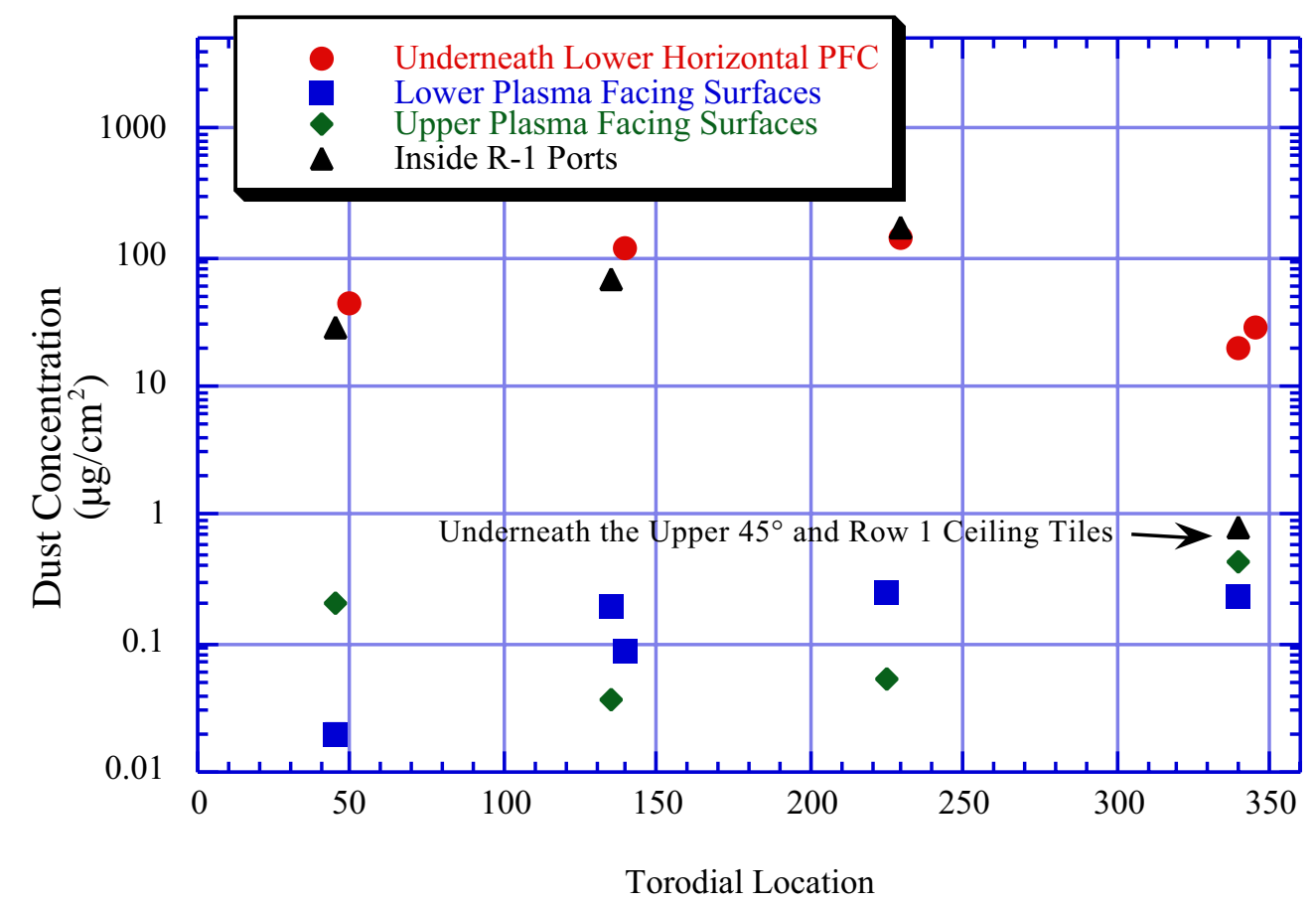

Figure 2.19. Graph of the toroidal mass distribution of dust around the DIII-D machine.

The largest quantity of dust is found on the lower horizontal surfaces of the machine, specifically underneath the floor tiles. The dust concentrations of horizontal surfaces in areas protected from the plasma, such as ports and underneath tiles, ranged between 10 and $100 \mu \mathrm{g} / \mathrm{cm}^{2}$. This is believed to be due to the fact that these surfaces are much cooler during operation than the plasma facing surfaces of the machine and particles are easily deposited on cold surfaces. The ports located in the R-1 plane (just below the horizontal mid-plane of the machine) collect larger amounts of material due to the horizontal surfaces. Dust concentrations in these ports ranged from 10 to $100 \mu \mathrm{g} / \mathrm{cm}^{2}$. 


\subsection{BET Surface Area Analysis}

We use a Micromeritics Model ASAP 2010 (Accelerated Surface Area and Porosimetry System) to measure the surface areas of solid samples and particulate samples. The design of this system is based on the use of a static volumetric method for determining the volume of gas adsorbed on a sample. The volume of gas adsorbed at a constant temperature and a controlled pressure is obtained from mass balance equations, appropriate gas law, correction factors for non-ideal behavior, and accurate measurements of pressure and volumes of a manifold and free volume within a sample container. During analysis, the sample and a controlled portion of the sample container are maintained at a cryogenic temperature, generally near that of liquid nitrogen $\left(\mathrm{LN}_{2}\right)$. Well-regulated amounts of gas near ambient pressure and temperature are supplied through a manifold having accurately known volume and temperature. The molar quantity of gas adsorbed on the sample is computed once the pressure of the gas admitted from the manifold has equilibrated and been accurately measured. This procedure is repeated at several pressures allowing a plot of the quantity of adsorbed gas versus pressure to be established. This type of plot, referred to as an adsorption isotherm, is used to calculate the specific surface area of the sample material. This method was developed by Brunauer, Emmett, and Teller, (BET) $)^{2}$ and a complete description of our capabilities and methods is available in Anderl et $\mathrm{al}^{3}$ and Smolik et al. ${ }^{4}$

For our measurements, both $\mathrm{Kr}$ and $\mathrm{N}_{2}$ were used as the adsorptive gas in separate measurements and the adsorption measurements were made with the specimens at liquid nitrogen temperature $(77 \mathrm{~K})$. Generally, $\mathrm{Kr}$ gas is used when samples are expected to have very low total surface areas. $\mathrm{N}_{2}$ gas is used when samples are expected to have larger total surface areas. Typically, measurements were made for relative pressures ranging from 0.02 to 0.3 , where the relative pressure, $\mathrm{P}_{\text {rel }}$, is defined as the actual adsorptive gas pressure, $\mathrm{P}$, divided by the saturation vapor pressure, $\mathrm{P}_{\mathrm{o}}$, for the adsorptive gas at the analysis temperature. Usually, four to ten measurements of the gas adsorption isotherm were made over the designated pressure range using an automated analysis sequence that was controlled by the ASAP 2010 instrument computer.

We analyzed the dust collected from beneath the Lower $45^{\circ}$ and Row 1 floor tiles for specific surface area. We were unable to obtain an accurate measurement of the specific surface area from the four samples taken from underneath these floor tiles. This is because the cascade impactor collection substrates were coated with a layer of vacuum grease to help eliminate particle bounce and subsequent loss in the impactors. The grease coats the particle's surface such that the BET analysis gas cannot adsorb to the particle surface area thus effectively reducing the measured BET specific surface area. We were not able to eliminate the grease from the dust samples even after repeated attempts.

Specific surface area measurements were obtained for samples CI-MSS-05 and 02-0250SS although the results are not reliable due to the grease contamination. Specific surface area was not detectable for samples CI-MSS-01 and CI-MSS-03 due to grease contamination.

We also analyzed a combined sample of FH1, FH5, FH7, and FH11 through FH17 vacuum samples for specific surface area. The samples were combined to obtain enough dust to provide a detectable surface area. Since these samples were not collected with cascade impactors there was no grease contamination on them. An average of the two measurements of the combined filter housing samples yielded a specific surface area of $3.1478 \pm 0.0156 \mathrm{~m}^{2} / \mathrm{g}$ from a total sample weight of 0.0408 grams. 
Following BET surface area analysis, the samples were analyzed for composition by ICP-MS. This analysis by ICP-MS was performed to determine the composition of the sample that was analyzed by BET surface area analysis and is presented in Section 4.1 .

Table 3.1 Table of BET specific surface area measurements for DIII-D (April 1998)

\begin{tabular}{|c|c|c|c|}
\hline Measurement & $\begin{array}{c}\text { Mass } \\
(\mathrm{g})\end{array}$ & $\begin{array}{c}\text { Specific Surface Area } \\
\left(\mathrm{m}^{2} / \mathrm{g}\right)\end{array}$ & Uncertainty $\left(\mathrm{m}^{2} / \mathrm{g}\right)$ \\
\hline $\begin{array}{c}\text { FH7, FH5, } \\
\text { FH17 }\end{array}$ & 0.0408 & 3.1478 & \pm 0.0156 \\
\hline & 0.0408 & 3.0581 & \pm 0.0145 \\
\hline CI-MSS-01 $^{\dagger}$ & 0.4543 & 2.8450 & \pm 0.0131 \\
\hline CI-MSS-03 $^{\dagger}$ & 0.3148 & - & - \\
\hline CI-MSS-05 $^{\dagger}$ & 0.5128 & -0.0744 & \pm 0.0003 \\
\hline & 0.5128 & 0.0820 & \pm 0.0002 \\
\hline $02-250-S S^{\dagger}$ & 0.2865 & 0.1088 & \pm 0.0010 \\
\hline & 0.2865 & 0.1090 & \pm 0.0009 \\
\hline & 0.2865 & 0.1274 & \pm 0.0009 \\
\hline
\end{tabular}

Samples contaminated with vacuum grease closing the surface area available for measurement. 


\subsection{ICP-MS and ESEM/EDS Composition Analysis}

We used two techniques to analyze the collected dust for elemental composition: inductively coupled mass spectroscopy (ICP-MS) and environmental scanning electron mass spectroscopy (ESEM/EDS). Using the EDS capability of the ESEM allowed qualitative elemental composition analysis of individual particulate down to approximately $1 \mu \mathrm{m}$ in size. Particles smaller than $1 \mu \mathrm{m}$ are smaller than the EDS analysis zone and therefore cannot be reliably analyzed using EDS. Bulk sample composition was quantitatively measured using ICP-MS. ICP-MS analysis was carried out on the sample collected from underneath the K-port floor modules. This sample was also analyzed for specific surface area as described in Section 3.0.

\subsection{ICP-MS Analysis}

Chemical constituent characterization was carried out by two methods. ICP-MS was used to measure the metallic elements present in the dust. A Carlo Erba EA1108 Carbon Hydrogen Nitrogen Oxygen Sulfur (CHNOS) Elemental Analyzer combustion analysis instrument was used to measure the amount of carbon, nitrogen, and hydrogen contained in the samples. The samples were split to provide sample material for both the ICP-MS and the CHNOS analysis.

Five samples were analyzed using an ICP-MS. The samples were first dissolved in 50\% hydrofluoric acid. They were placed on a hotplate and heated to dryness. Then $10 \mathrm{ml}$ of nitric acid was added and the samples were again heated on the hotplate. The samples did not completely dissolve in the HF solution. This was also experienced during analysis of Alcator C-MOD samples and is most likely due to insulator material such as silicon oxide or some other very inert material (i.e. Inconel) used in the vacuum vessel. The samples were allowed to cool, then analytically transferred to $100 \mathrm{ml}$ volumetric flasks, and diluted to volume with Nanopure water. All of samples were filtered through a 0.2 micron filter and spiked with yttrium (an internal ICP-MS standard) before being analyzed by ICP-MS. The results of the ICP-MS analysis are summarized in Table 4.1.

Table 4.1 Results of initial dissolution and analysis with ICP-MS (wt\%).

\begin{tabular}{|l|c|c|c|c|c|c|c|c|c|c|}
\hline \multicolumn{1}{|c|}{ Sample } & $\mathbf{A l}$ & $\mathbf{B}$ & $\mathbf{C a}$ & $\mathbf{M o}$ & $\mathbf{Z n}$ & $\mathbf{A g}$ & $\mathbf{C r}$ & $\mathbf{C u}$ & $\mathbf{F e}$ & $\mathbf{N i}$ \\
\hline CI-MSS-01 & 2.6 & 0.28 & 0.12 & 1.8 & 0.10 & 0.09 & 7.82 & 0.4 & 14.2 & 19.8 \\
\hline CI-MSS-03 & 3.0 & 0.62 & 0.10 & 3.1 & 0.13 & 0.07 & 8.92 & 0.8 & 8.4 & 23.6 \\
\hline CI-MSS-05 & 2.0 & 0.38 & 0.09 & 2.5 & 0.12 & 0.03 & 7.79 & 0.5 & 5.8 & 22.5 \\
\hline $\mathbf{0 2 - 2 5 0}$ & 1.9 & 2.85 & 0.17 & 1.3 & 0.08 & 0.03 & 7.76 & 4.1 & 20.9 & 11.7 \\
\hline Filter Sub. & 6.9 & 6.72 & 0.22 & 2.5 & 0.28 & 0.17 & 6.25 & 1.5 & 5.8 & 17.9 \\
\hline $\begin{array}{l}\text { Mean \% } \\
\text { Error }\end{array}$ & $-3.2 \pm 0.4$ & $-1.5 \pm 0.9$ & $-2.3 \pm 2.6$ & $1.6 \pm 0.4$ & $2.7 \pm 0.6$ & $-2.5 \pm 1.8$ & $0.1 \pm 1.0$ & $1.8 \pm 0.5$ & $1.5 \pm 0.2$ & $2.0 \pm 0.3$ \\
\hline
\end{tabular}

Approximately $1-5 \mathrm{mg}$ of each sample was weighed into tared $8 \times 5 \mathrm{~mm}$ tin containers. Each sample was analyzed three times with the Carlo Erba EA1108 and the average of these measurements reported in Table 4.2. The samples were placed into an autosampler on the analyzer behind a set of weighed standards. The analyzer combusts each standard, measures the effluent, and calculates the elemental composition of the 
standards. Each sample is then combusted while the instrument measures the effluent and calculates the elemental composition for each sample.

The mean \% error reported above in Table 4.1 reflects the total error incurred by the ICPMS instrument based upon measurement of the internal standards at the beginning of the sample analysis.

Table 4.2 Results of analysis for carbon, hydrogen, nitrogen by combustion.

\begin{tabular}{|l|c|c|c|}
\hline Sample & Carbon (wt\%) & Hydrogen (wt\%) & Nitrogen (wt\%) \\
\hline CI-MSS-01 & $22.92 \pm 4.44$ & $3.02 \pm 0.57$ & $0.40 \pm 0.09$ \\
\hline CI-MSS-03 & $35.43 \pm 3.21$ & $3.52 \pm 0.22$ & $0.66 \pm 0.14$ \\
\hline CI-MSS-05 & $21.23 \pm 8.33$ & $2.78 \pm 1.08$ & $0.64 \pm 0.22$ \\
\hline 02-250 & $27.00 \pm 4.64$ & $2.35 \pm 1.36$ & $0.53 \pm 0.13$ \\
\hline Filter Housings & $44.52 \pm 3.29$ & $0.87 \pm 0.10$ & $0.76 \pm 0.10$ \\
\hline
\end{tabular}

Chemical analysis of the DIII-D dust samples indicates that the bulk of the materials found in the dust are carbon or an Inconel alloy. A variety of materials are used in DIII-D for various instrumentation and diagnostic equipment. These materials appear in the elemental analyses. The above weight percent results from the two analysis techniques do not add to a complete mass balance primarily due to materials that we do not include in the analysis. A primary constituent that is present in DIII-D but not quantified is silicon. Silicon is used in a variety of insulation materials in DIII-D. Silicon analyses is difficult to accomplish using ICP-MS without interfering with the results of the above elements that we consider more important from a safety point of view.

\subsection{ESEM/EDS Analysis}

Results were obtained from ESEM/EDS analysis of four samples FH5, FH7, FH9, and FH12. The main purpose of this analysis was to obtain spot compositional analysis of individual particles. EDS analysis of the samples was accomplished by mounting a section of the filter substrate on an examination stub and vapor depositing a thin (approximately 10 angstroms) coating of carbon to the entire stub and sample. This provides a conduction path for the electrons generated by the instrument for analysis. This coating is too thin to affect the performance of the EDS detector. Unfortunately, only qualitative elemental compositions are available due to the very low secondary electron emission of carbon materials. Individual particles $(<1 \mu \mathrm{m}$ in diameter) can not be analyzed for quantitative or even qualitative elemental composition using EDS because the spot size of the EDS analysis is larger than $1 \mu \mathrm{m}$. Therefore, EDS analysis of particles have diameters less than $1 \mu \mathrm{m}$ is unreliable at best. ESEM analysis is extremely useful in visualizing very small features, even as small as a few nanometers. The following figures in this section illustrate the general particulate found in the DIII-D samples as well as some general composition. Figure 4.1 is a photomicrograph showing the substrate of the FH5 sample. Note that the pores are relatively uniform at approximately $0.2 \mu \mathrm{m}$. These filter substrates are rated at a total porosity of $0.02 \mu \mathrm{m}$ due to the thickness of the substrate. 


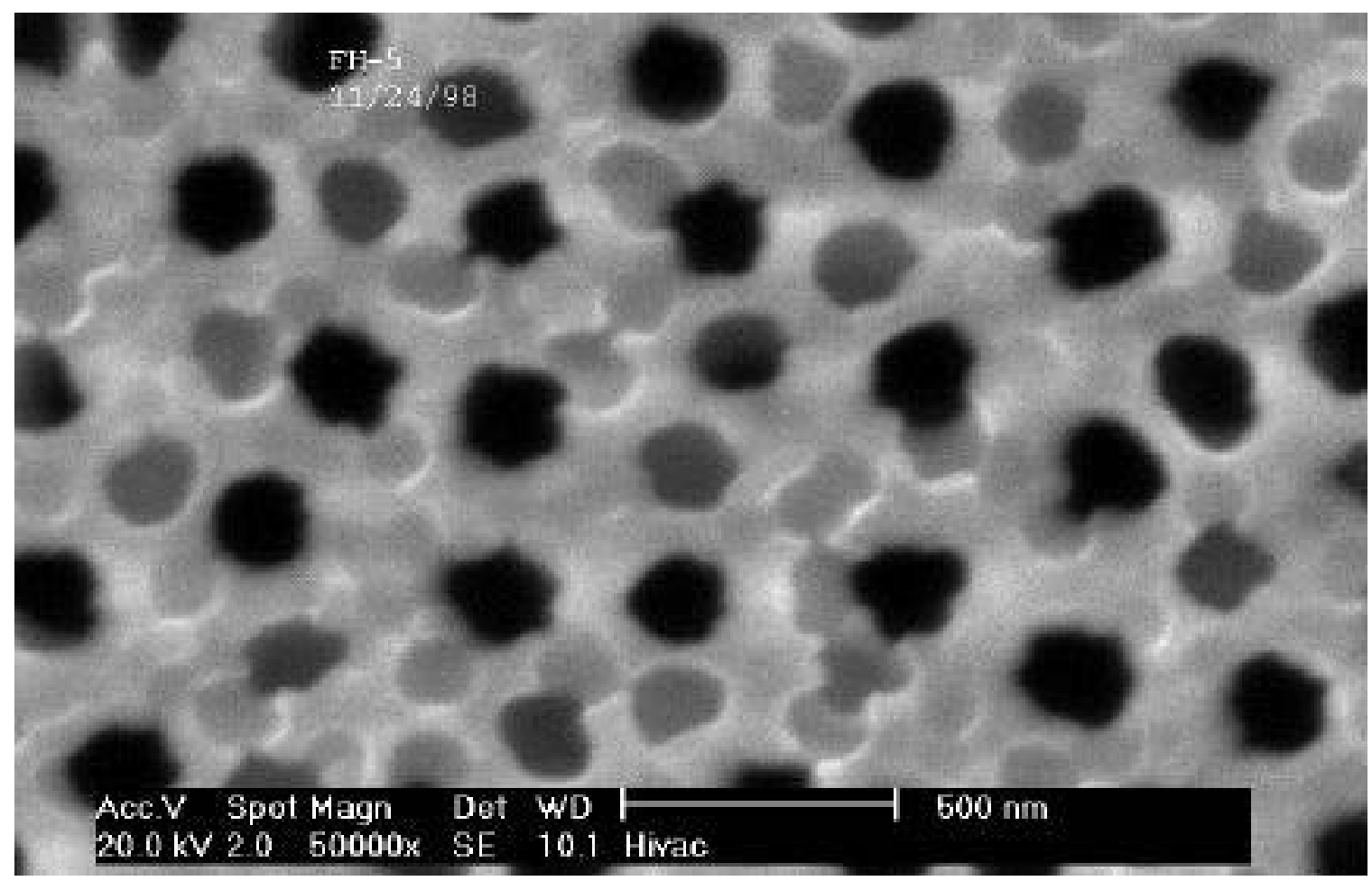

Figure 4.1. Photomicrograph showing the porosity of the FH5 filter substrate.

Figures 4.2 through 4.4 show particulate observed on sample FH5. Figure 4.2 indicates that a variety of particulate was observed including carbon, aluminum, zinc, calcium, oxygen, and copper. Figures 4.3 and 4.4 both show spherical particles with diameters less than $1 \mu \mathrm{m}$.

Figures 4.5 to 4.9 show photomicrographs of particulate observed on sample $\mathrm{FH} 7$. The FH7 sample was taken from surfaces in the R-1 $0-90^{\circ}$ port. The area was visibly covered with a fine coating of particulate. The figures indicate a wide variety of spherical particles.

Figures 4.10 through 4.14 show particulate found on sample FH9, a sample taken from surfaces in the $90-180^{\circ} \mathrm{R}-1$ ports. A variety of particle compositions are shown ranging from aluminum and oxygen to nickel, chromium, and iron. A spherical particle with carbon composition is also shown.

Figures 4.15 through 4.19 show particulate observed on the FH12 sample. This sample was collected from the plasma facing surfaces of the $90-180^{\circ}$ Upper $45^{\circ}$ and Row 1 ceiling tiles. A variety of flaky particulate was observed on this sample having compositions including aluminum, carbon, phosphorous, and oxygen. The phosporous may be exitation lines generated by other elemental spectrums. 


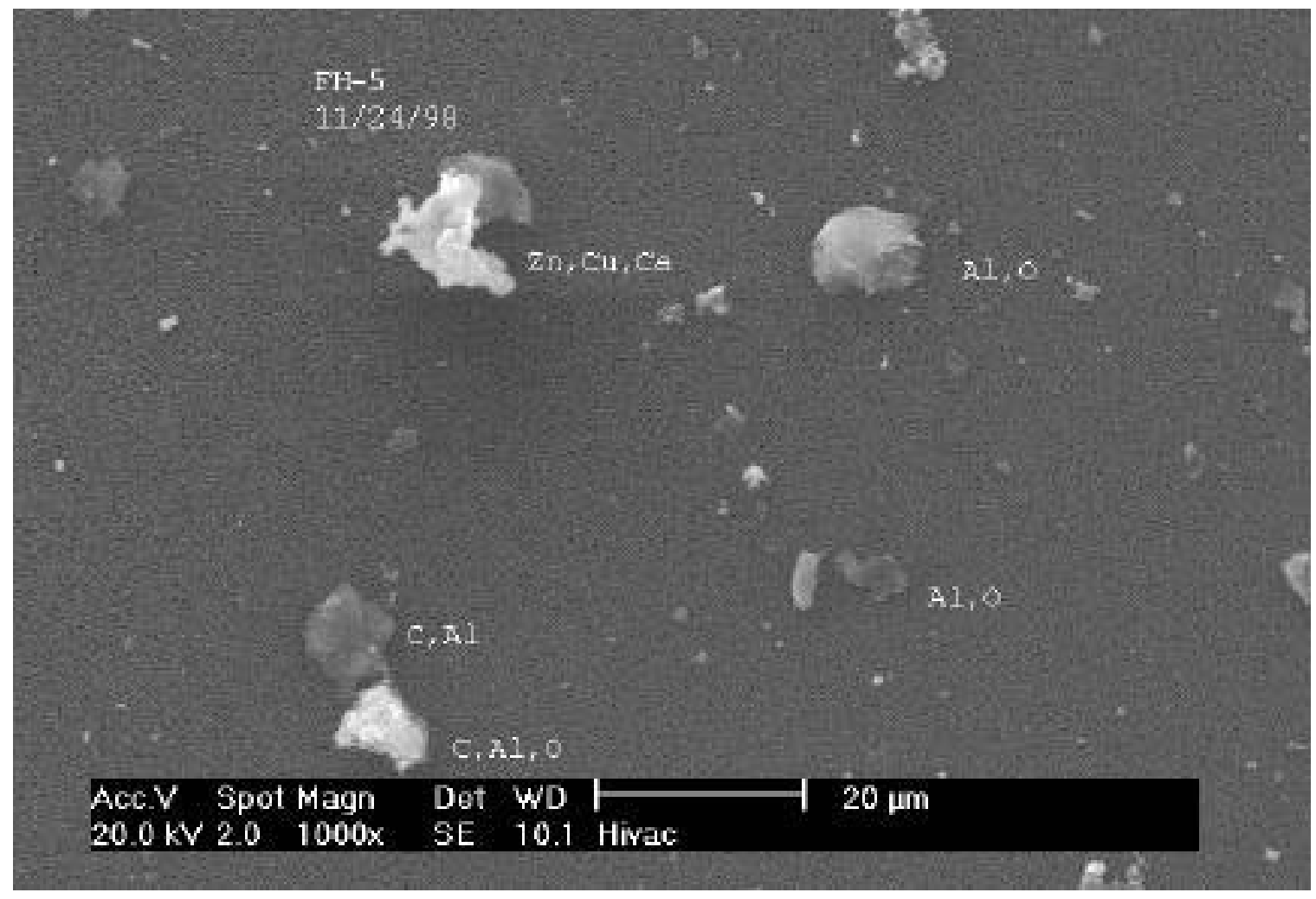

Figure 4.2. Photomicrograph of FH5 sample at 1000X showing a variety of materials.

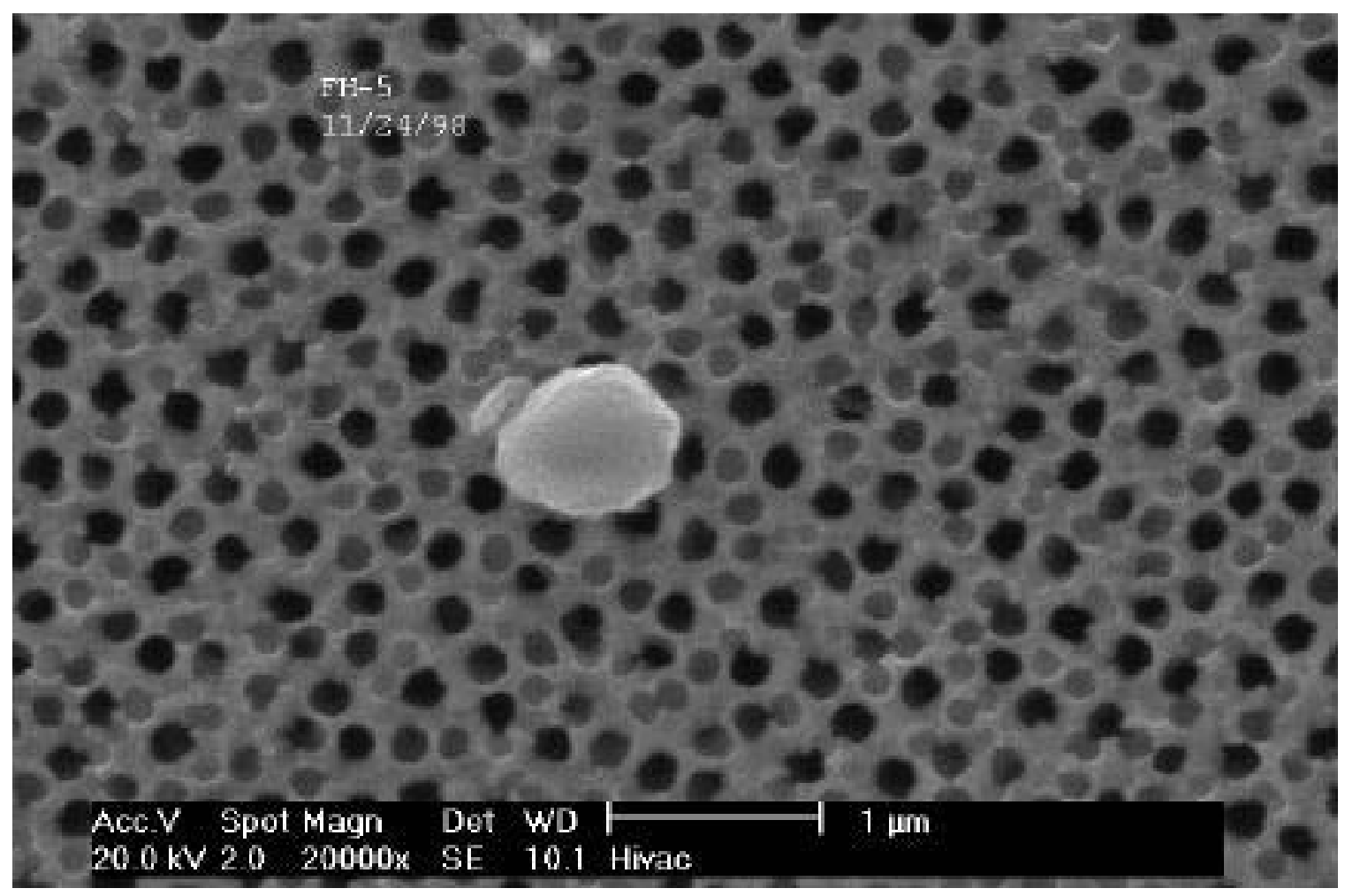

Figure 4.3. Photomicrograph of FH5 sample showing a high magnification image of a sub-micron spherical particle. 


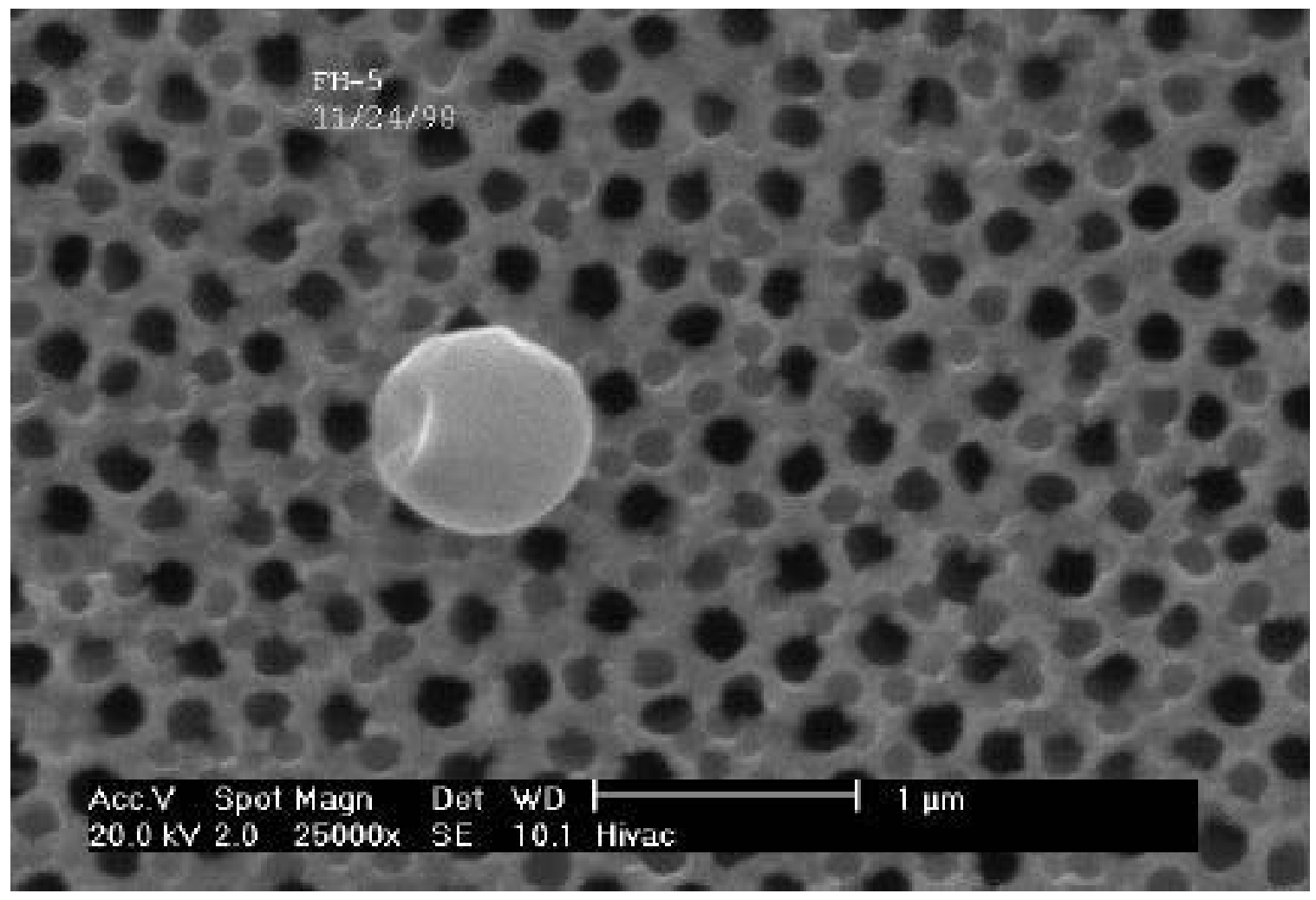

Figure 4.4. Photomicrograph of a sub-micron spherical particle found in the FH5 sample.

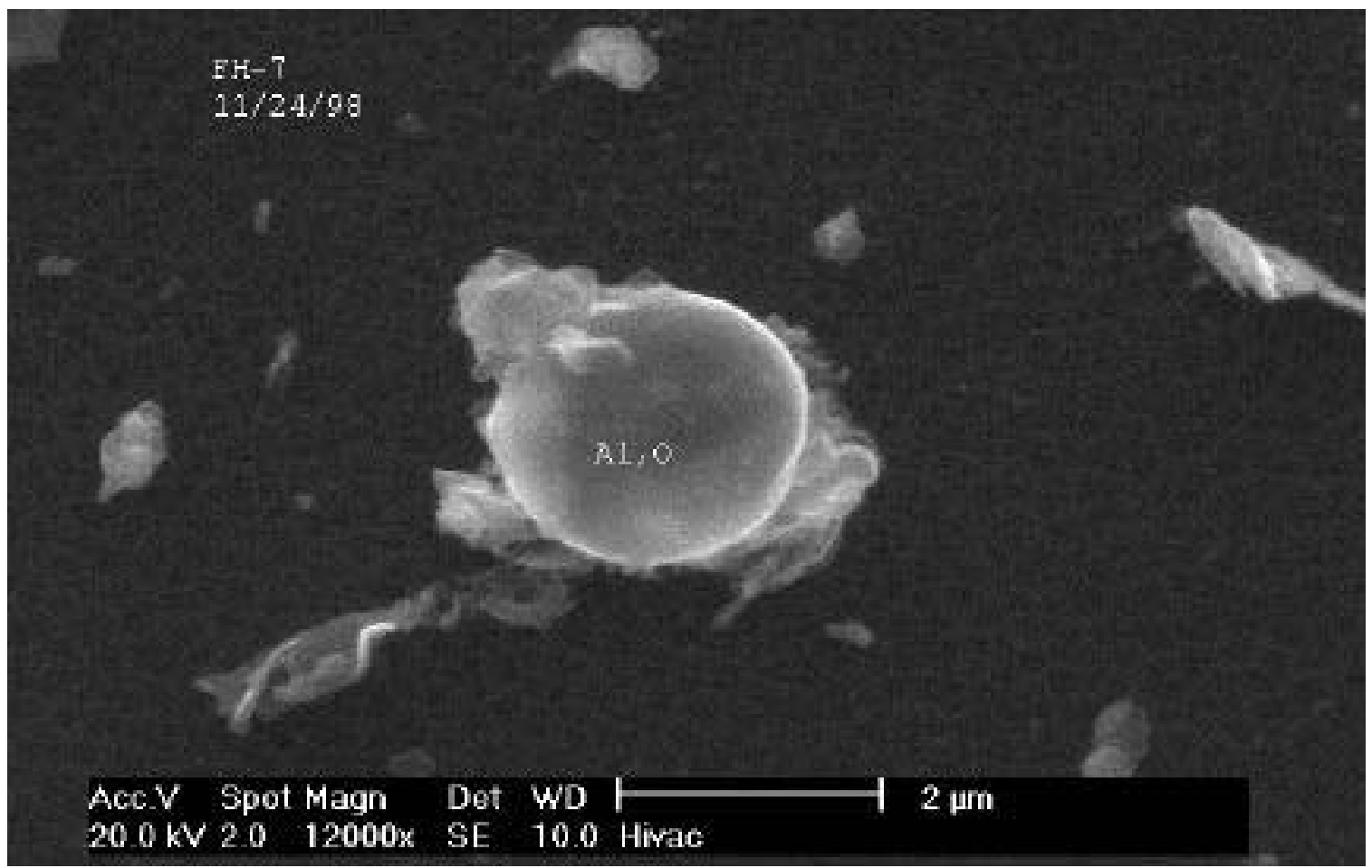

Figure 4.5. Photomicrograph of an aluminum and oxygen particle found in the FH7 sample. 


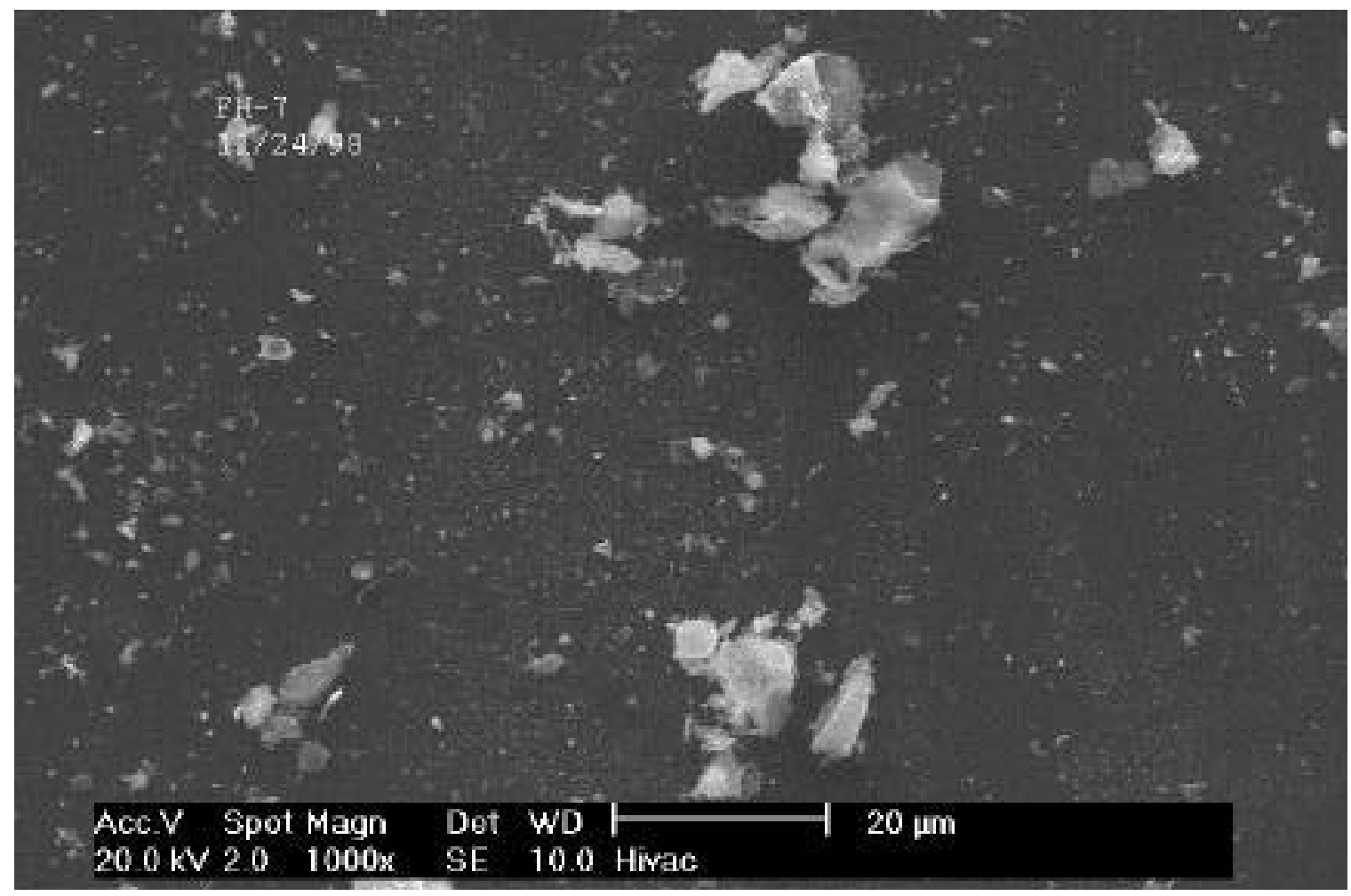

Figure 4.6. Photomicrograph of particulate found in the FH7 sample.

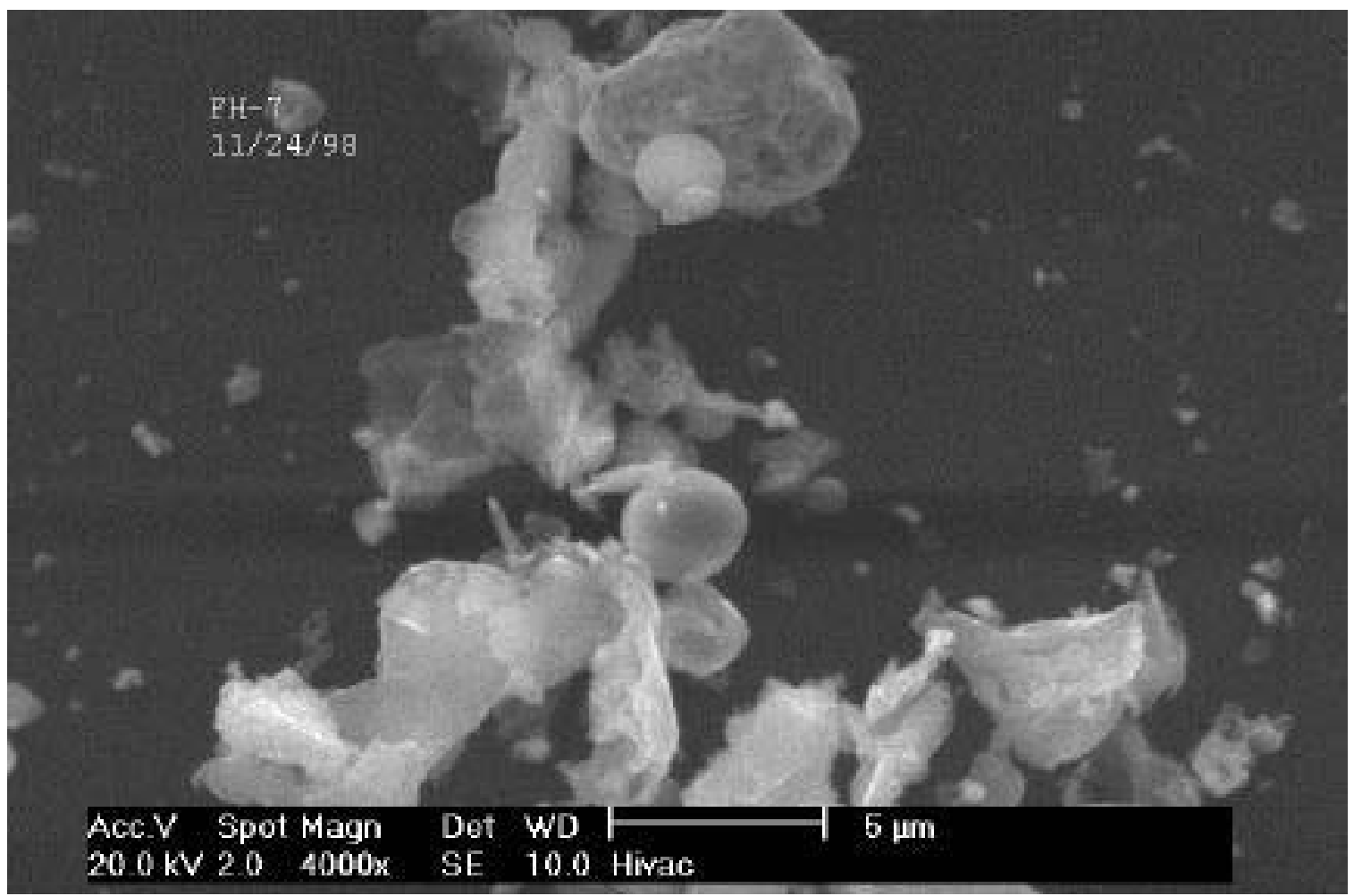

Figure 4.7. Photomicrograph of particulate found in the FH7 sample including spherical particles. 


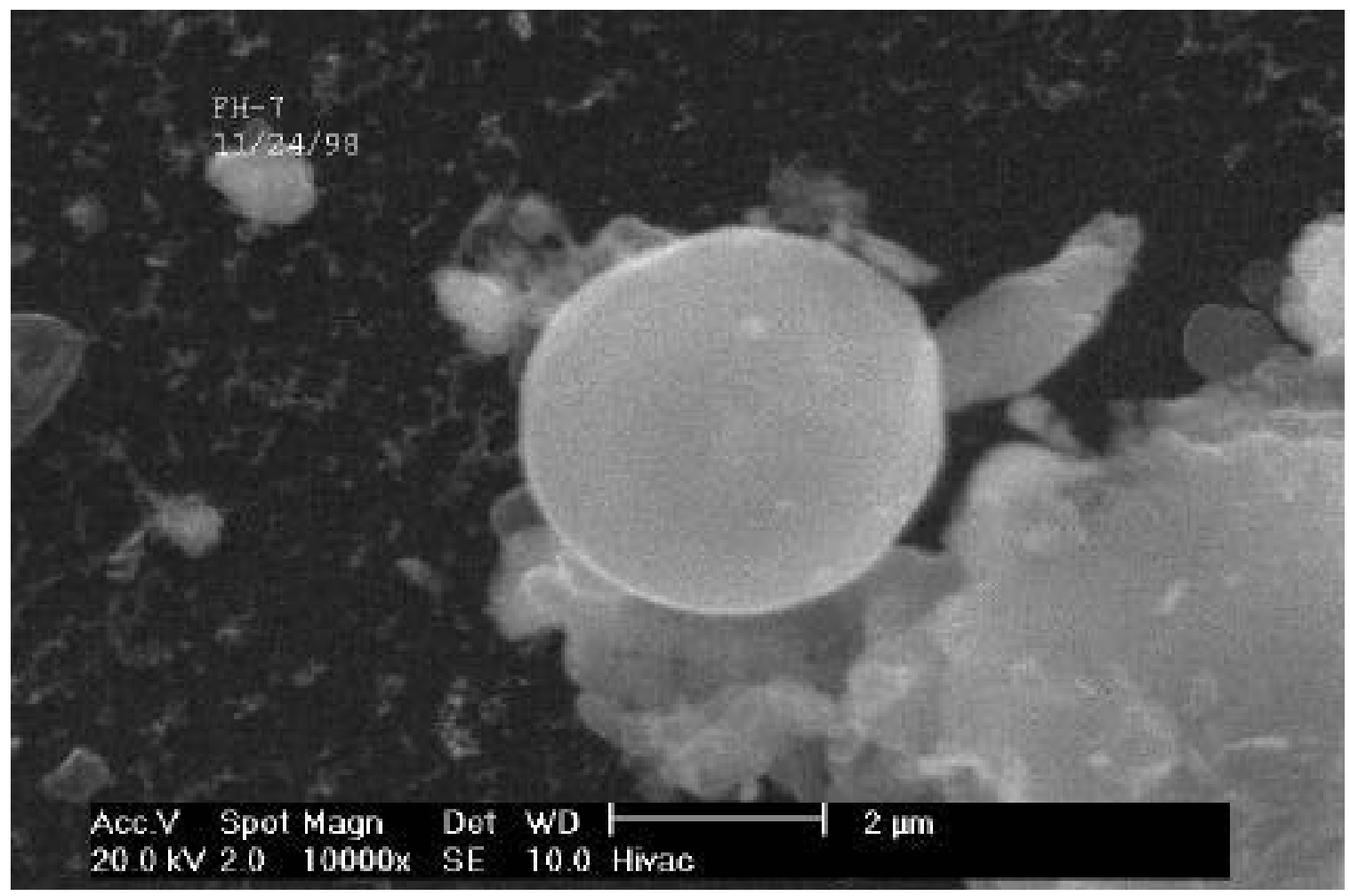

Figure 4.8. Photomicrograph of particulate found in the FH7 sample including a larger spherical particle.

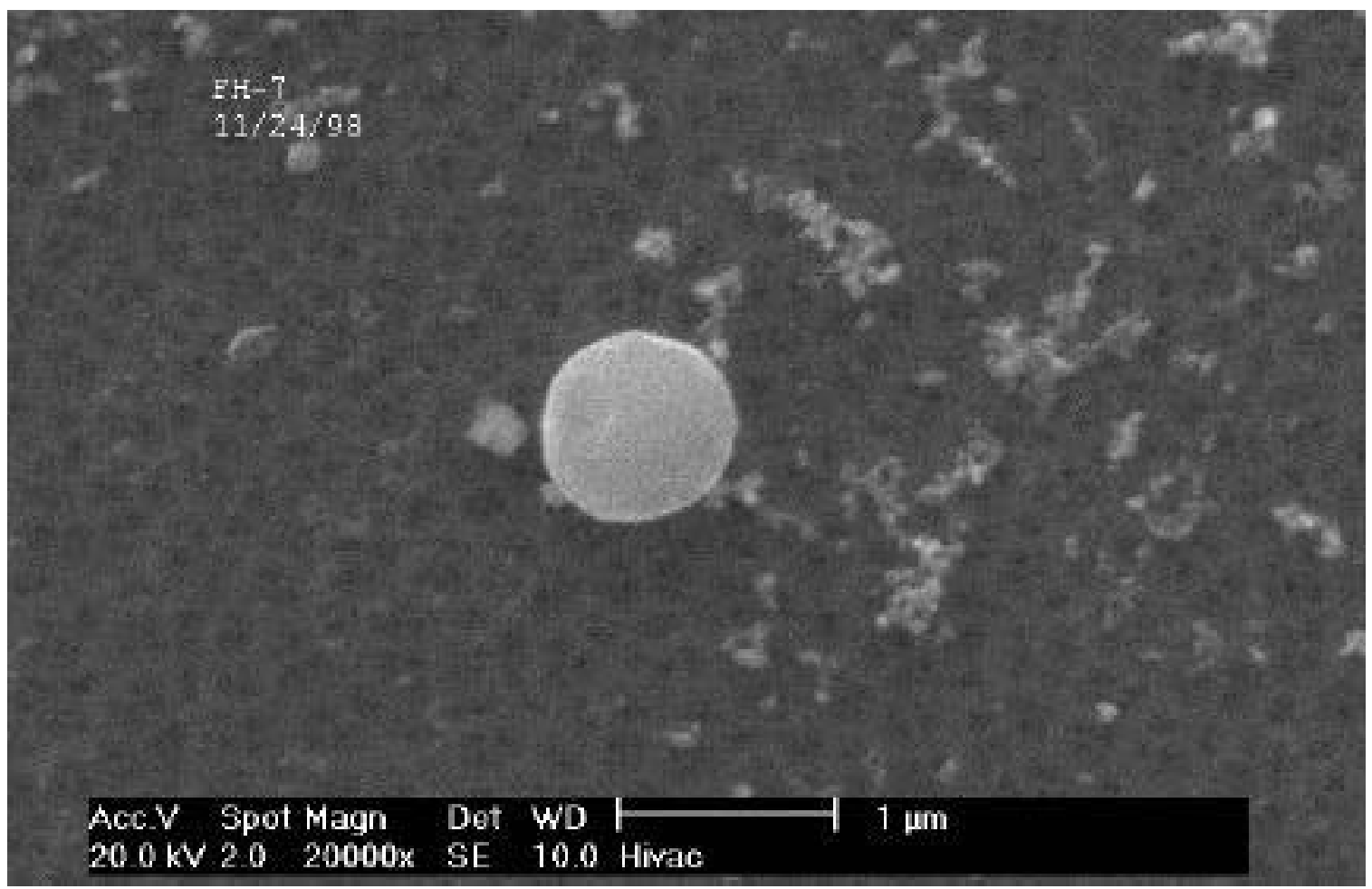

Figure 4.9. Photomicrograph of particulate found in the FH7 sample including a submicron spherical particle. 


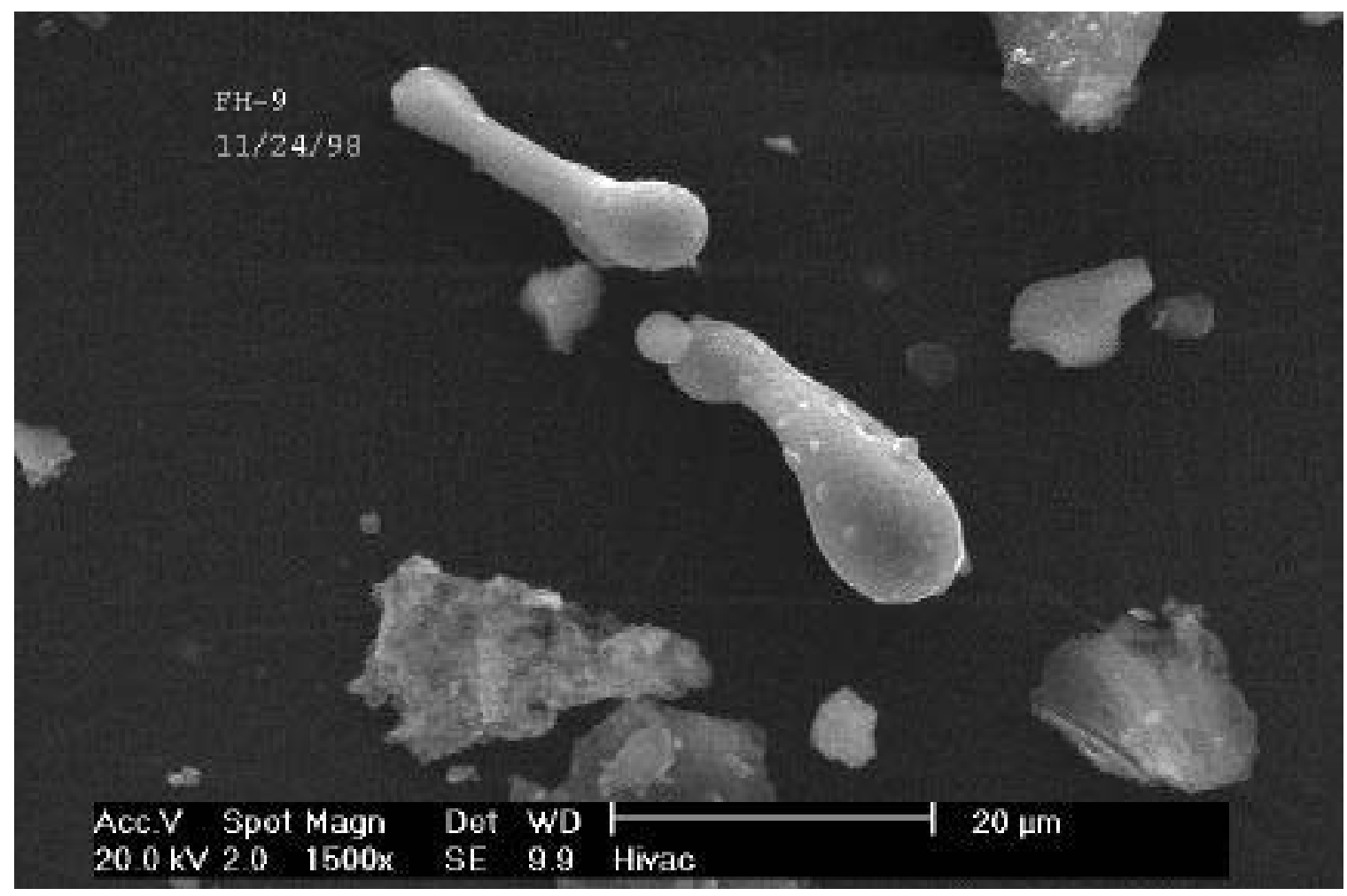

Figure 4.10. Photomicrograph of particulate found in the FH9 sample including a spherical particle.

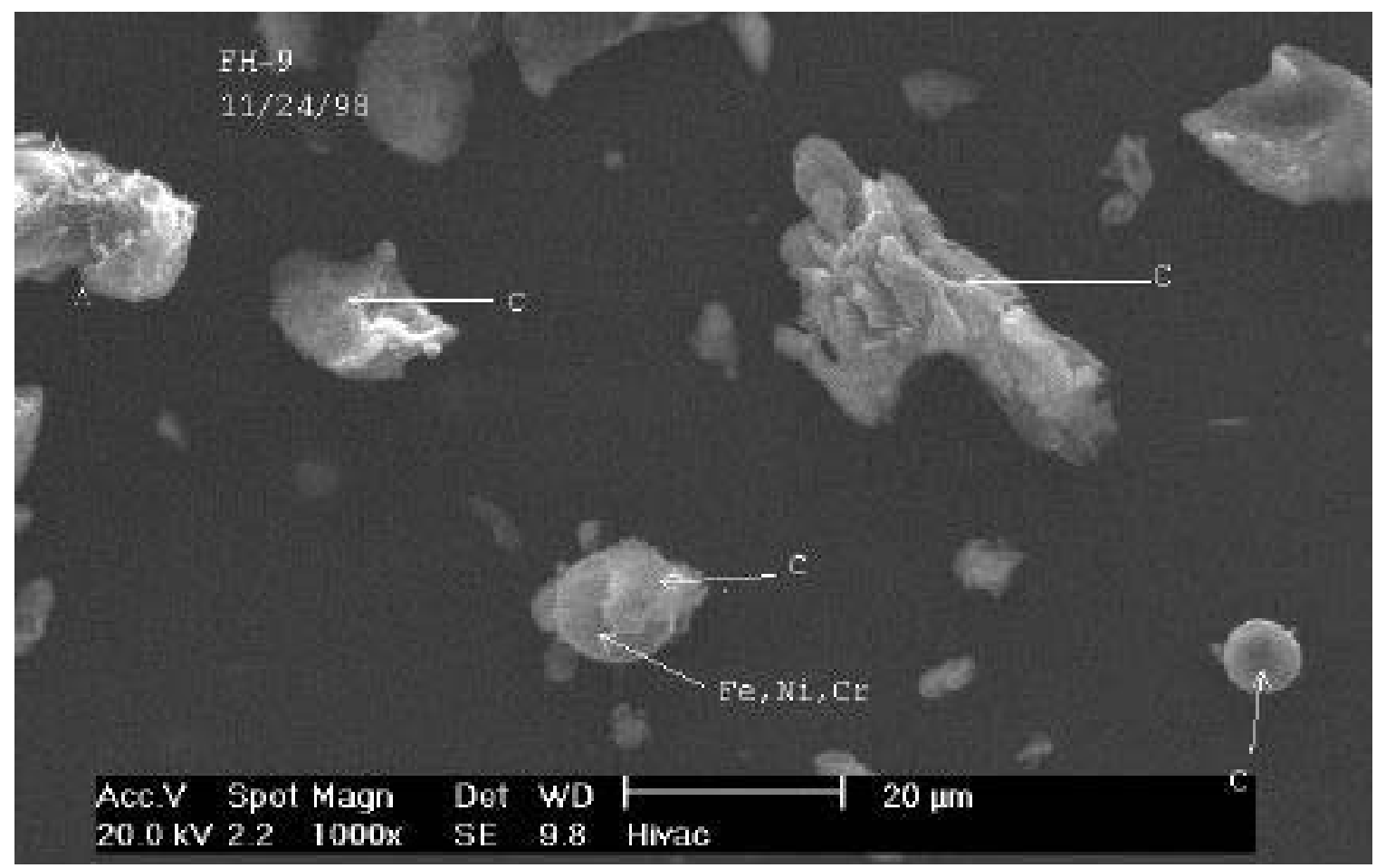

Figure 4.11. Photomicrograph of carbon, steel, and spherical carbon particles in sample FH9. 


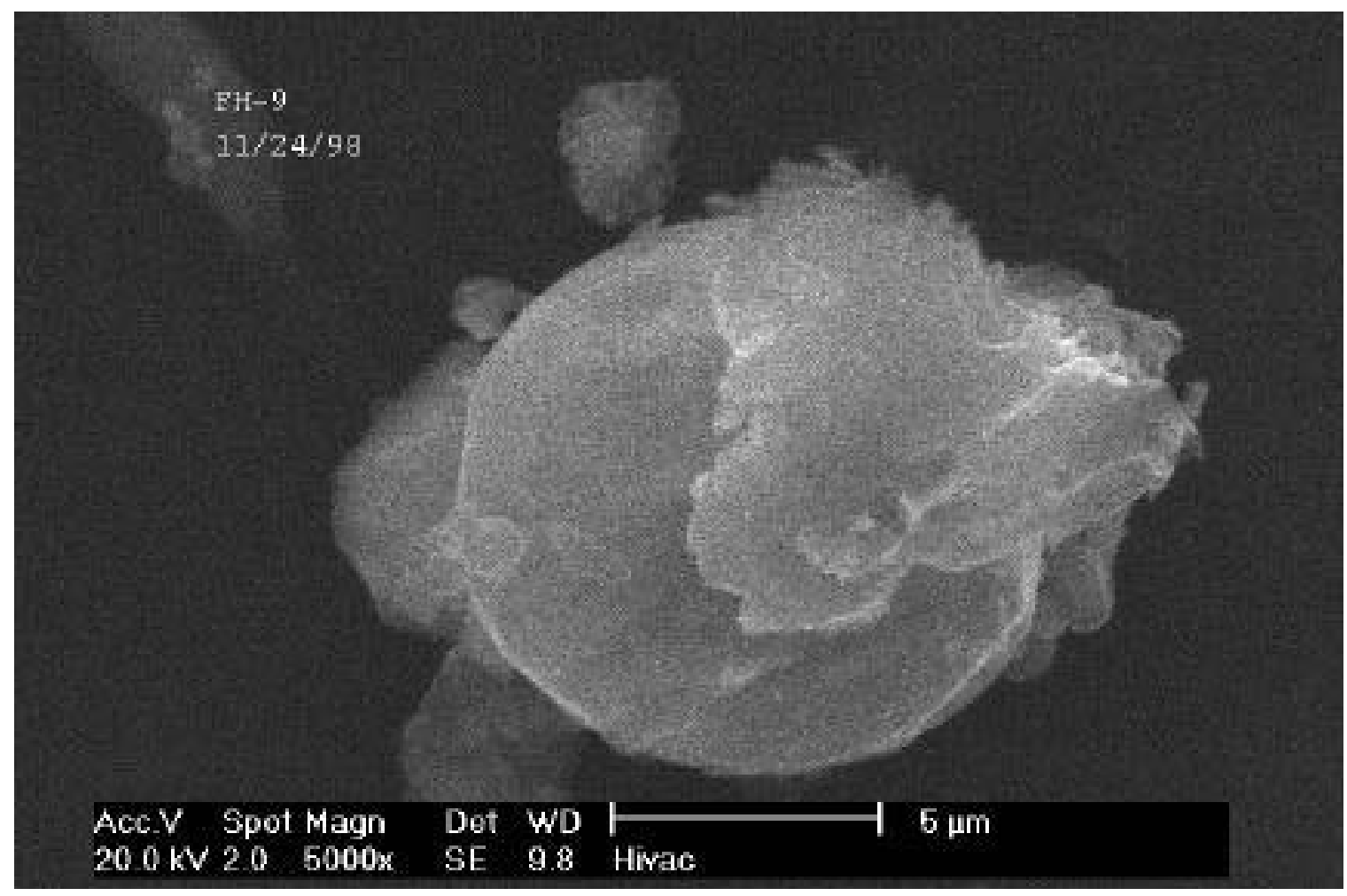

Figure 4.12. High magnification photomicrograph of the $\mathrm{Fe}, \mathrm{Ni}, \mathrm{Cr}$ particle shown in Figure 4.11.

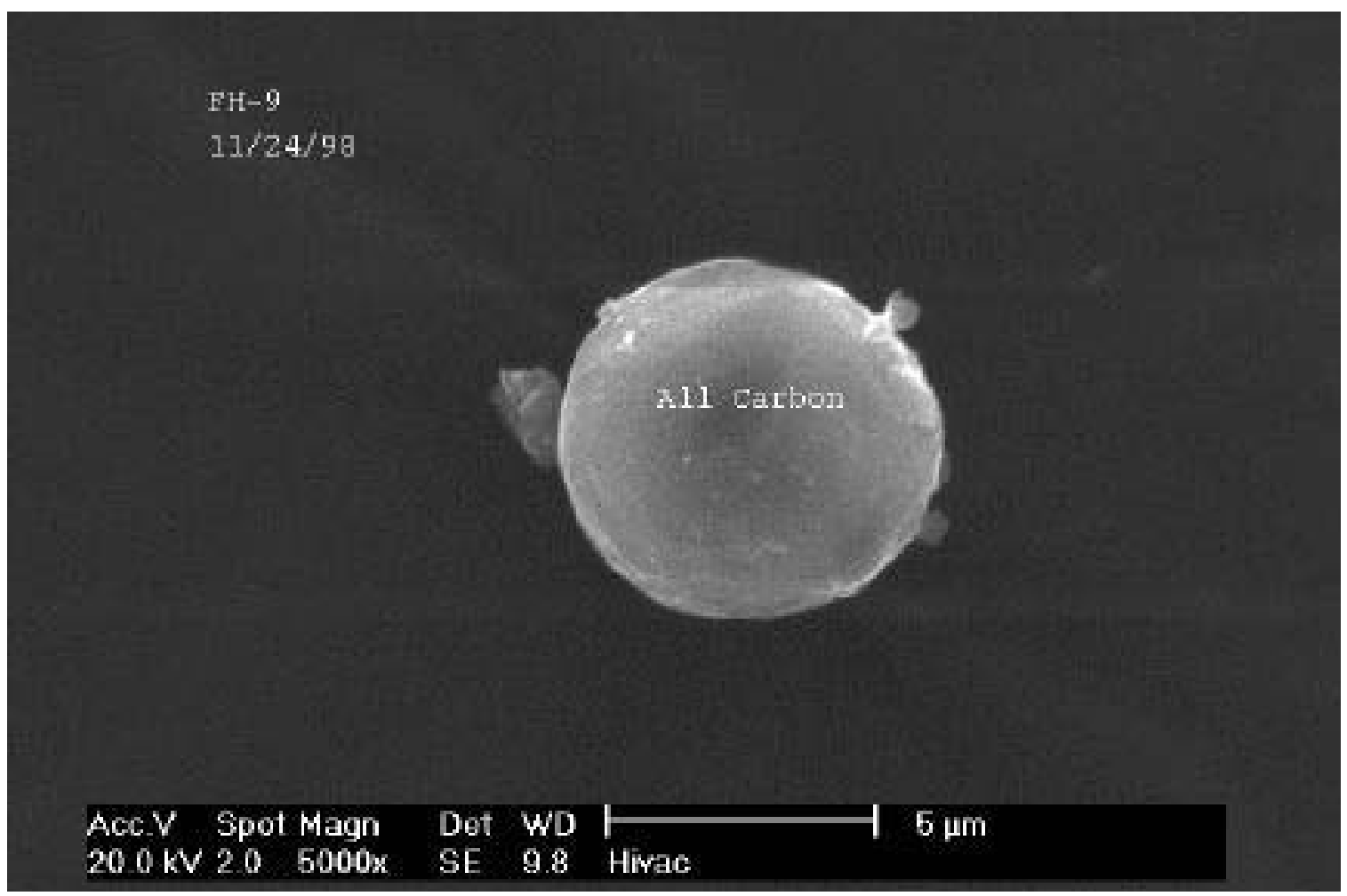

Figure 4.13. Photomicrograph of a spherical carbon particle found in sample FH9. 
EH-9

$11 / 24 / 98$

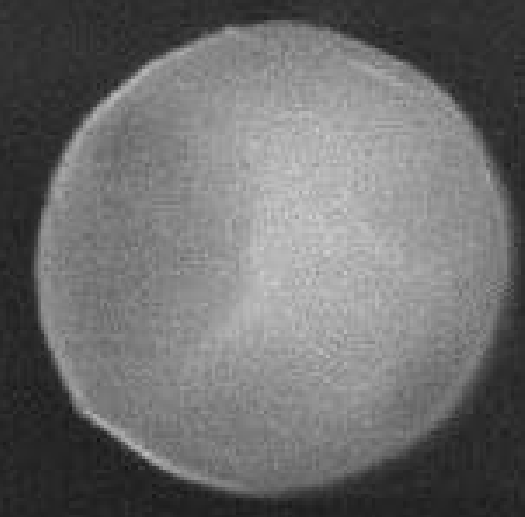

\section{Acc.V Spot Magn Det WD} $20.0 \mathrm{kV} 2.0 \quad 15000 \mathrm{x}$ SE 9.9 Hivac

Figure 4.14. Photomicrograph of a 2 micron particle found in sample FH9.

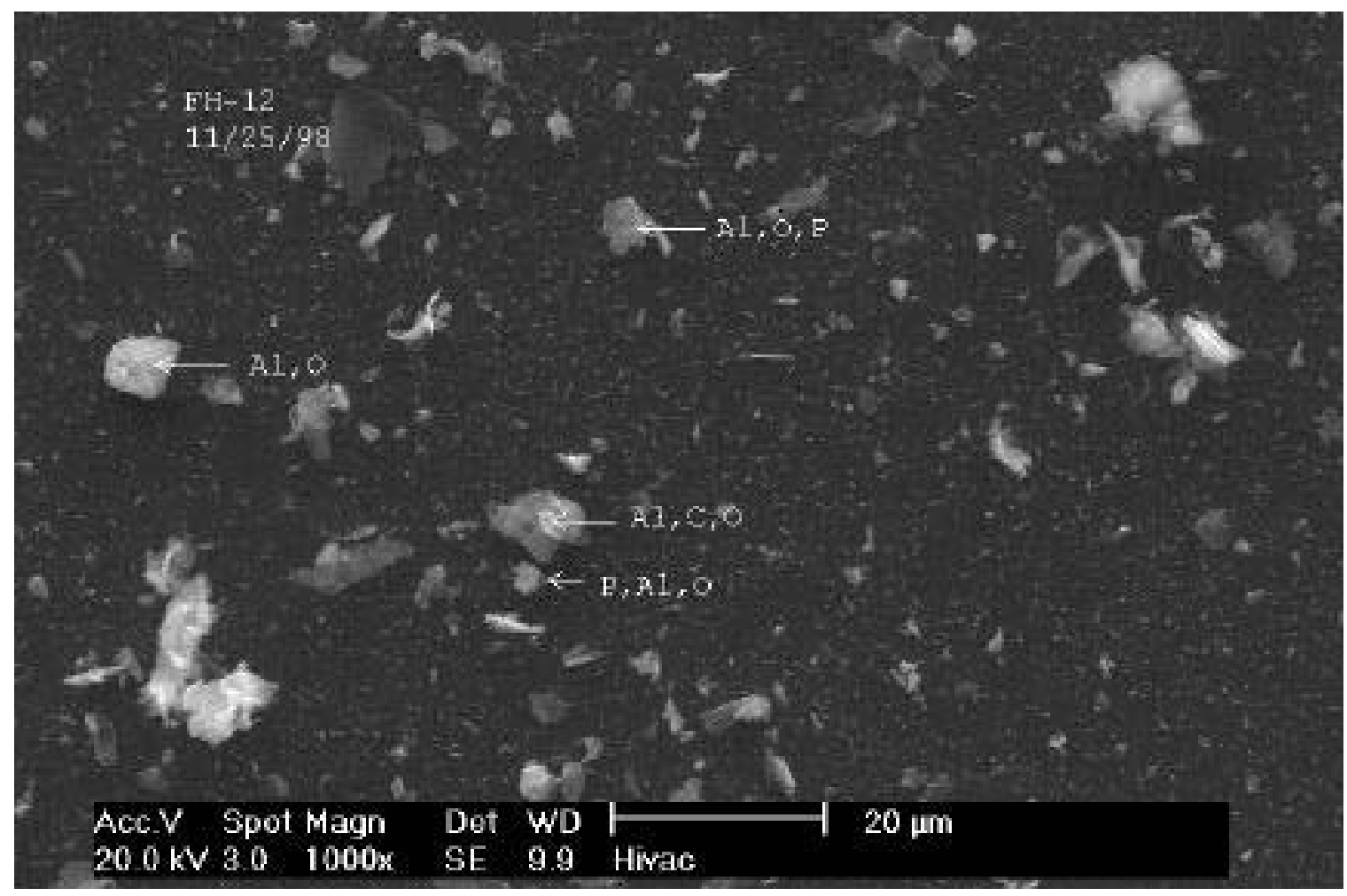

Figure 4.15. Photomicrograph showing compositions of particles found in FH12. 


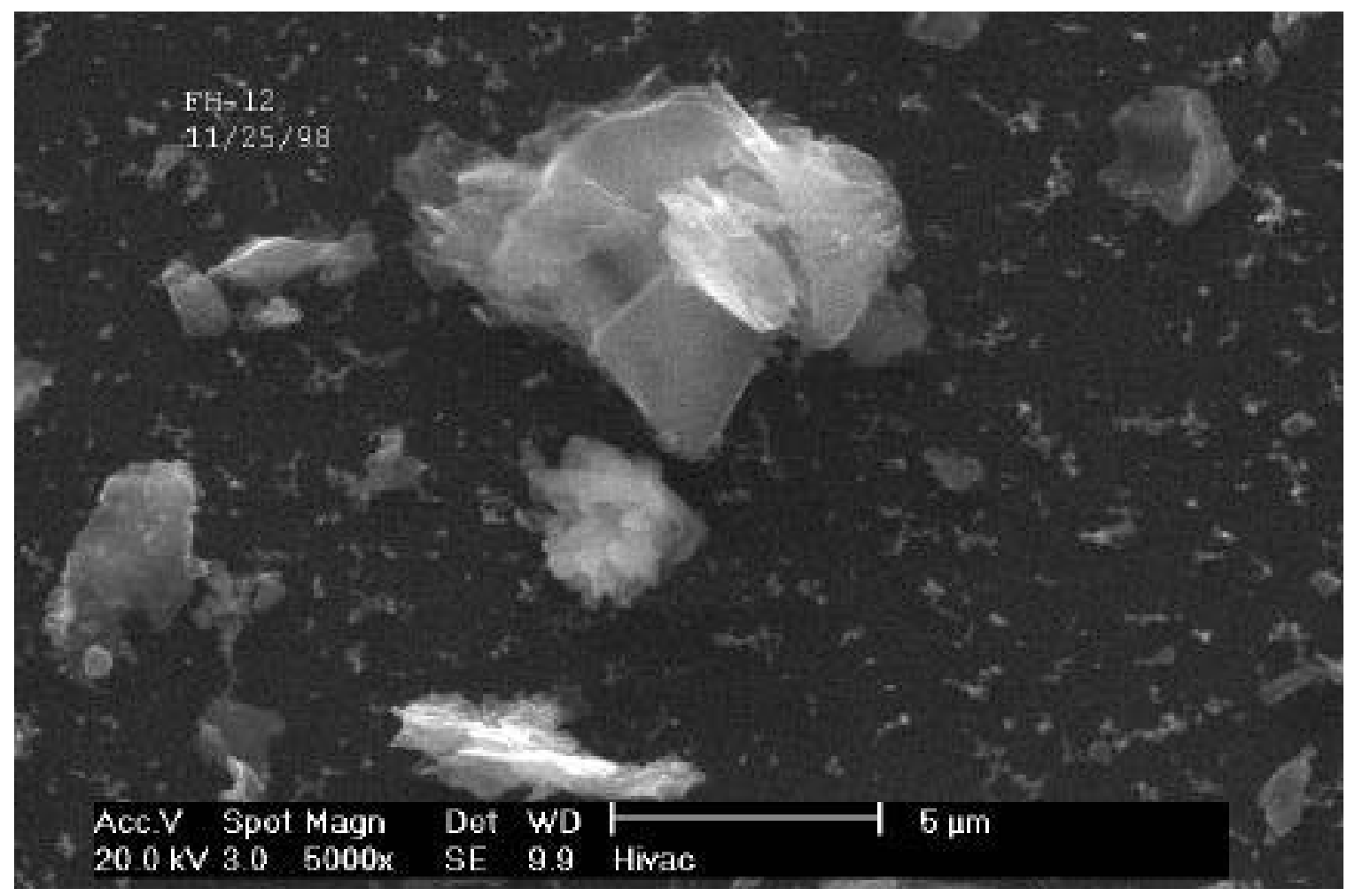

Figure 4.16. Photomicrograph of particles found in FH12 at 5000 X.

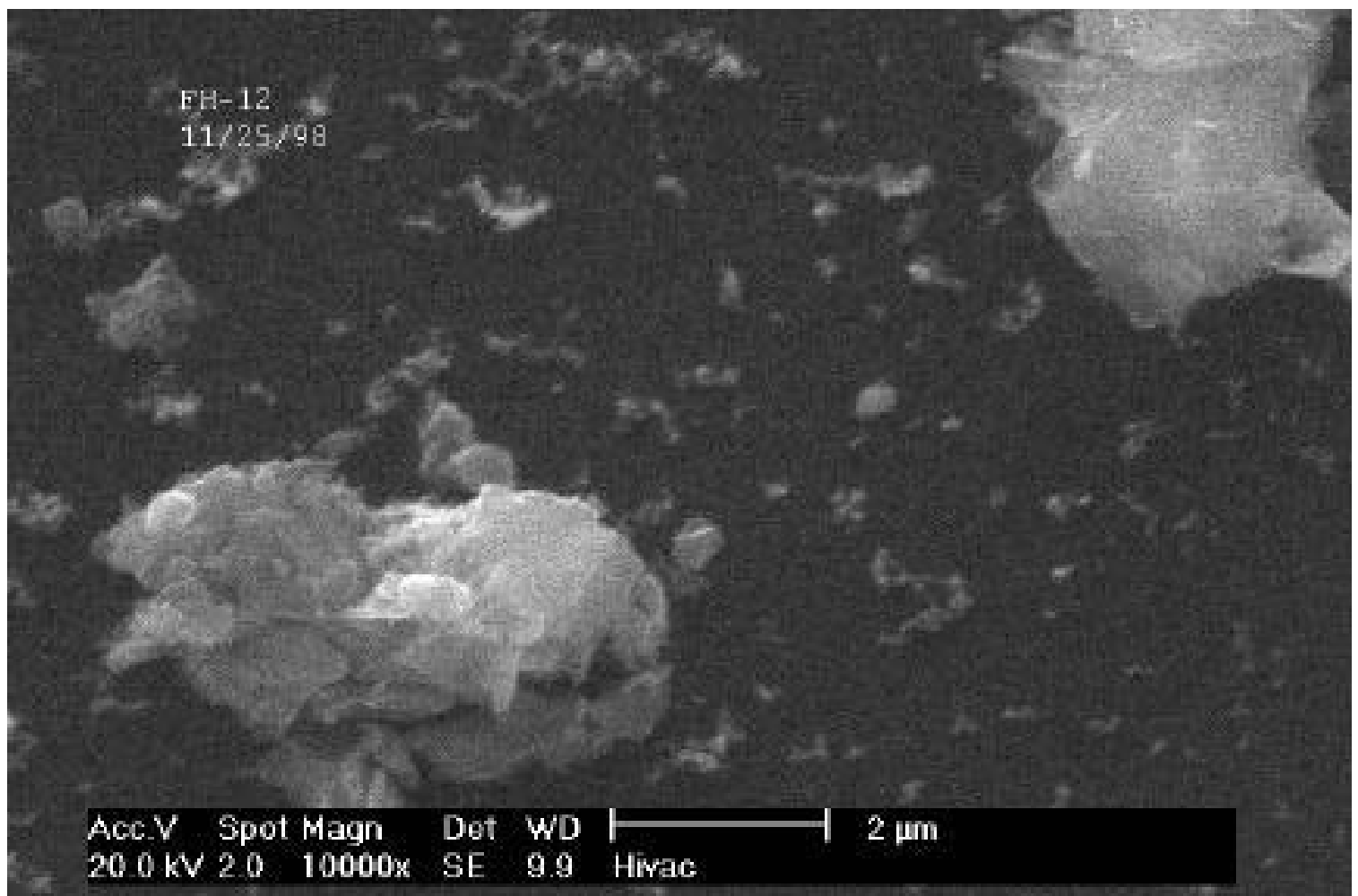

Figure 4.17. Photomicrograph of particles found in FH12 at 10000 X magnification. 


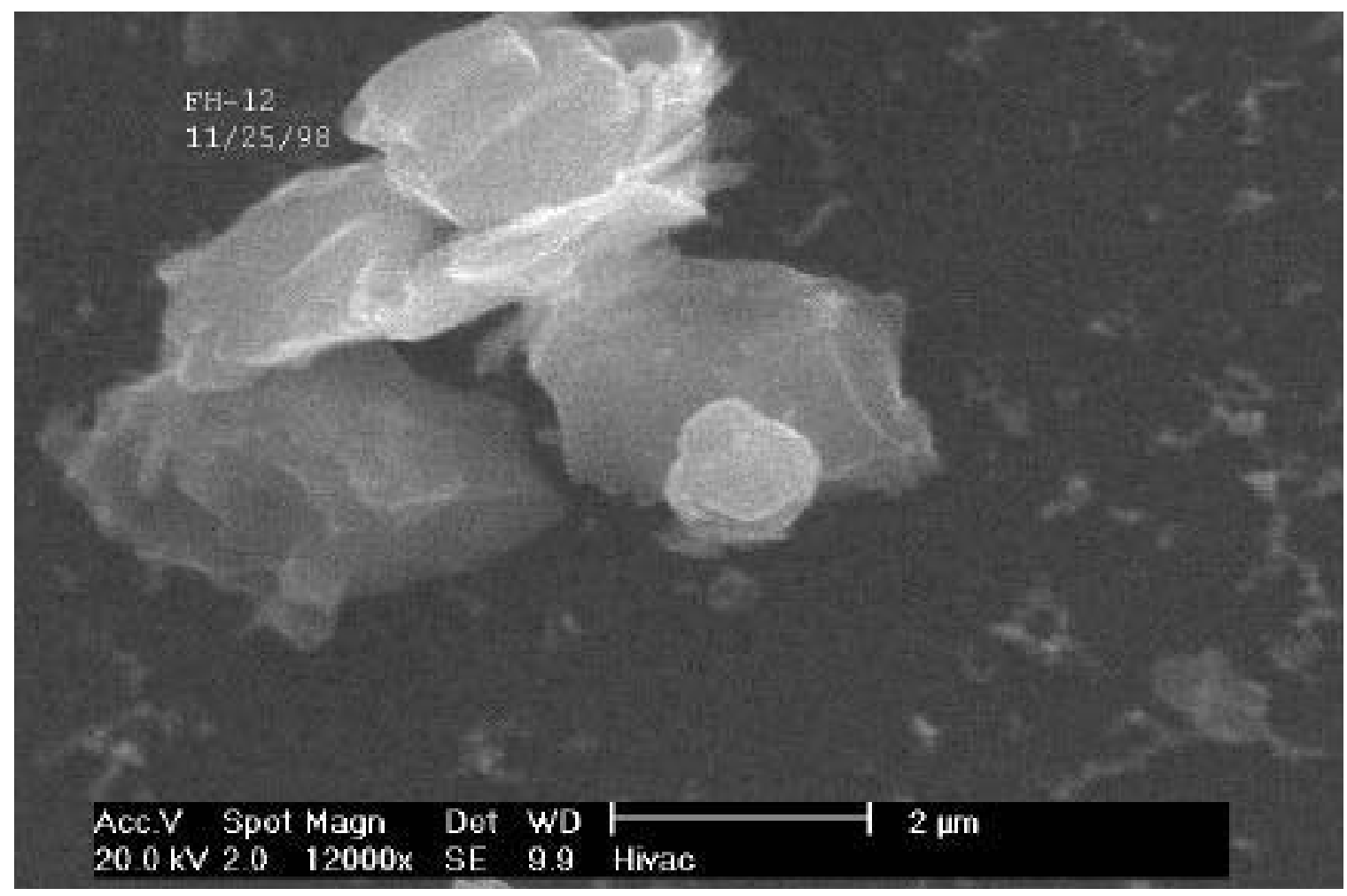

Figure 4.18. Photomicrograph of particles found in FH12 at $12000 \mathrm{X}$ magnification.

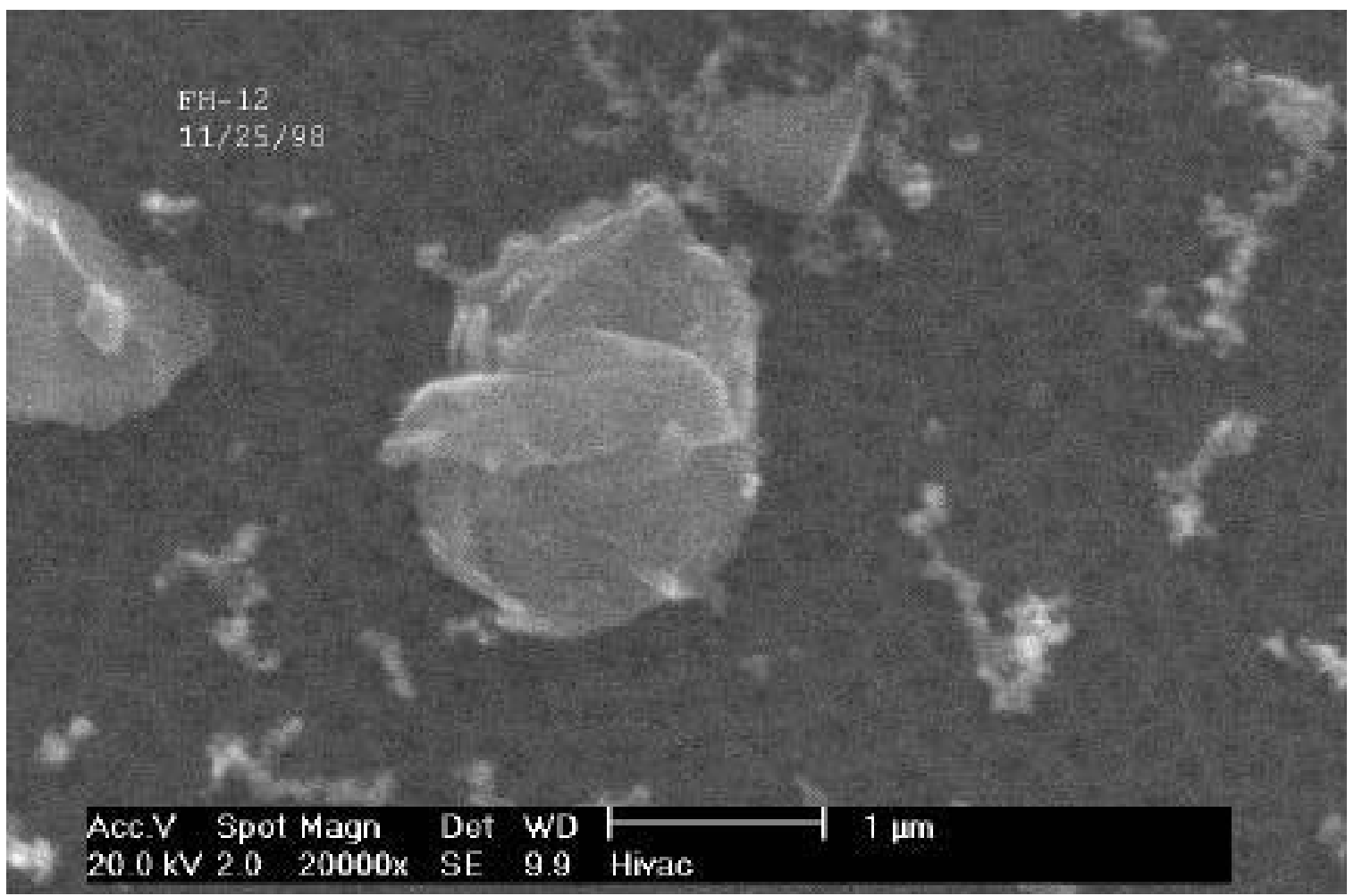

Figure 4.19. Photomicrograph of particles found in FH12 at 20000 X magnification. 


\subsection{Particle Size Distribution Analysis}

Particle size distribution analysis was performed on 17 filter vacuum samples. Particle size distribution information was also obtained from four cascade impactor measurements. Three samples were collected using metallurgical replicating tape. The replicating tape samples were analyzed first with an LS130 Coulter Counter and then using the optical microscope technique described below and used for the vacuum filter samples.

\subsection{Optical Particle Size Analysis Methodology}

The optical microscope analysis samples were analyzed according to the methods outlined in Carmack et al. ${ }^{1}$ A flow chart schematic of the particle size distribution construction method is shown in Figure 5.1.

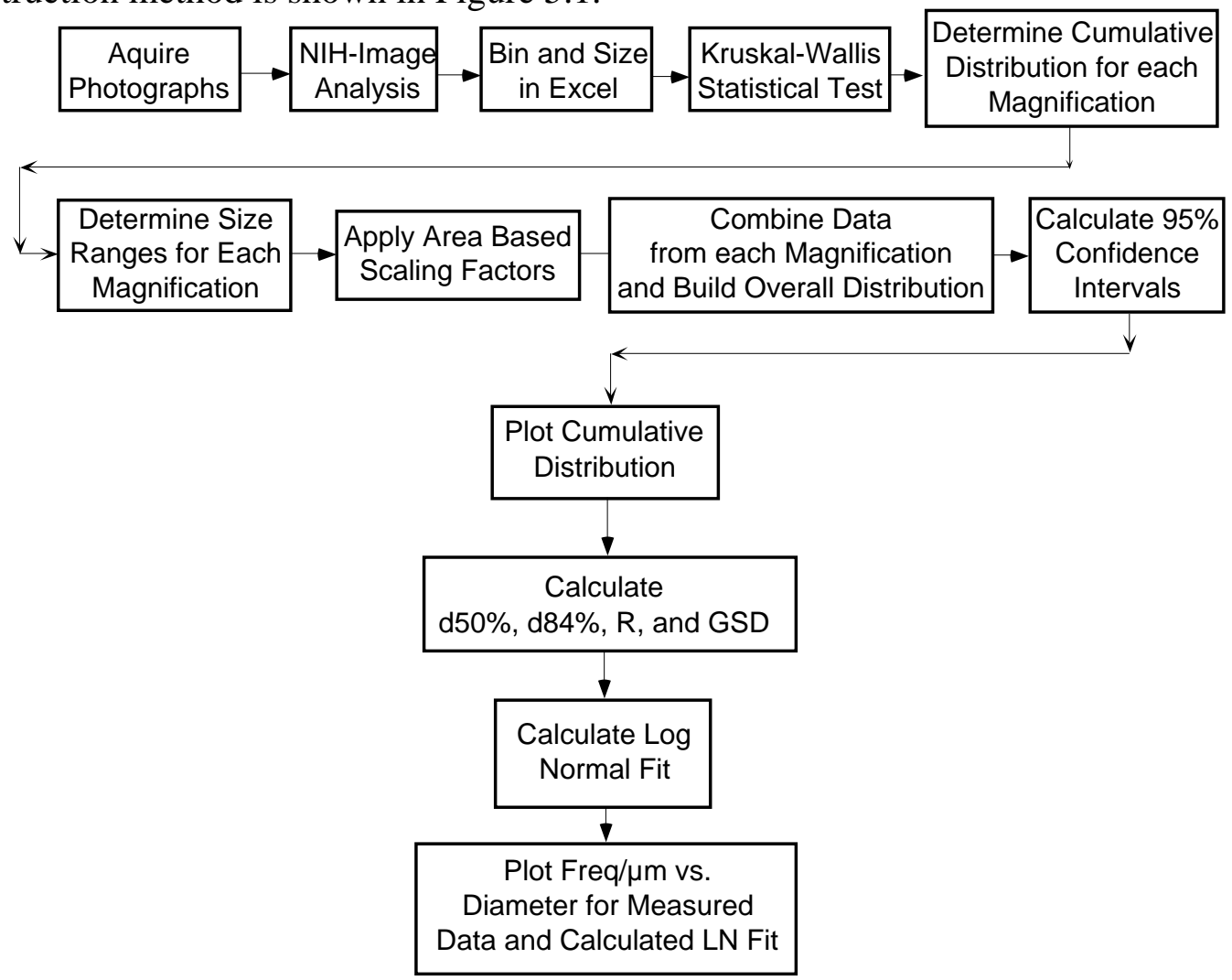

Figure 5.1. Flow chart schematic of particle size distribution construction.

Photographs were acquired at 50x, 100x, 200x, 500x and 1000x magnification in four or five different areas of each sample. These images were then analyzed using NIHImage $^{5}$ and individual cumulative distributions constructed. Before these distributions were constructed, a Kruskal-Wallis ${ }^{6}$ statistical test was performed to ensure that the data from different photographs represented the same underlying distribution. If data from one or more photographs did not pass the test with the other sets, the data were not used in the analysis. The data were then combined in one spreadsheet and a scaling factor was applied based on the magnification at which the data were acquired. Ninety-five percent confidence intervals were calculated for each distribution. After generating the $95 \%$ 
confidence intervals the $\mathrm{d}_{50 \%}$ (Count Median Diameter, CMD), the $\mathrm{d}_{15.9 \%}$, the $\mathrm{d}_{84.1 \%}$, the GSD, and the corresponding 95\% confidence intervals were determined.

The mass median diameter (MMD) and the surface area mean diameter $\left(\mathrm{D}_{\mathrm{Mvs}}\right)$ can also be calculated from the data as is described fully in Hinds ${ }^{7}$. The equation for calculating the MMD is

$$
M M D=\exp \left[\frac{\sum n_{i} d_{i}^{3} \ln (d)}{\sum n_{i} d_{i}^{3}}\right]
$$

where;

$$
\begin{array}{lll}
\mathrm{MMD} & = & \text { mass median diameter, } \mu \mathrm{m}, \\
\mathrm{n}_{\mathrm{I}} & = & \text { number of particles in the } i \text { th group, } \\
\mathrm{d}_{\mathrm{I}} & = & \text { midpoint diameter of the } i \text { th group. }
\end{array}
$$

The value for the $\mathrm{D}_{\mathrm{Mvs}}$ is the surface average diameter, also referred to as the Sauter diameter or mean volume-surface diameter. The $\mathrm{D}_{\mathrm{Mvs}}$ value is used when comparing particle size measurements with specific surface area measurements. The equation for calculating the $\mathrm{D}_{\mathrm{MvS}}$ is

$$
D_{M V S}=\frac{\sum s_{i} d_{i}}{S}=\frac{\sum n_{i} d_{i}^{3}}{\sum n_{i} d_{i}^{2}}
$$

where,

$$
\begin{array}{lll}
\mathrm{D}_{\mathrm{MVS}} & = & \text { surface area mean diameter, } \\
\mathrm{s}_{\mathrm{i}} & = & \text { group surface area, } \\
\mathrm{S} & = & \text { total surface area, } \\
\mathrm{n}_{\mathrm{i}} & = & \text { number of particles in the } i \text { th group, } \\
\mathrm{d}_{\mathrm{i}} & = & \text { midpoint diameter of the } i \text { th group. }
\end{array}
$$

In addition to performing data analysis as reported in Carmack et al. ${ }^{1}$ that includes calculating the $95 \%$ confidence intervals for the cumulative distribution functions (CDF), we now report CMD values and GSD values with their associated $95 \%$ confidence intervals as described in Appendix B of Carmack et al. ${ }^{1}$ Ninety-five percent confidence intervals on the CDFs are still used to evaluate percentage distributions as previously reported. Our procedure for calculating the CMD and GSD confidence intervals allows general comparison of CMDs and GSDs obtained from the CDFs.

\subsection{Particle Size Distribution Measurement Results from Vacuum Total Filter Samples.}

The particle size data from each sample were combined to build an overall size distribution using the methodology described in Carmack et al. ${ }^{1}$ The number of particles, magnification, and number of photographs used to create the overall distributions are shown in Table 5.1. The number of particles, magnification, and number of photographs used to create the overall distributions for the replicating tape samples are shown in Table 5.2. The ranges used from each magnification are shown in Table 5.3 (filter housing samples) and 5.4 (replicating tape samples) respectively. 
Table 5.1 Analysis details for filter housing samples.

\begin{tabular}{|c|c|c|c|c|c|}
\hline & \multicolumn{5}{|c|}{ Magnification } \\
\hline Sample & $1000 x$ & $500 x$ & $200 x$ & $100 x$ & $50 x$ \\
\hline $\begin{array}{c}\text { FH1 } \\
\text { Number of Particles } \\
\text { Number of Photographs }\end{array}$ & $\begin{array}{c}113 \\
3 \\
\end{array}$ & Not Used & $\begin{array}{c}906 \\
4\end{array}$ & $\begin{array}{c}170 \\
4 \\
\end{array}$ & $\begin{array}{c}557 \\
3 \\
\end{array}$ \\
\hline $\begin{array}{c}\text { FH2 } \\
\text { Number of Particles } \\
\text { Number of Photographs }\end{array}$ & $\begin{array}{c}214 \\
3\end{array}$ & $\begin{array}{c}189 \\
4\end{array}$ & Not Used & $\begin{array}{c}118 \\
4\end{array}$ & $\begin{array}{c}183 \\
3\end{array}$ \\
\hline $\begin{array}{c}\text { FH3 } \\
\text { Number of Particles } \\
\text { Number of Photographs }\end{array}$ & $\begin{array}{c}182 \\
4 \\
\end{array}$ & $\begin{array}{c}294 \\
4 \\
\end{array}$ & $\begin{array}{c}604 \\
4 \\
\end{array}$ & Not Used & $\begin{array}{c}1570 \\
3 \\
\end{array}$ \\
\hline $\begin{array}{c}\text { FH4 } \\
\text { Number of Particles } \\
\text { Number of Photographs }\end{array}$ & $\begin{array}{c}121 \\
4 \\
\end{array}$ & $\begin{array}{c}228 \\
4 \\
\end{array}$ & $\begin{array}{c}282 \\
3 \\
\end{array}$ & Not Used & $\begin{array}{c}2607 \\
4 \\
\end{array}$ \\
\hline $\begin{array}{c}\text { FH5 } \\
\text { Number of Particles } \\
\text { Number of Photographs }\end{array}$ & $\begin{array}{c}164 \\
4 \\
\end{array}$ & $\begin{array}{c}274 \\
4 \\
\end{array}$ & $\begin{array}{c}914 \\
4 \\
\end{array}$ & Not Used & $\begin{array}{c}2261 \\
2 \\
\end{array}$ \\
\hline $\begin{array}{c}\text { FH6 } \\
\text { Number of Particles } \\
\text { Number of Photographs }\end{array}$ & $\begin{array}{c}141 \\
4\end{array}$ & $\begin{array}{c}75 \\
3\end{array}$ & $\begin{array}{c}110 \\
3\end{array}$ & Not Used & $\begin{array}{c}286 \\
4\end{array}$ \\
\hline $\begin{array}{c}\text { FH7 } \\
\text { Number of Particles } \\
\text { Number of Photographs }\end{array}$ & $\begin{array}{c}1010 \\
4\end{array}$ & $\begin{array}{c}468 \\
4\end{array}$ & $\begin{array}{c}169 \\
3\end{array}$ & Not Used & $\begin{array}{c}514 \\
4\end{array}$ \\
\hline $\begin{array}{c}\text { FH8 } \\
\text { Number of Particles } \\
\text { Number of Photographs }\end{array}$ & $\begin{array}{c}366 \\
4 \\
\end{array}$ & $\begin{array}{c}259 \\
4 \\
\end{array}$ & $\begin{array}{c}383 \\
4 \\
\end{array}$ & Not Used & $\begin{array}{c}766 \\
4 \\
\end{array}$ \\
\hline $\begin{array}{c}\text { FH9 } \\
\text { Number of Particles } \\
\text { Number of Photographs }\end{array}$ & $\begin{array}{c}92 \\
4 \\
\end{array}$ & $\begin{array}{c}85 \\
4 \\
\end{array}$ & $\begin{array}{c}106 \\
4 \\
\end{array}$ & Not Used & $\begin{array}{c}193 \\
3 \\
\end{array}$ \\
\hline $\begin{array}{c}\text { FH10 } \\
\text { Number of Particles } \\
\text { Number of Photographs }\end{array}$ & Not Used & $\begin{array}{c}378 \\
4 \\
\end{array}$ & $\begin{array}{c}234 \\
4 \\
\end{array}$ & Not Used & $\begin{array}{c}739 \\
4 \\
\end{array}$ \\
\hline $\begin{array}{c}\text { FH11 } \\
\text { Number of Particles } \\
\text { Number of Photographs }\end{array}$ & $\begin{array}{c}60 \\
5 \\
\end{array}$ & $\begin{array}{c}612 \\
3\end{array}$ & $\begin{array}{c}295 \\
4\end{array}$ & Not Used & $\begin{array}{c}423 \\
4\end{array}$ \\
\hline $\begin{array}{c}\text { FH12 } \\
\text { Number of Particles } \\
\text { Number of Photographs }\end{array}$ & $\begin{array}{c}370 \\
3\end{array}$ & $\begin{array}{c}443 \\
3\end{array}$ & $\begin{array}{c}651 \\
3\end{array}$ & Not Used & $\begin{array}{c}1437 \\
2\end{array}$ \\
\hline $\begin{array}{c}\text { FH13 } \\
\text { Number of Particles } \\
\text { Number of Photographs }\end{array}$ & $\begin{array}{c}83 \\
4 \\
\end{array}$ & $\begin{array}{c}289 \\
4 \\
\end{array}$ & $\begin{array}{c}536 \\
4\end{array}$ & Not Used & $\begin{array}{c}1004 \\
2\end{array}$ \\
\hline $\begin{array}{c}\text { FH14 } \\
\text { Number of Particles } \\
\text { Number of Photographs }\end{array}$ & $\begin{array}{c}139 \\
4 \\
\end{array}$ & $\begin{array}{c}415 \\
4 \\
\end{array}$ & $\begin{array}{c}713 \\
4 \\
\end{array}$ & Not Used & $\begin{array}{c}1395 \\
2 \\
\end{array}$ \\
\hline $\begin{array}{c}\text { FH15 } \\
\text { Number of Particles } \\
\text { Number of Photographs }\end{array}$ & $\begin{array}{c}933 \\
4 \\
\end{array}$ & $\begin{array}{c}805 \\
4 \\
\end{array}$ & $\begin{array}{c}1101 \\
3 \\
\end{array}$ & Not Used & $\begin{array}{c}2173 \\
3 \\
\end{array}$ \\
\hline $\begin{array}{c}\text { FH16 } \\
\text { Number of Particles } \\
\text { Number of Photographs }\end{array}$ & $\begin{array}{c}446 \\
3 \\
\end{array}$ & $\begin{array}{c}465 \\
2 \\
\end{array}$ & $\begin{array}{c}974 \\
3 \\
\end{array}$ & Not Used & $\begin{array}{c}2856 \\
3 \\
\end{array}$ \\
\hline $\begin{array}{c}\text { FH17 } \\
\text { Number of Particles } \\
\text { Number of Photographs }\end{array}$ & $\begin{array}{c}237 \\
4 \\
\end{array}$ & $\begin{array}{c}270 \\
4 \\
\end{array}$ & $\begin{array}{c}504 \\
3 \\
\end{array}$ & Not Used & $\begin{array}{c}3622 \\
4\end{array}$ \\
\hline
\end{tabular}

* - Not used because either no particles were found at this magnification or the data overlapped in the adjacent magnifications. 
Table 5.2 Analysis details for optical analysis of replicating tape samples.

\begin{tabular}{|c|c|c|c|c|c|}
\hline & \multicolumn{5}{|c|}{ Magnification } \\
\hline Sample & $\mathbf{1 0 0 0 x}$ & $\mathbf{5 0 0 x}$ & $\mathbf{2 0 0 x}$ & $\mathbf{1 0 0 x}$ & $\mathbf{5 0 x}$ \\
\hline RT 1 & 32 & 22 & 28 & Not Used & 39 \\
Number of Particles & 4 & 4 & 4 & & 4 \\
Number of Photographs & Not Used & 11 & 24 & Not Used & 14 \\
\hline RT 2 & & 4 & 3 & & 4 \\
Number of Particles & & Not Used & 5 & 21 & 9 \\
Number of Photographs & RT 3 & & 4 & 4 & 3 \\
Number of Particles & 10 & & 4 & \\
Number of Photographs & 4 & & & & \\
\hline
\end{tabular}

* - Not used because either no particles were found at this magnification or the data overlapped in the adjacent magnifications.

Table 5.3 Ranges used to construct overall distributions for filter housing samples.

\begin{tabular}{|c|c|c|c|c|c|}
\hline & \multicolumn{5}{|c|}{ Magnification } \\
\hline Sample & 1000x & 500x & $\mathbf{2 0 0 x}$ & 100x & 50x \\
\hline FH1 & 0 to $1.0 \mu \mathrm{m}$ & Not Used & 1.0 to $5.0 \mu \mathrm{m}$ & 5.0 to $7.0 \mu \mathrm{m}$ & 7.0 to $37 \mu \mathrm{m}$ \\
\hline FH2 & 0 to $1.0 \mu \mathrm{m}$ & 1.0 to $5.0 \mu \mathrm{m}$ & Not Used & 5.0 to $12 \mu \mathrm{m}$ & 12 to $25 \mu \mathrm{m}$ \\
\hline FH3 & 0 to $1.0 \mu \mathrm{m}$ & 1.0 to $3.0 \mu \mathrm{m}$ & 3.0 to $8.0 \mu \mathrm{m}$ & Not Used & 8.0 to $48 \mu \mathrm{m}$ \\
\hline FH4 & 0 to $1.0 \mu \mathrm{m}$ & 1.0 to $3.0 \mu \mathrm{m}$ & 3.0 to $8.0 \mu \mathrm{m}$ & Not Used & 8.0 to $48 \mu \mathrm{m}$ \\
\hline FH5 & 0 to $1.0 \mu \mathrm{m}$ & 1.0 to $3.0 \mu \mathrm{m}$ & 3.0 to $8.0 \mu \mathrm{m}$ & Not Used & 8.0 to $48 \mu \mathrm{m}$ \\
\hline FH6 & 0 to $1.0 \mu \mathrm{m}$ & 1.0 to $3.0 \mu \mathrm{m}$ & 3.0 to $8.0 \mu \mathrm{m}$ & Not Used & 8.0 to $48 \mu \mathrm{m}$ \\
\hline FH7 & 0 to $1.0 \mu \mathrm{m}$ & 1.0 to $3.0 \mu \mathrm{m}$ & 3.0 to $8.0 \mu \mathrm{m}$ & Not Used & 8.0 to $60 \mu \mathrm{m}$ \\
\hline FH8 & 0 to $1.0 \mu \mathrm{m}$ & 1.0 to $3.0 \mu \mathrm{m}$ & 3.0 to $8.0 \mu \mathrm{m}$ & Not Used & 8.0 to $40 \mu \mathrm{m}$ \\
\hline FH9 & 0 to $1.0 \mu \mathrm{m}$ & 1.0 to $3.0 \mu \mathrm{m}$ & 3.0 to $8.0 \mu \mathrm{m}$ & Not Used & 8.0 to $48 \mu \mathrm{m}$ \\
\hline FH10 & Not Used & 0 to $3.0 \mu \mathrm{m}$ & 3.0 to $8.0 \mu \mathrm{m}$ & Not Used & 8.0 to $46 \mu \mathrm{m}$ \\
\hline FH11 & 0 to $0.6 \mu \mathrm{m}$ & 0.6 to $3.0 \mu \mathrm{m}$ & 3.0 to $8.0 \mu \mathrm{m}$ & Not Used & 8.0 to $80 \mu \mathrm{m}$ \\
\hline FH12 & 0 to $1.0 \mu \mathrm{m}$ & 1.0 to $3.0 \mu \mathrm{m}$ & 3.0 to $8.0 \mu \mathrm{m}$ & Not Used & 8.0 to $88 \mu \mathrm{m}$ \\
\hline FH13 & 0 to $1.0 \mu \mathrm{m}$ & 1.0 to $3.0 \mu \mathrm{m}$ & 3.0 to $8.0 \mu \mathrm{m}$ & Not Used & 8.0 to $46 \mu \mathrm{m}$ \\
\hline FH14 & 0 to $1.0 \mu \mathrm{m}$ & 1.0 to $3.0 \mu \mathrm{m}$ & 3.0 to $8.0 \mu \mathrm{m}$ & Not Used & 8.0 to $40 \mu \mathrm{m}$ \\
\hline FH15 & 0 to $1.4 \mu \mathrm{m}$ & 1.4 to $3.0 \mu \mathrm{m}$ & 3.0 to $8.0 \mu \mathrm{m}$ & Not Used & 8.0 to $60 \mu \mathrm{m}$ \\
\hline FH16 & 0 to $1.0 \mu \mathrm{m}$ & 1.0 to $3.0 \mu \mathrm{m}$ & 3.0 to $8.0 \mu \mathrm{m}$ & Not Used & 8.0 to $78 \mu \mathrm{m}$ \\
\hline FH17 & 0 to $1.0 \mu \mathrm{m}$ & 1.0 to $3.0 \mu \mathrm{m}$ & 3.0 to $8.0 \mu \mathrm{m}$ & Not Used & 8.0 to $82 \mu \mathrm{m}$ \\
\hline
\end{tabular}

* - Not used because either no particles were found at this magnification or the data overlapped in the adjacent magnifications.

Table 5.4 Ranges used to construct overall distributions for replicating tape samples.

\begin{tabular}{|c|c|c|c|c|c|}
\hline & \multicolumn{5}{|c|}{ Magnification } \\
\hline Sample & $\mathbf{1 0 0 0 x}$ & $\mathbf{5 0 0 x}$ & $\mathbf{2 0 0 x}$ & $\mathbf{1 0 0 x}$ & $\mathbf{5 0 x}$ \\
\hline RT 1 & 0 to $1.0 \mu \mathrm{m}$ & 1.0 to $3.0 \mu \mathrm{m}$ & 3.0 to $8.0 \mu \mathrm{m}$ & Not Used & 8.0 to $32 \mu \mathrm{m}$ \\
\hline RT 2 & Not Used & 0 to $1.0 \mu \mathrm{m}$ & 1.0 to $8.0 \mu \mathrm{m}$ & Not Used & 8.0 to $18 \mu \mathrm{m}$ \\
\hline RT 3 & 0 to $2.0 \mu \mathrm{m}$ & Not Used & 2.0 to $3.0 \mu \mathrm{m}$ & 3.0 to $13 \mu \mathrm{m}$ & 13 to $62 \mu \mathrm{m}$ \\
\hline
\end{tabular}

* - Not used because either no particles were found at this magnification or the data overlapped in the adjacent magnifications.

Figures 5.2 through 5.6 are representative photographs of dust from various filter housings at various magnifications. There are large flakes and spherical particles visible in the majority of all of the samples. Long cylindrical rods seen in most DIII-D dust samples are fibers of insulation material. The insulation material is used extensively throughout DIII-D on thermocouples and other instrumentation. 


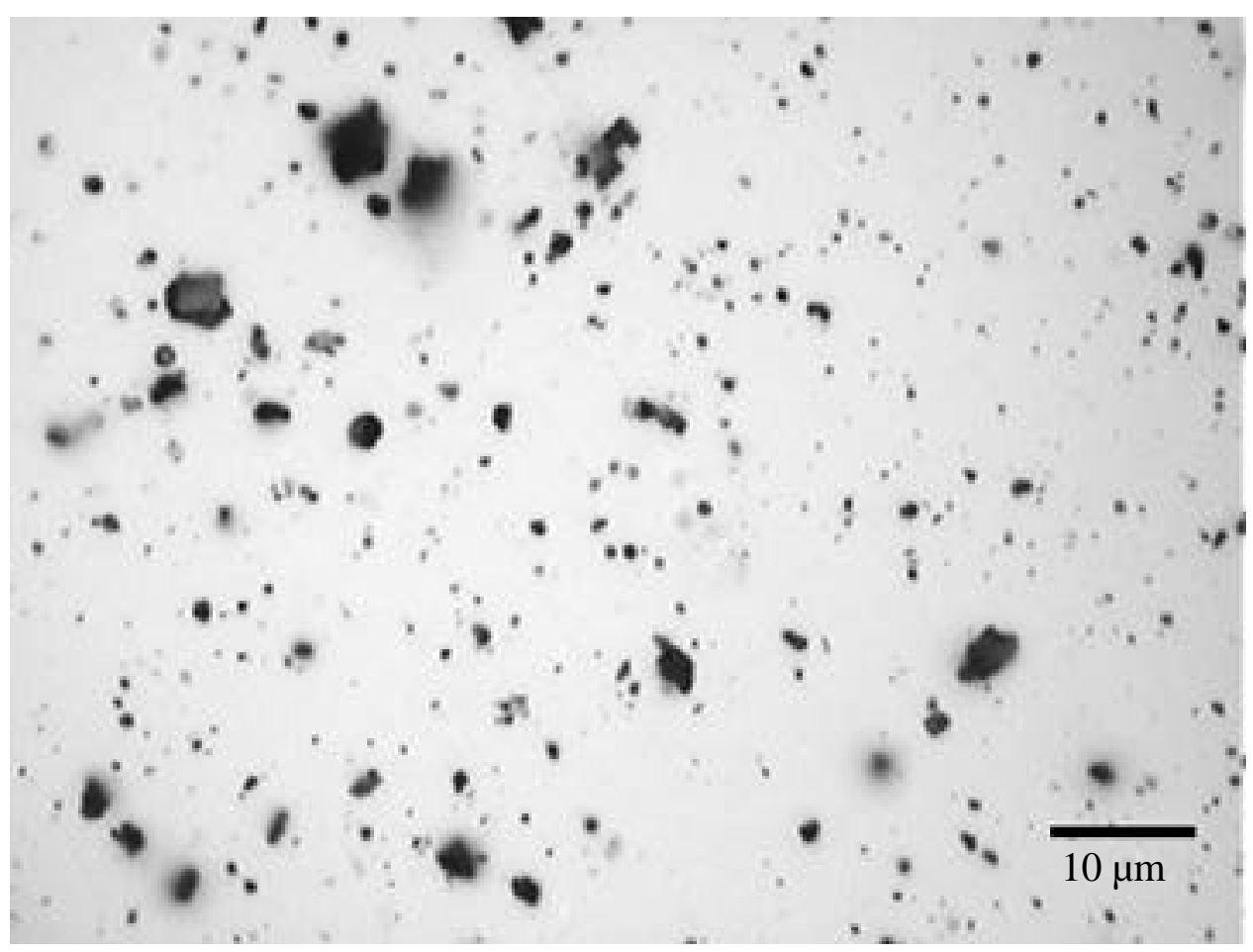

Figure 5.2. Photograph of DIII-D filter housing sample FH7 at 1000x magnification.

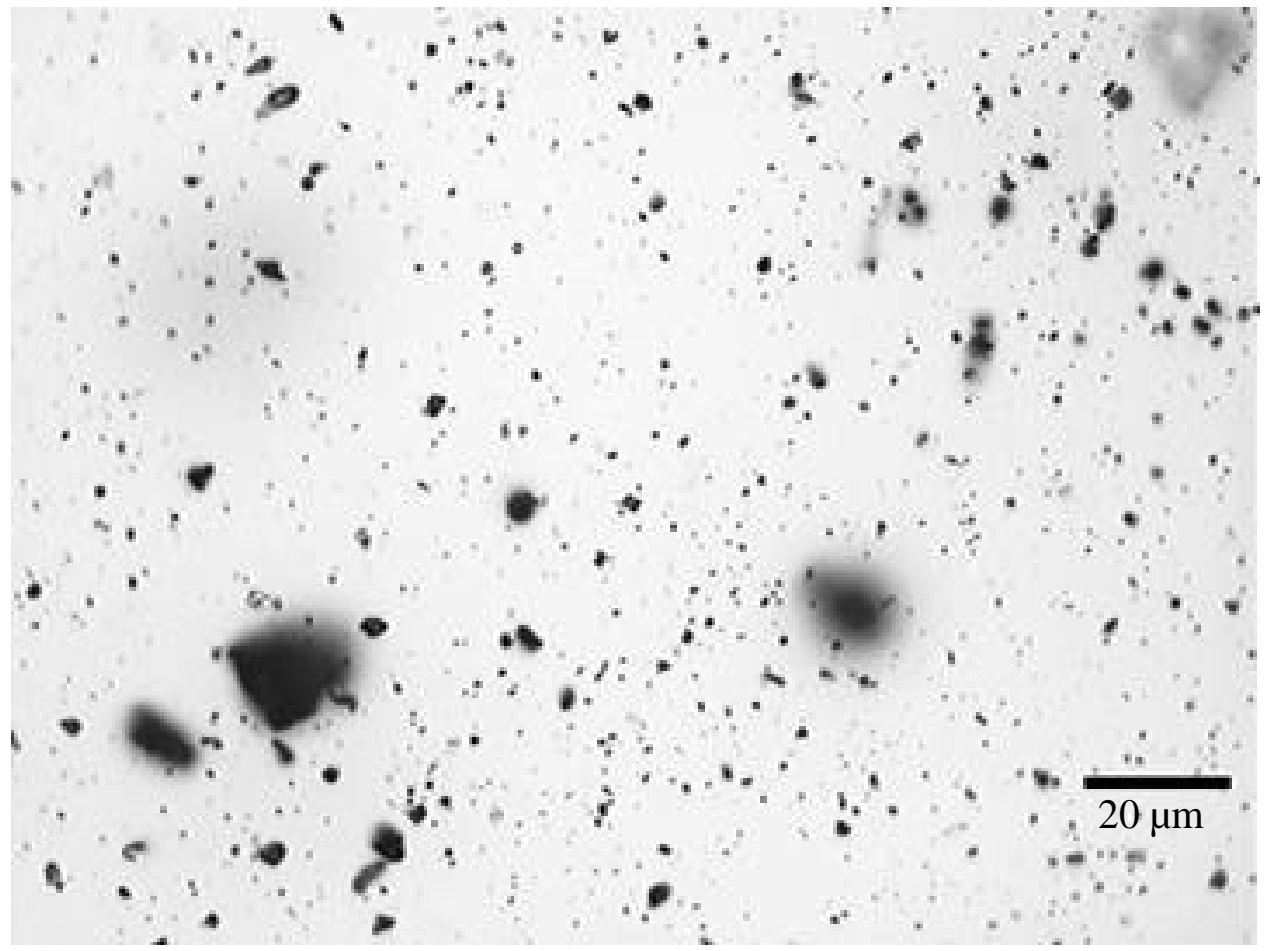

Figure 5.3. Photograph of DIII-D sample 14 at 500x magnification. 


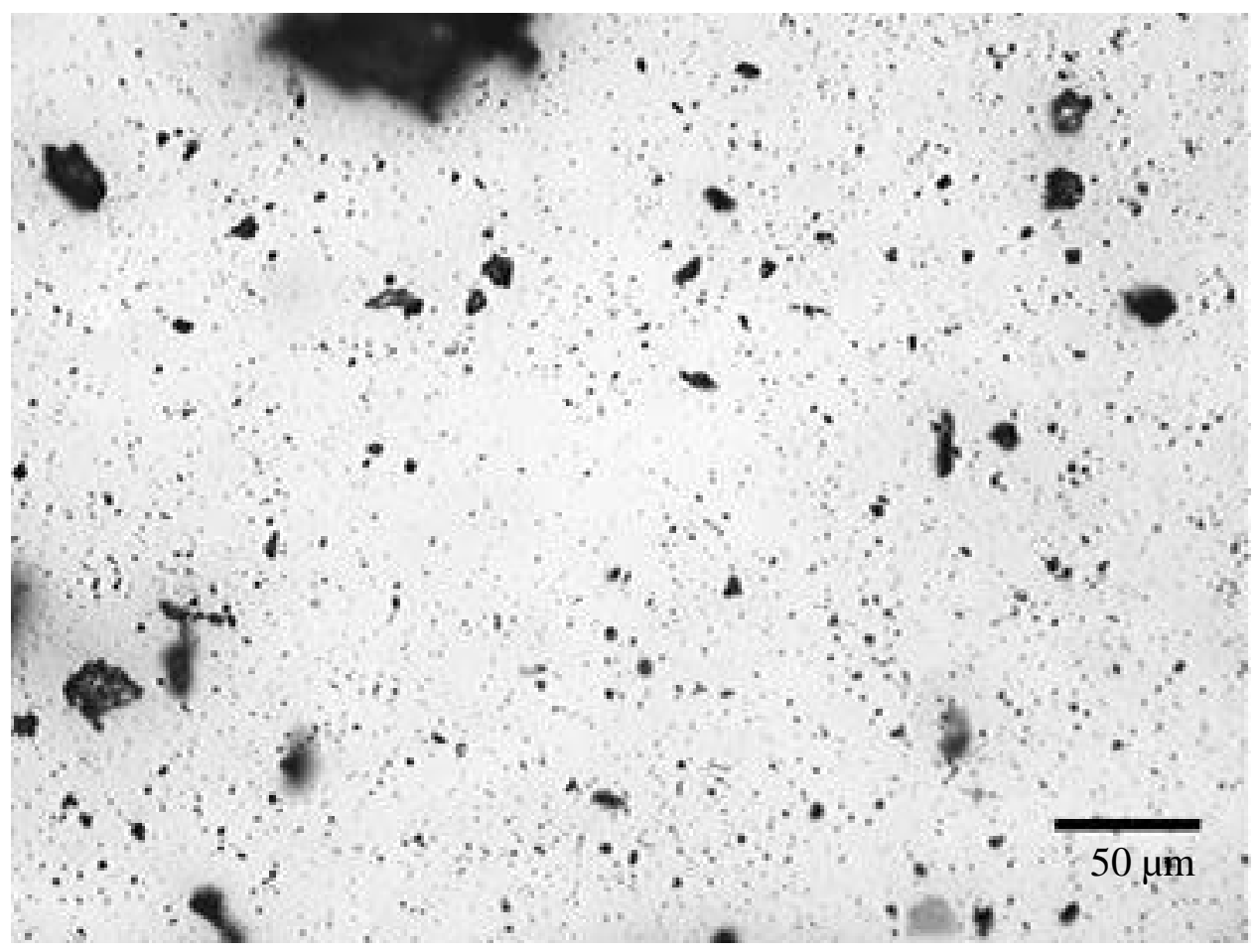

Figure 5.4. Photograph of DIII-D filter housing sample 15 at 200x magnification.

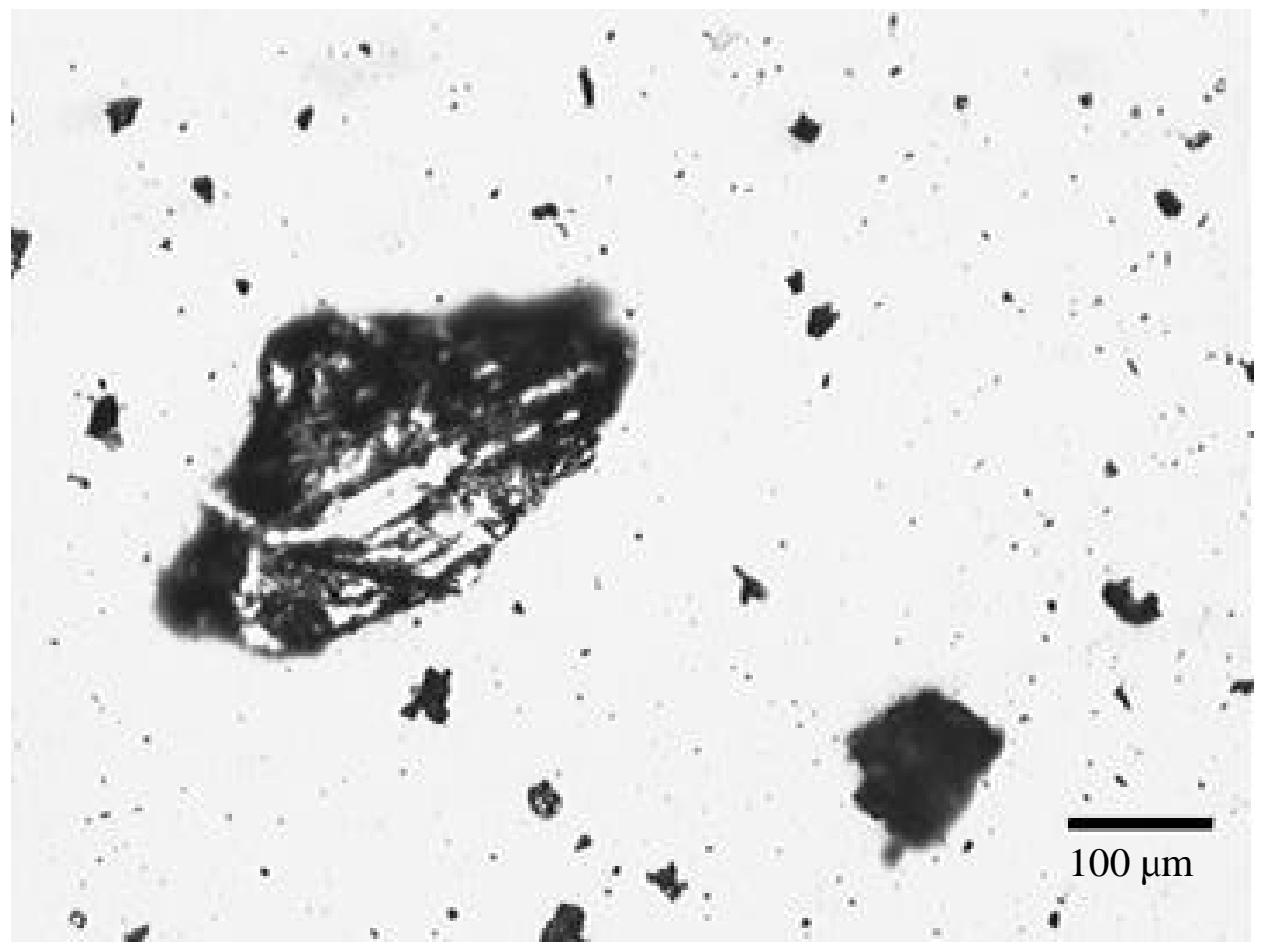

Figure 5.5. Photograph of DIII-D sample FH7 at 100x magnification. 


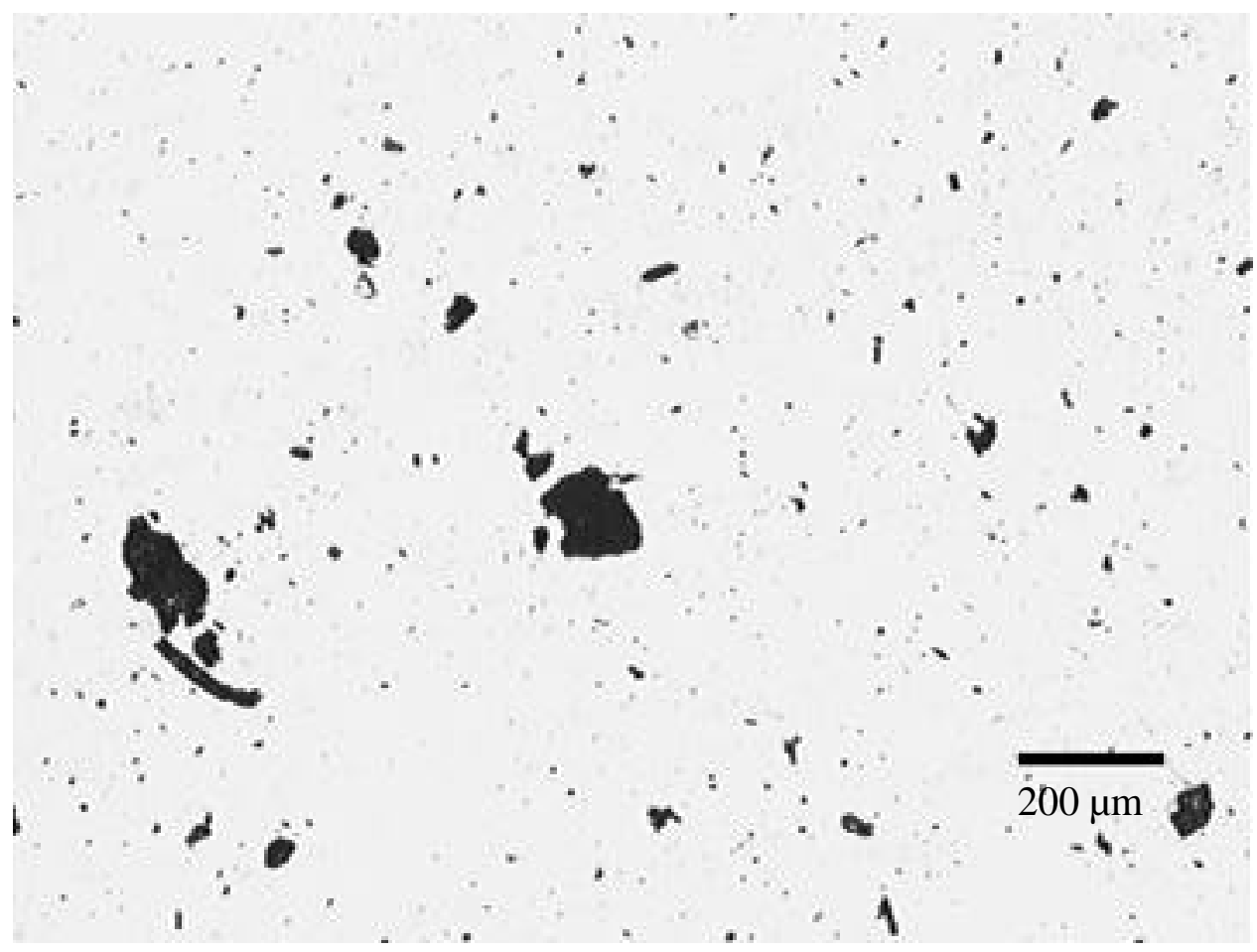

Figure 5.6. Photograph of DIII-D filter housing sample 5 at 50x magnification.

The results from analysis of the DIII-D samples using the optical microscope method are shown in Table 5.5. The last two columns of the table show the values calculated for the MMD and the $\mathrm{D}_{\mathrm{MVs}}$. The data were combined from each data set using the ranges in Table 5.2 and 5.3. Ninety-five percent confidence intervals were constructed for the CDFs from these data. Figures 5.7 to 5.26 show the CDFs with the associated $95 \%$ confidence interval plots constructed from the data obtained in the analysis. The upper confidence interval is labeled $+95 \%$ conf., the data collected is labeled Data, and the lower confidence interval is labeled $-95 \%$ conf. Each graph shows the values for the CMD and the GSD calculated using both the data and the curve fit. We do this for two reasons. We believe that obtaining these values directly from the data instead of the numerical fit is more representative of the distribution. The numerical fit is primarily used for determining how well the distribution conforms to a log-normal distribution and should be used for that purpose and not for reporting data characteristics, although the data and the fit descriptions do not vary significantly. In addition the corresponding $95 \%$ confidence intervals for the CMD and the GSD are shown. 


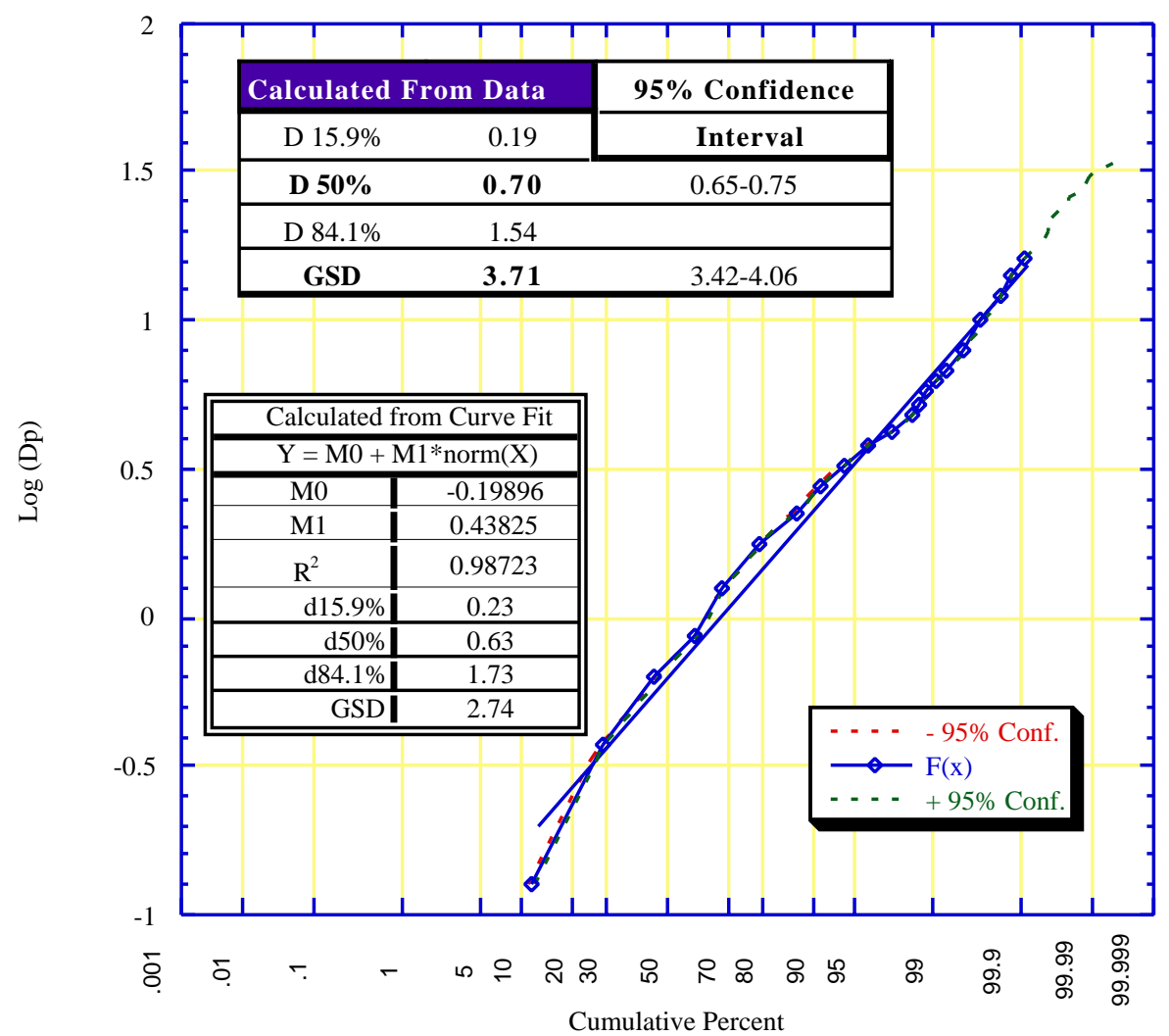

Figure 5.7. Cumulative log probability distribution generated with $95 \%$ confidence intervals for DIII-D FH1.

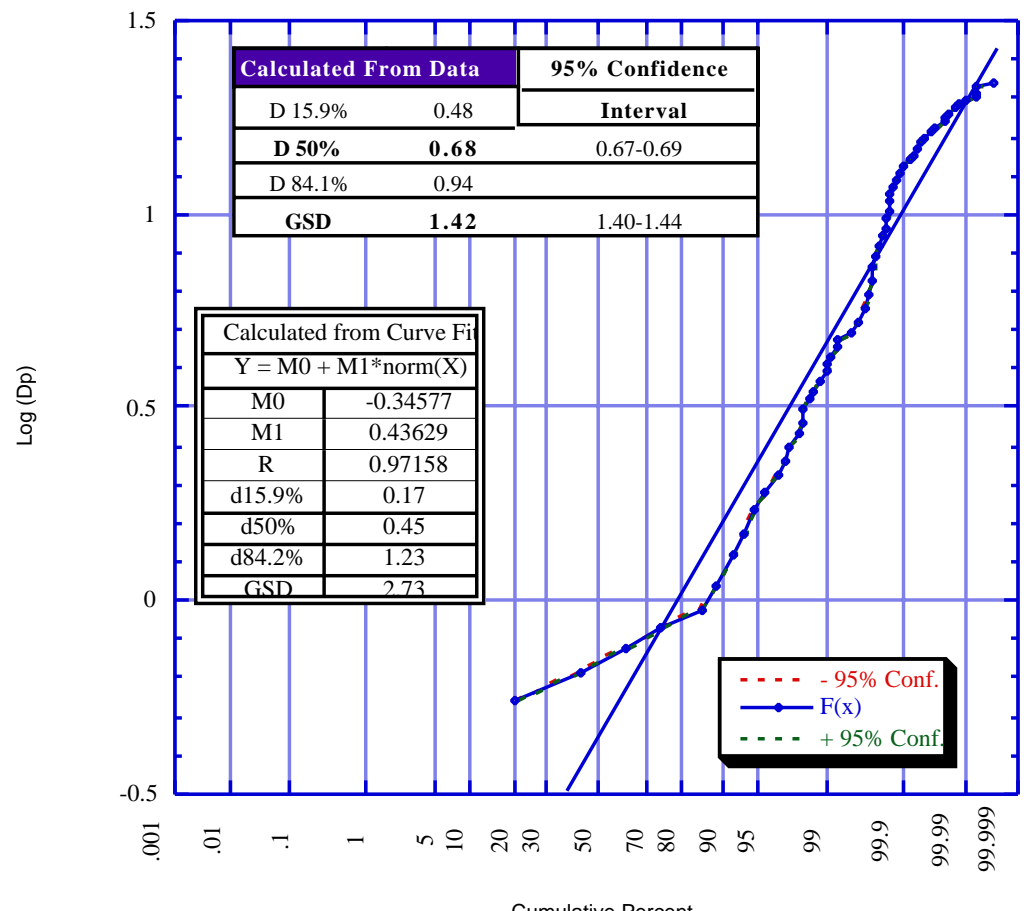

Figure 5.8. Cumulative log probability distribution generated with $95 \%$ confidence intervals for DIII-D FH2. 


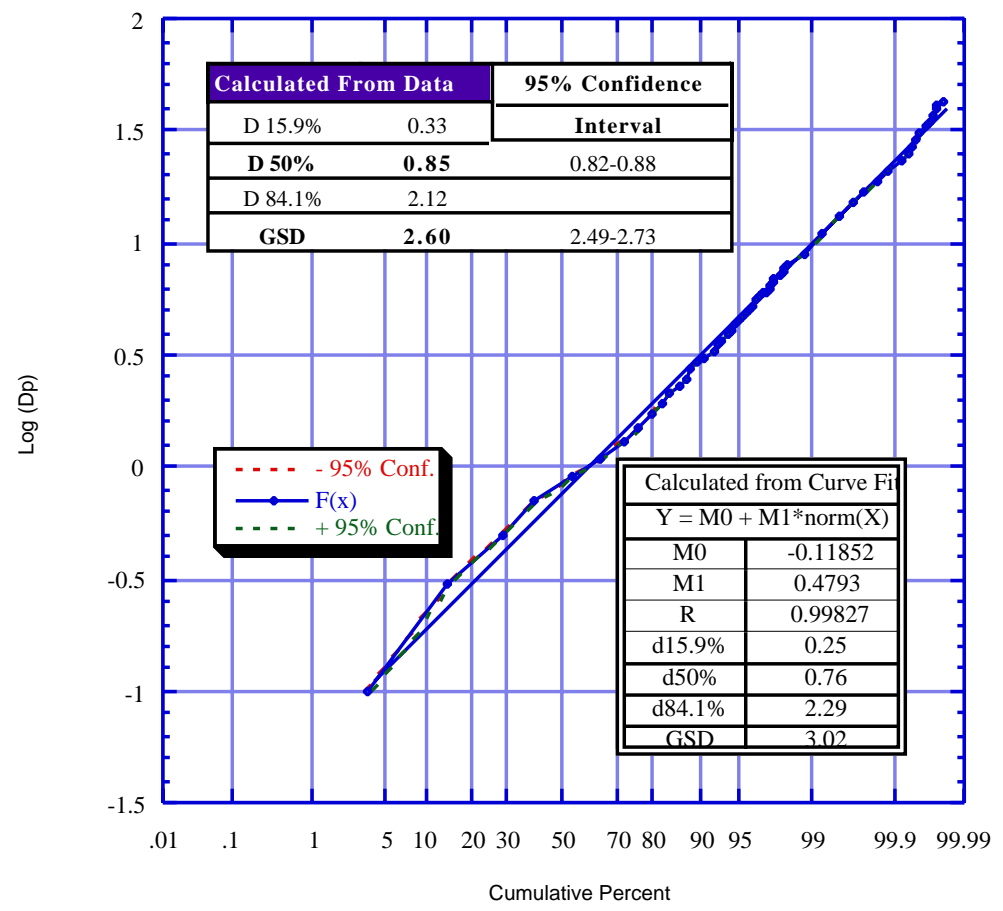

Figure 5.9. Cumulative log probability distribution generated with $95 \%$ confidence intervals for DIII-D FH3.

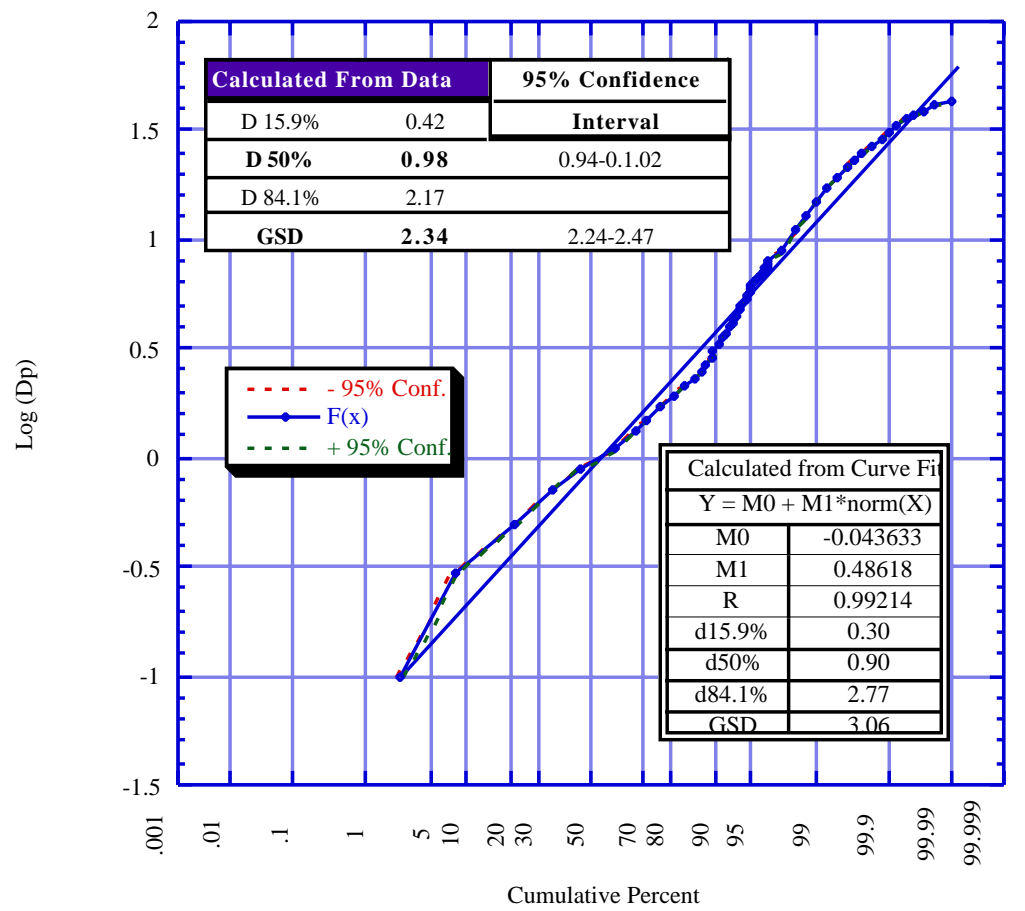

Figure 5.10. Cumulative log probability distribution generated with $95 \%$ confidence intervals for DIII-D FH4. 


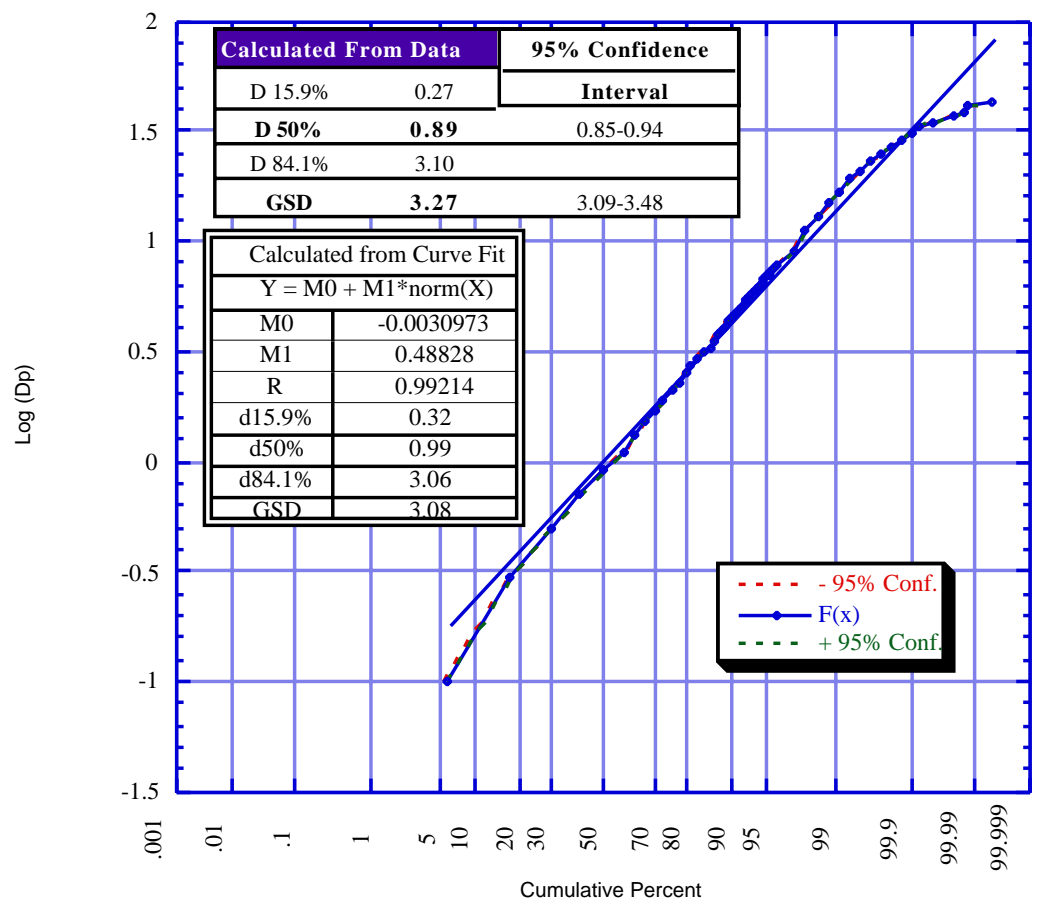

Figure 5.11. Cumulative log probability distribution generated with $95 \%$ confidence intervals for DIII-D FH5.

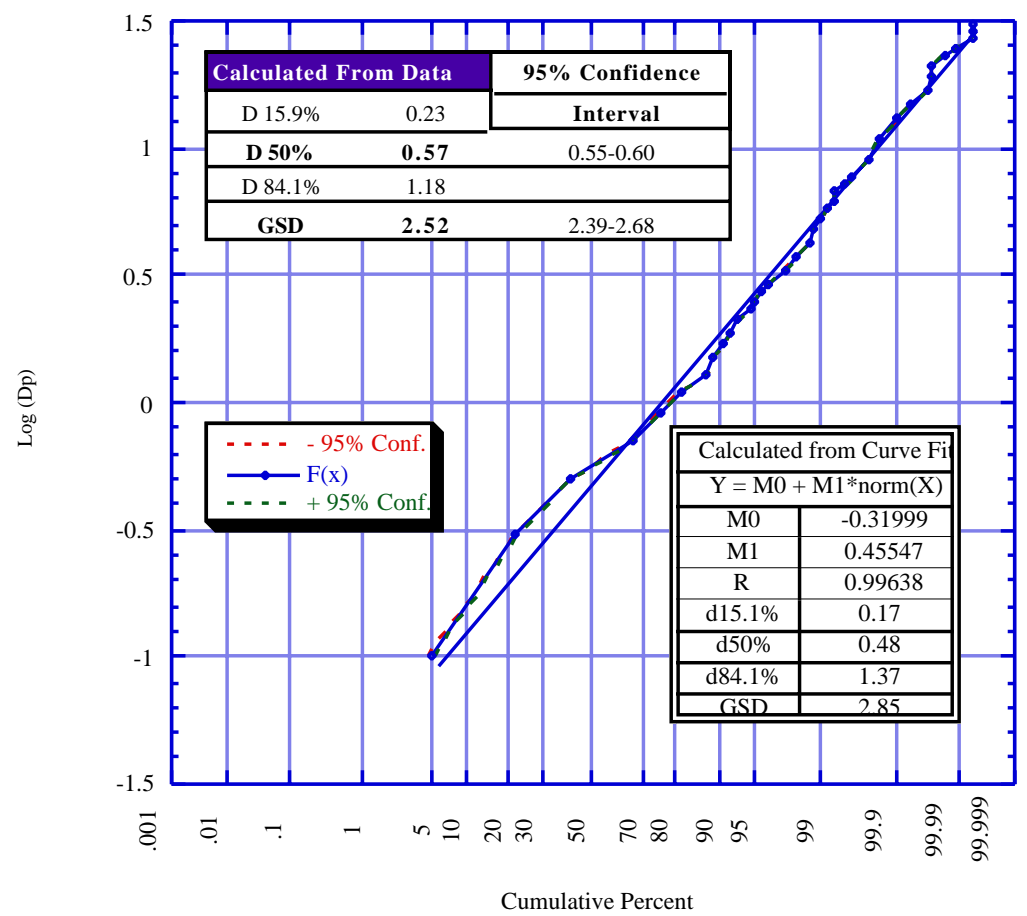

Figure 5.12. Cumulative log probability distribution generated with $95 \%$ confidence intervals for DIII-D FH6. 


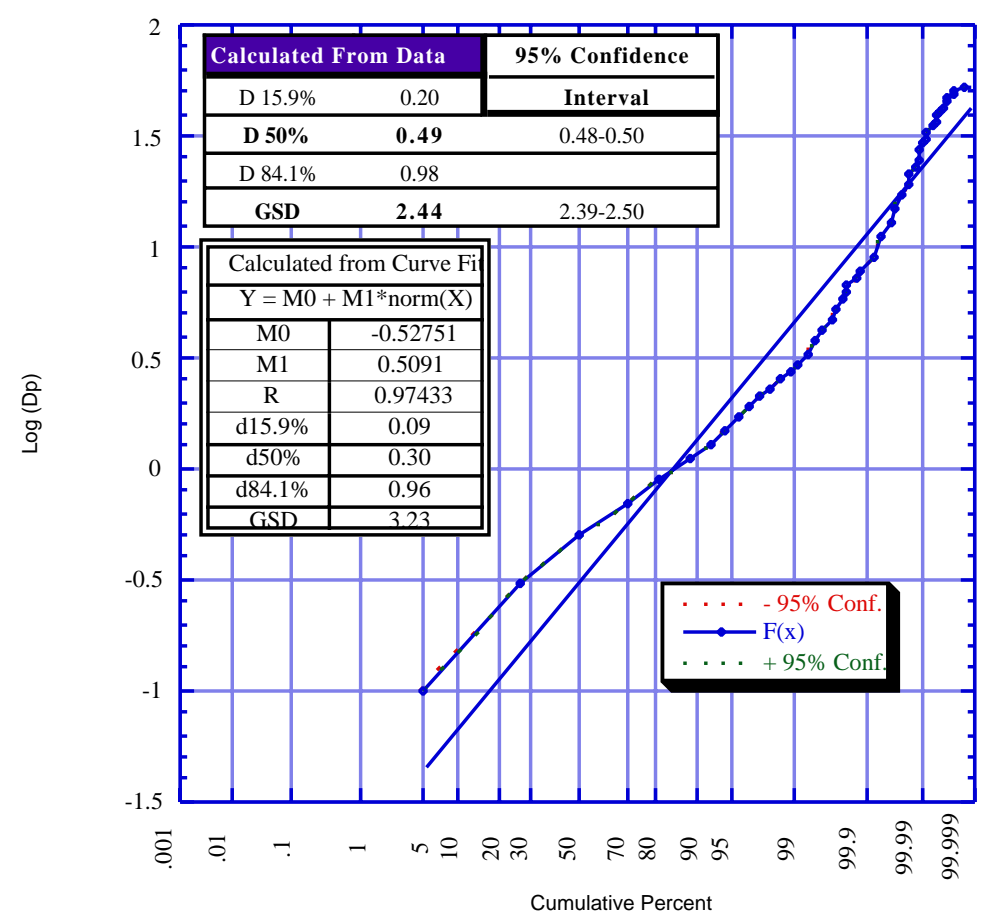

Figure 5.13. Cumulative log probability distribution generated with $95 \%$ confidence intervals for DIII-D FH7.

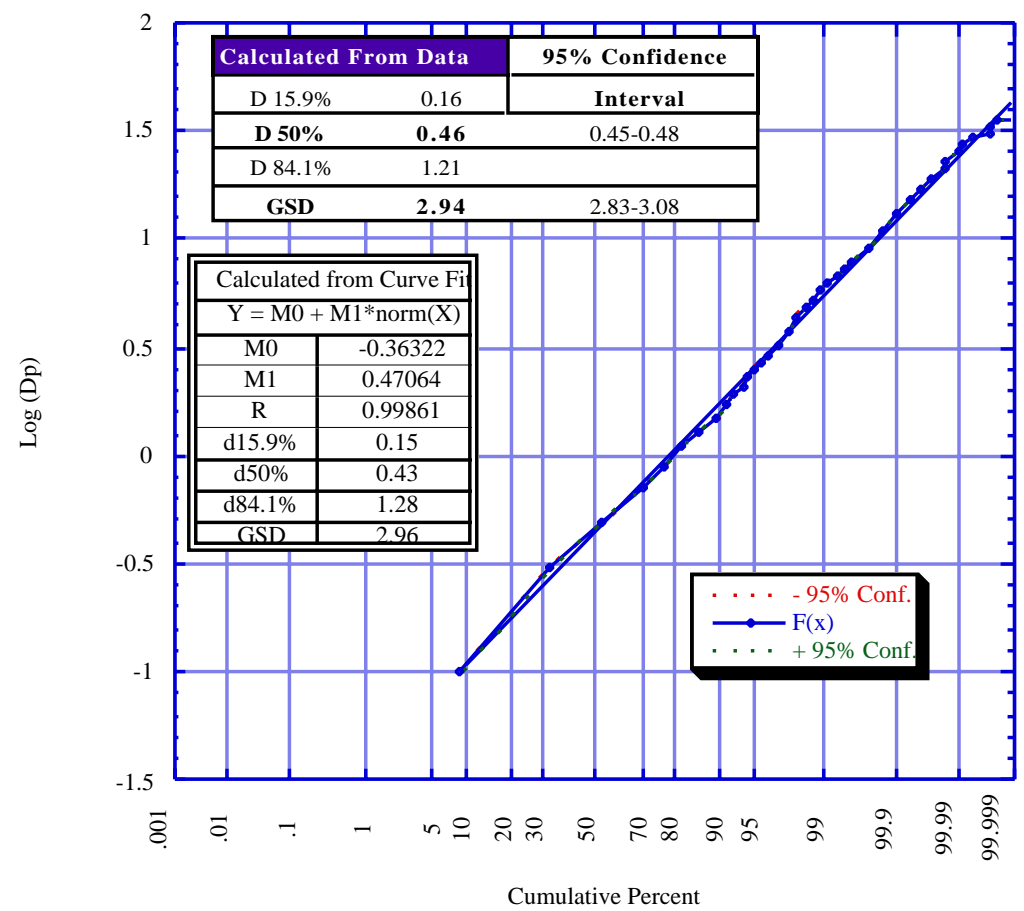

Figure 5.14. Cumulative log probability distribution generated with $95 \%$ confidence intervals for DIII-D FH8. 


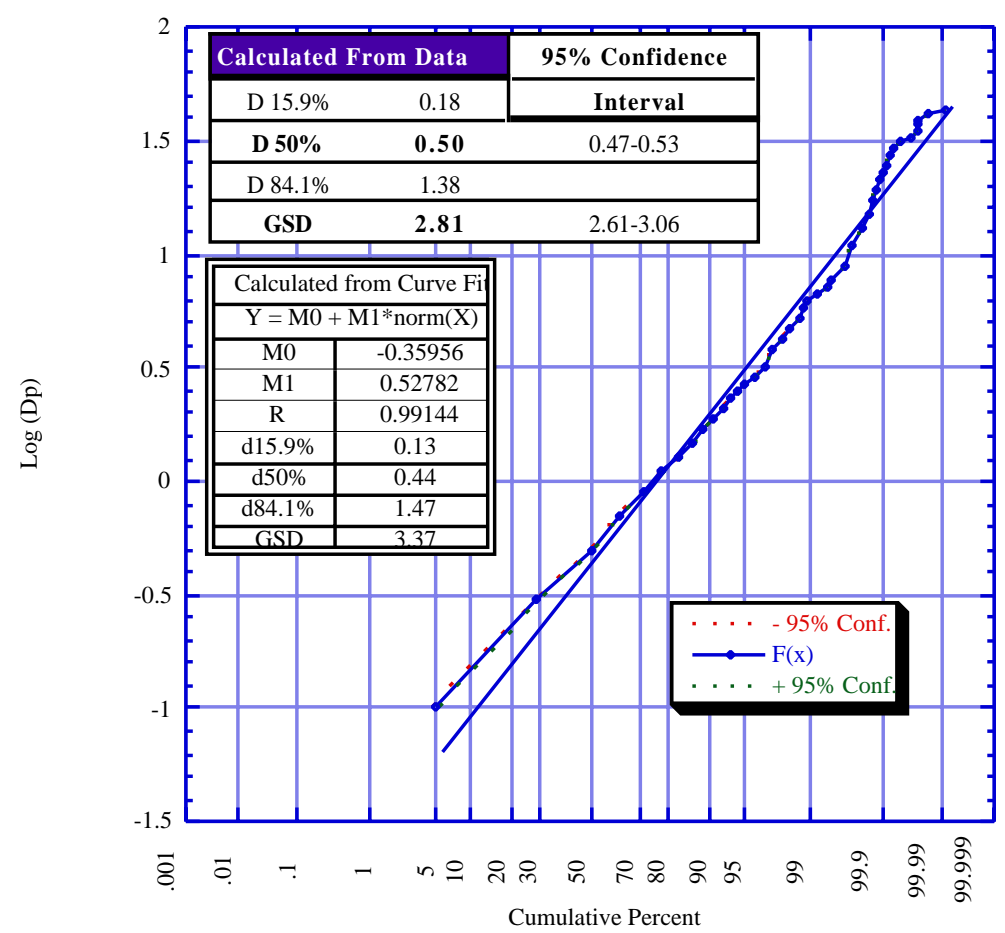

Figure 5.15. Cumulative log probability distribution generated with $95 \%$ confidence intervals for DIII-D FH9.

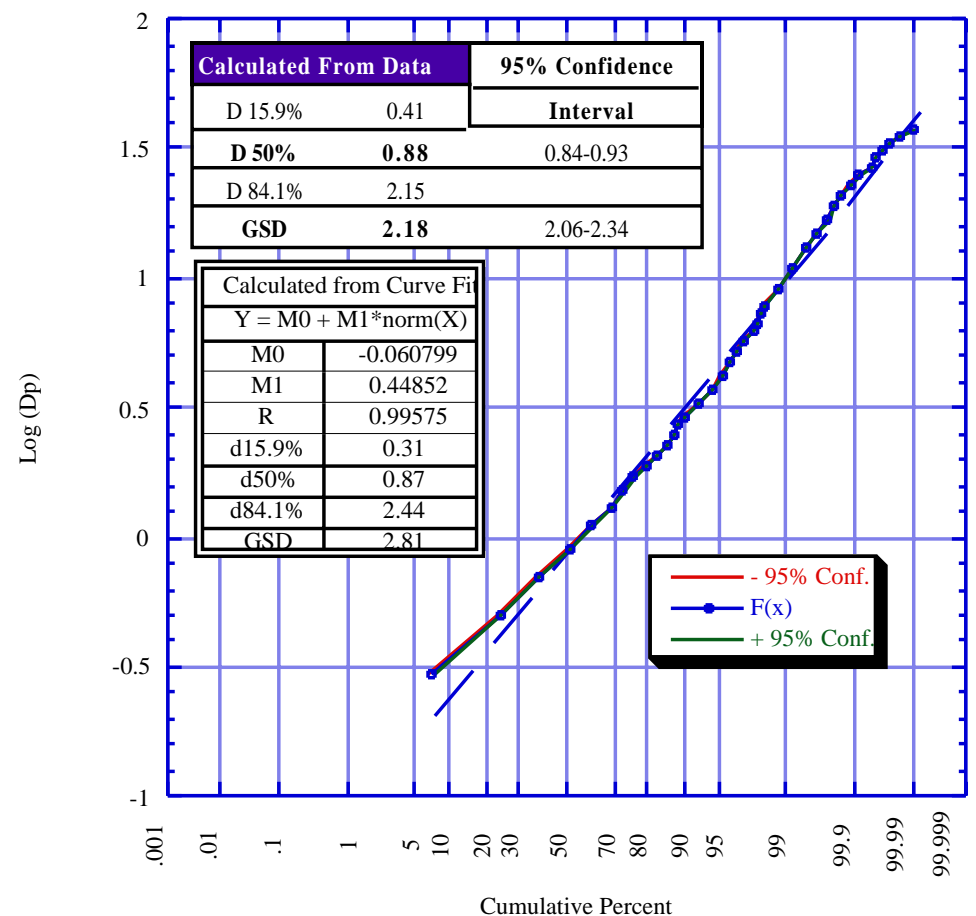

Figure 5.16. Cumulative log probability distribution generated with $95 \%$ confidence intervals for DIII-D FH10. 


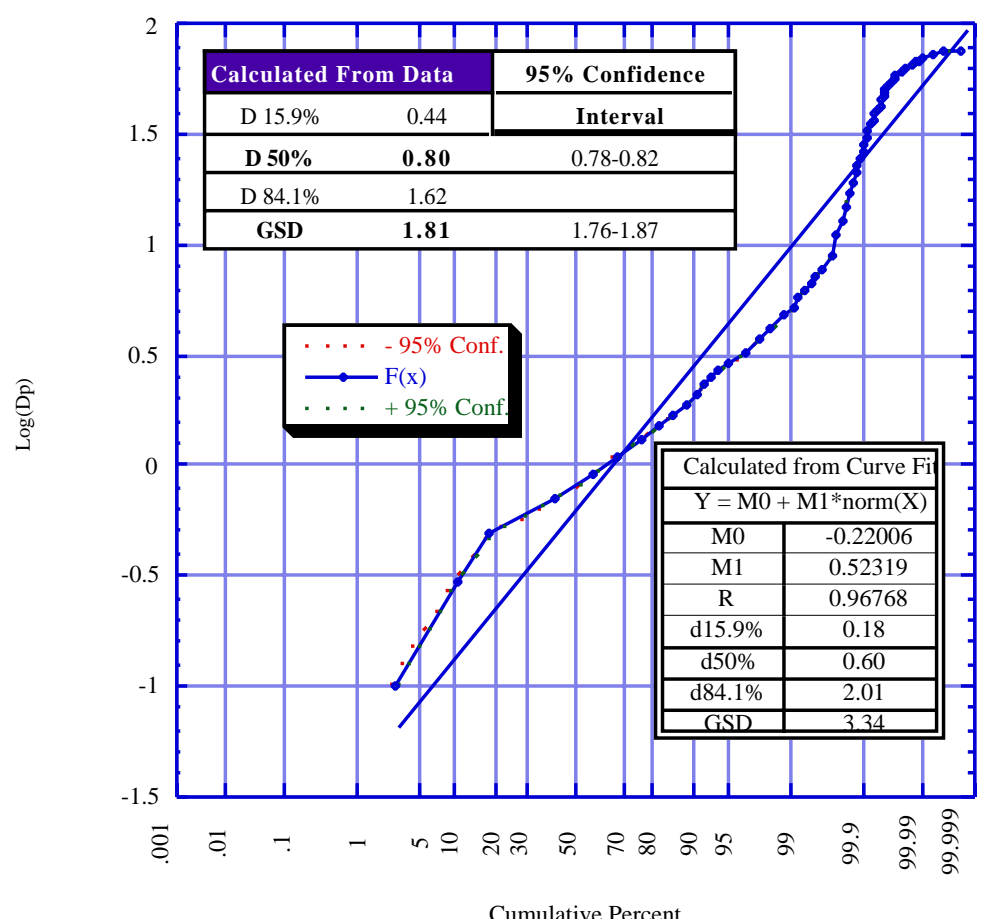

Figure 5.17. Cumulative log probability distribution generated with $95 \%$ confidence intervals for DIII-D FH11.

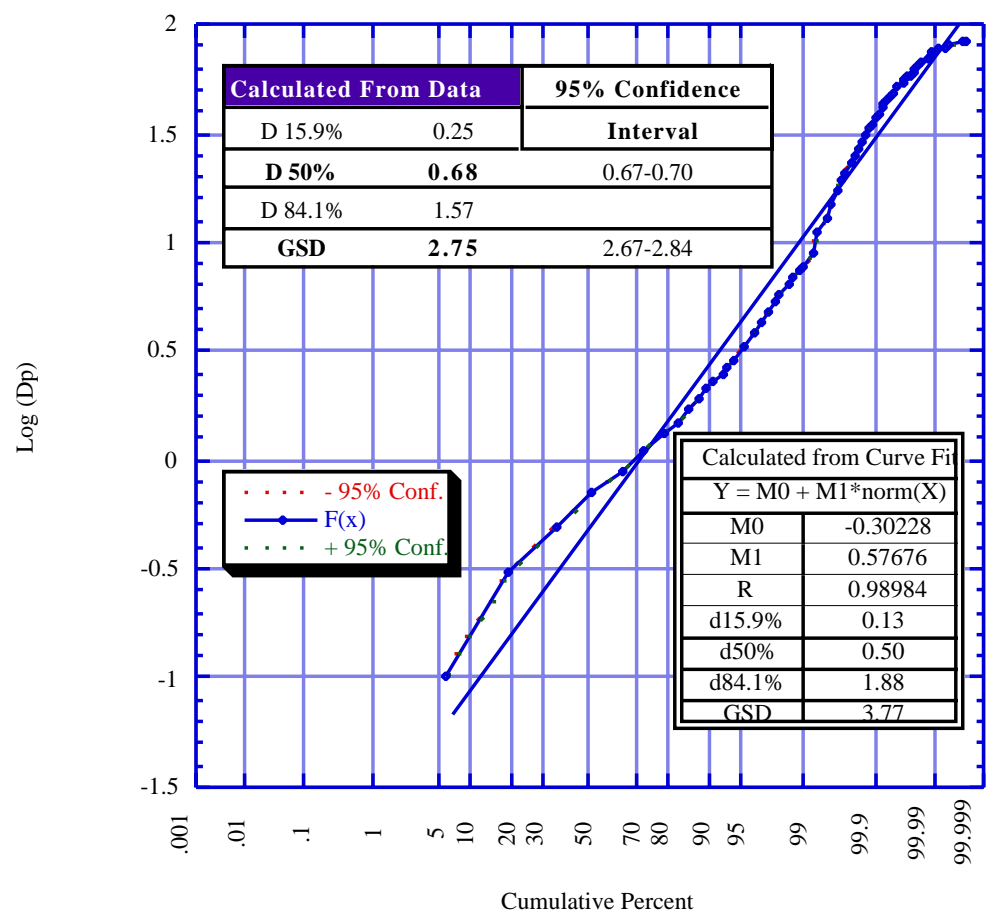

Figure 5.18. Cumulative log probability distribution generated with $95 \%$ confidence intervals for DIII-D FH12. 


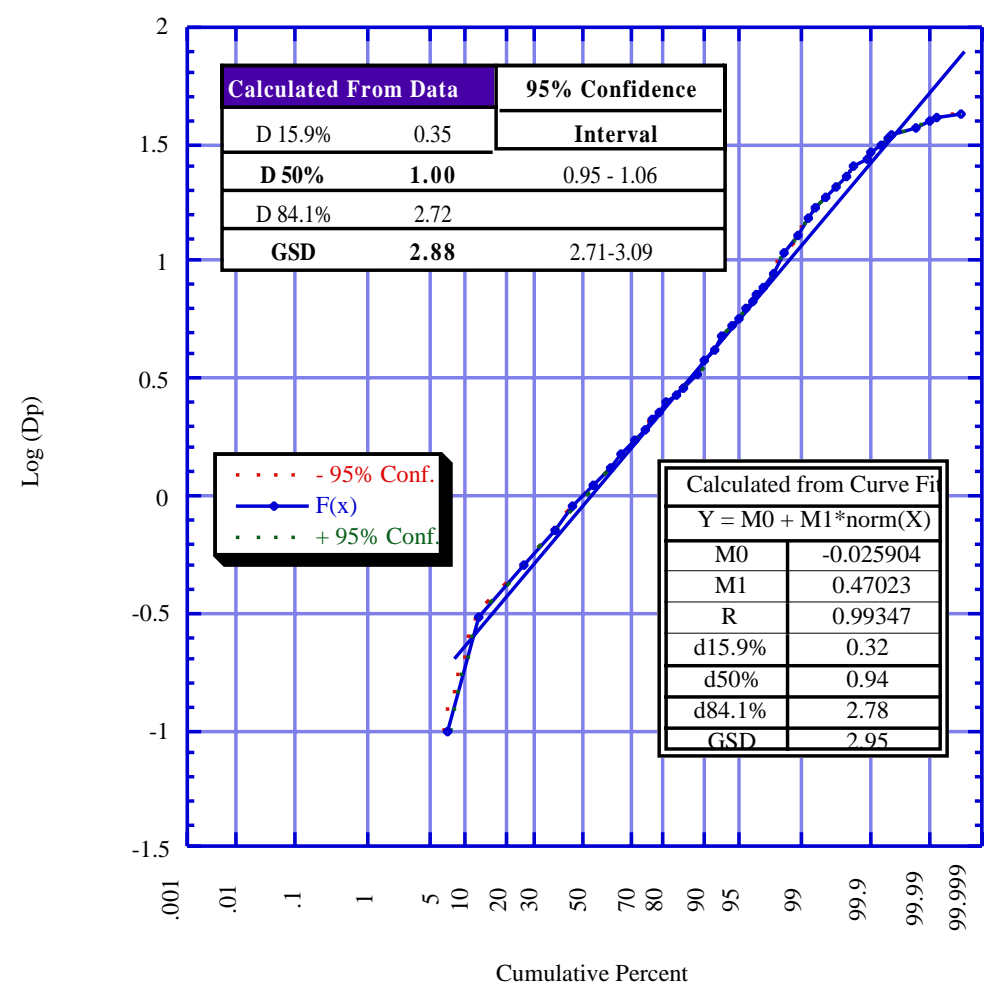

Figure 5.19. Cumulative log probability distribution generated with $95 \%$ confidence intervals for DIII-D 13.

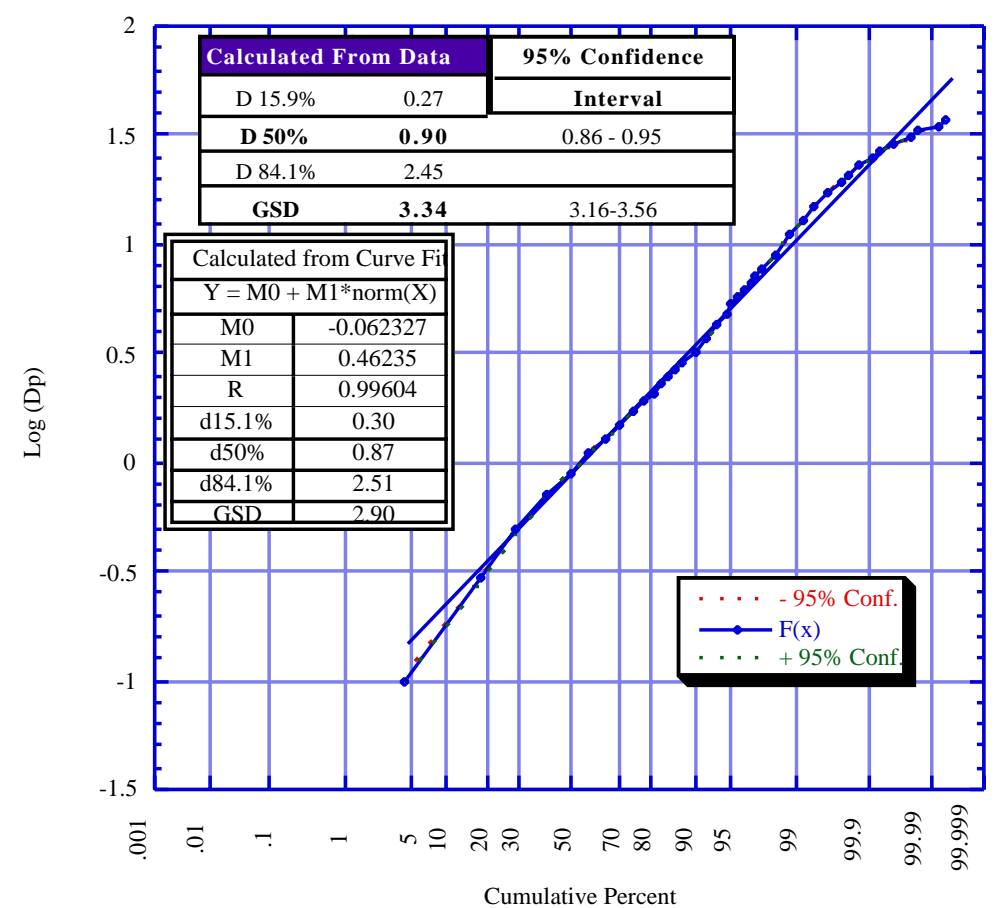

Figure 5.20. Cumulative log probability distribution generated with $95 \%$ confidence intervals for DIII-D 14. 


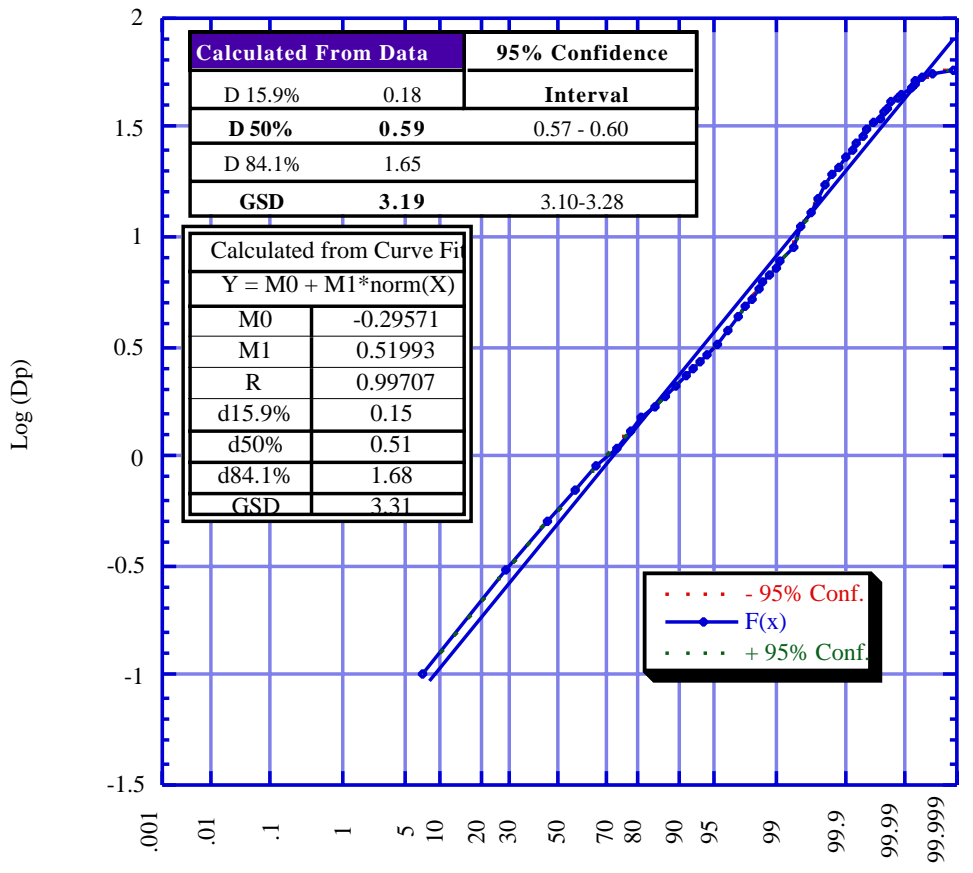

Cumulative Percent

Figure 5.21. Cumulative log probability distribution generated with $95 \%$ confidence intervals for DIII-D 15.

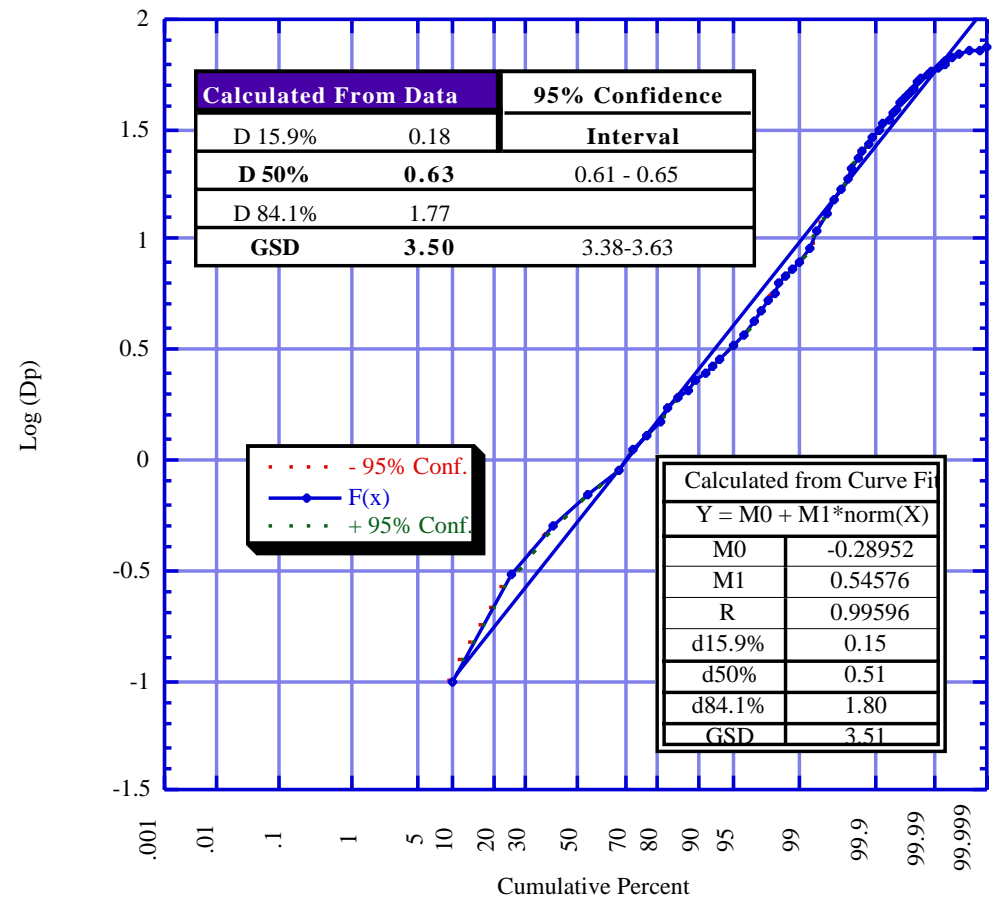

Figure 5.22. Cumulative log probability distribution generated with $95 \%$ confidence intervals for DIII-D 16. 


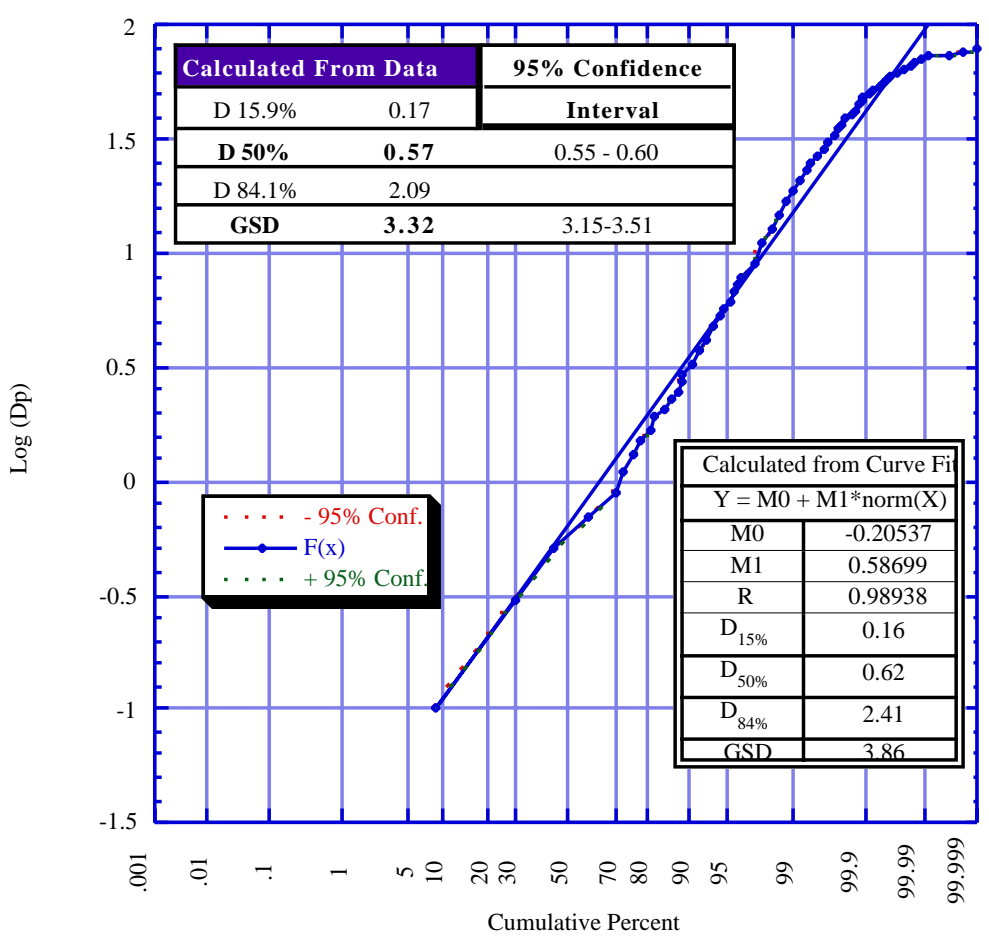

Figure 5.23. Cumulative log probability distribution generated with $95 \%$ confidence intervals for DIII-D 17.

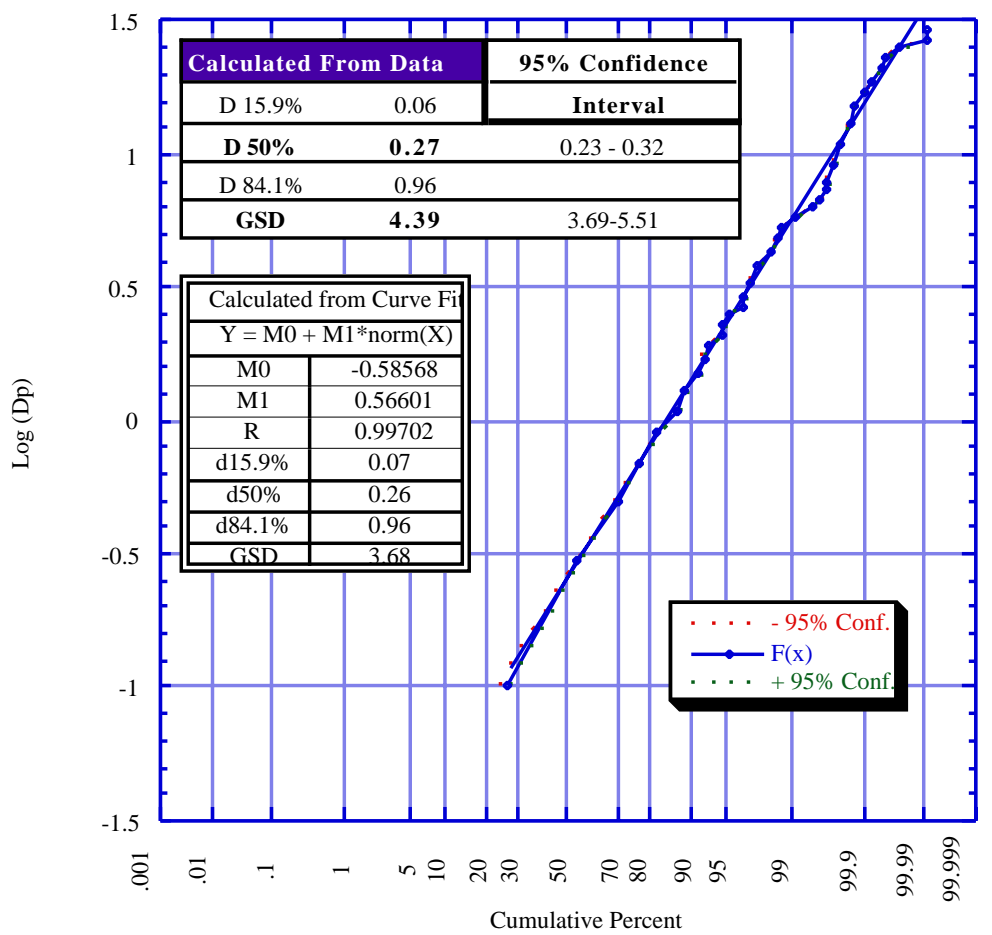

Figure 5.24. Cumulative log probability distribution generated with $95 \%$ confidence intervals for DIII-D RT1. 


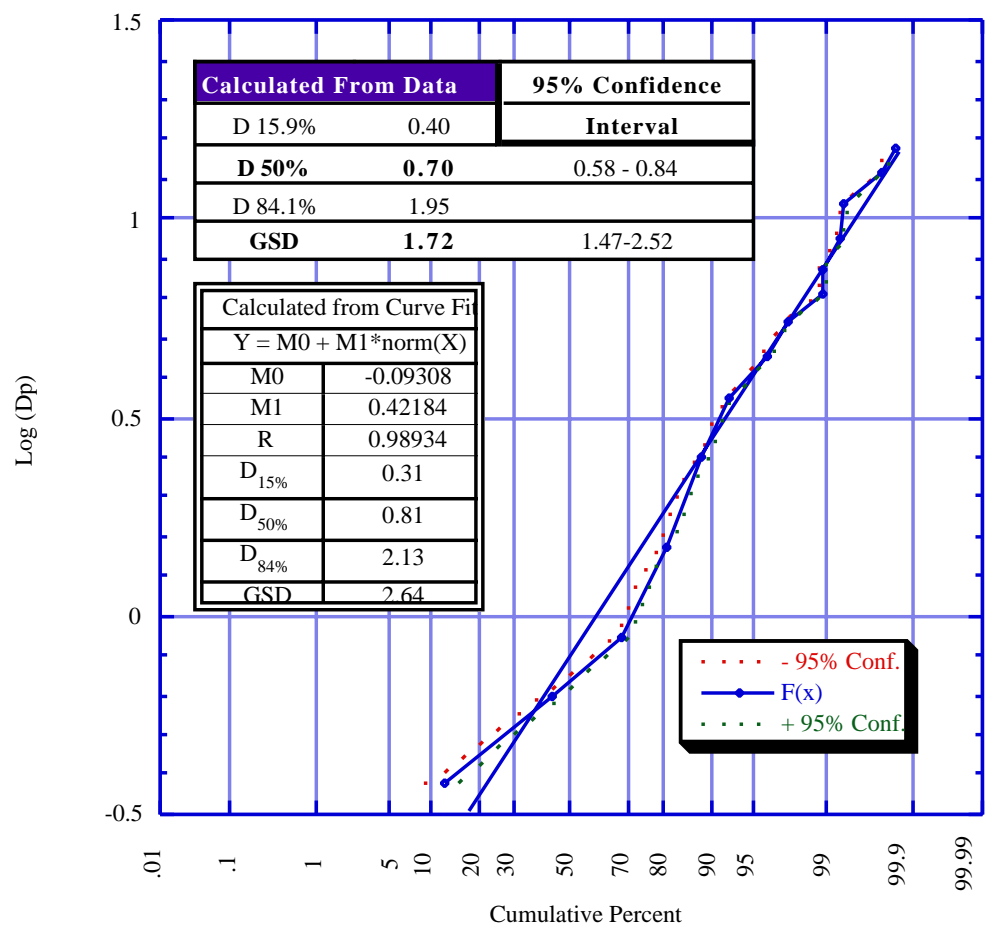

Figure 5.25. Cumulative log probability distribution generated with $95 \%$ confidence intervals for DIII-D RT2.

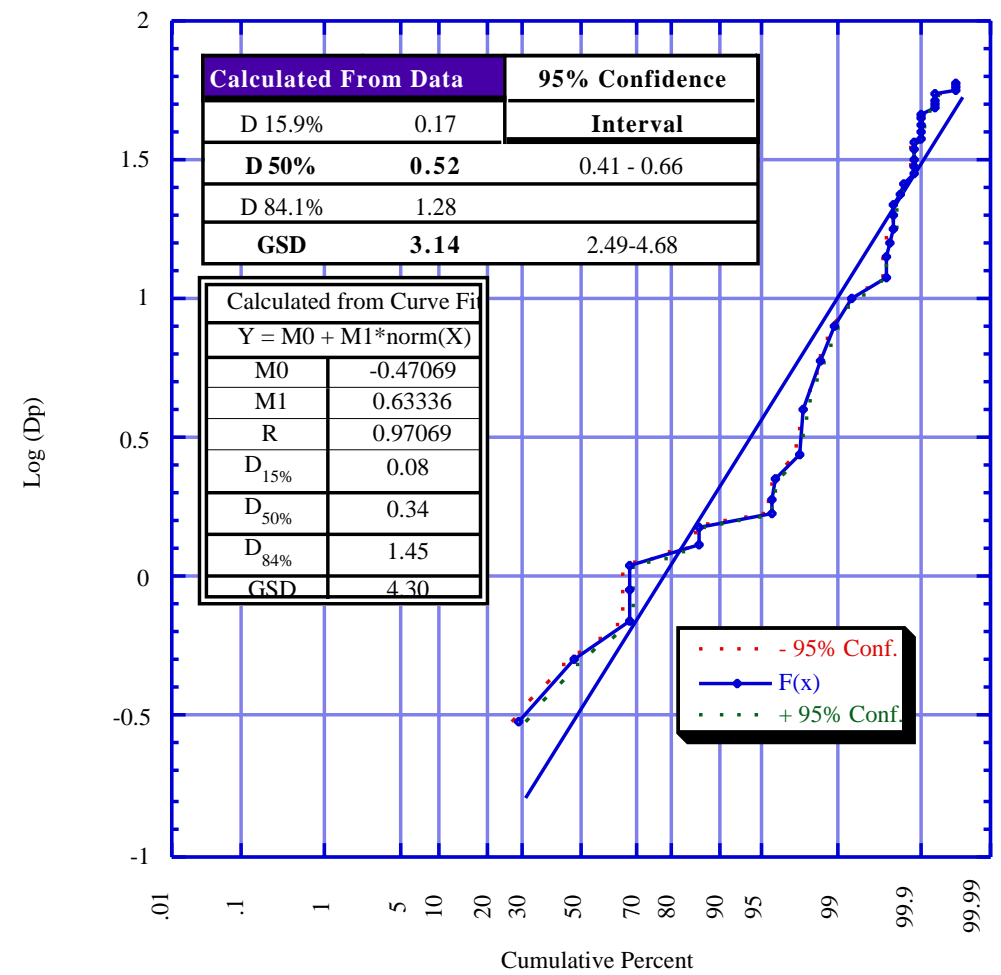

Figure 5.26. Cumulative log probability distribution generated with $95 \%$ confidence intervals for DIII-D RT3. 
A summary of the particle size analysis is shown in Table 5.5. The CMD and associated GSD are shown for each sample. The MMD (determined using Equation 1) and the $\mathrm{D}_{\mathrm{MVS}}$ (determined using Equation 2) for each sample are also shown.

Figure 5.27 shows a summary plot of particle CMD for each sample along with the associated ninety-five percent confidence intervals for each measurement. Similarly, Figure 5.28 shows the particle distribution GSD for each sample along with the associated ninety-five percent confidence interval. Very large confidence intervals in most of the cases in Figures 5.27 and 5.28 indicate that there were few particles found on the samples such as for the replicating tape samples.

Table 5.5. Summary of optical particle size analysis results.

\begin{tabular}{|c|c|c|c|c|c|c|}
\hline & $\begin{array}{l}\text { CMD } \\
(\mu \mathrm{m}) \\
\end{array}$ & $\begin{array}{l}\text { GSD } \\
(\mu \mathrm{m}) \\
\end{array}$ & $\begin{array}{l}D_{M V S} \\
(\mu \mathrm{m})\end{array}$ & $\begin{array}{c}D_{m} \\
(\mu \mathrm{m})\end{array}$ & $\begin{array}{l}\text { Toroidal } \\
\text { Location } \\
\end{array}$ & $\begin{array}{c}\text { Sample } \\
\text { Description }\end{array}$ \\
\hline FH1 & 0.70 & 3.71 & 7.44 & 10.80 & $337-345^{\circ}$ & BLH \\
\hline $\mathrm{FH} 2$ & 0.68 & 1.42 & 8.10 & 13.70 & $337-345^{\circ}$ & LPFS \\
\hline FH3 & 0.85 & 2.60 & 13.10 & 18.90 & $337-345^{\circ}$ & LPFS \\
\hline FH4 & 0.98 & 2.34 & 16.90 & 21.60 & $337-345^{\circ}$ & UPFS \\
\hline FH5 & 0.89 & 3.27 & 15.90 & 20.10 & $337-345^{\circ}$ & BUH \\
\hline FH6 & 0.57 & 2.52 & 8.10 & 13.20 & $0-90^{\circ}$ & LPFS \\
\hline FH7 & 0.49 & 2.44 & 9.65 & 22.70 & $0-90^{\circ}$ & R-1 \\
\hline FH8 & 0.46 & 2.94 & 7.91 & 12.00 & $90-180^{\circ}$ & LPFS \\
\hline FH9 & 0.50 & 2.81 & 16.00 & 25.10 & $90-180^{\circ}$ & R-1 \\
\hline FH10 & 0.88 & 2.18 & 12.10 & 17.30 & $180-270^{\circ}$ & LPFS \\
\hline FH11 & 0.80 & 1.81 & 32.00 & 50.30 & $180-270^{\circ}$ & R-1 \\
\hline FH12 & 0.68 & 2.75 & 31.90 & 45.60 & $90-180^{\circ}$ & UPFS \\
\hline FH13 & 1.00 & 2.88 & 14.70 & 19.40 & $180-270^{\circ}$ & UPFS \\
\hline FH14 & 0.90 & 3.34 & 12.50 & 16.40 & $270-360^{\circ}$ & UPFS \\
\hline FH15 & 0.59 & 3.19 & 16.10 & 24.80 & $45-55^{\circ}$ & LPFS \\
\hline FH16 & 0.63 & 3.50 & 22.20 & 33.50 & $135-145^{\circ}$ & LPFS \\
\hline FH17 & 0.57 & 3.32 & 30.50 & 38.92 & $225-235^{\circ}$ & LPFS \\
\hline RT1 & 0.27 & 4.39 & 10.70 & 15.50 & $30^{\circ}$ & RT \\
\hline RT2 & 0.70 & 1.72 & 7.20 & 9.20 & $95^{\circ}$ & RT \\
\hline RT3 & 0.52 & 3.14 & 33.30 & 44.60 & $105^{\circ}$ & RT \\
\hline BLH & \multicolumn{6}{|c|}{ Beneath Lower Horizontal Tiles } \\
\hline LPFS & \multicolumn{6}{|c|}{ Lower Plasma Facing Surface } \\
\hline UPFS & \multicolumn{6}{|c|}{ Upper Plasma Facing Surface } \\
\hline BUH & \multicolumn{6}{|c|}{ Behind Upper Horizontal Tiles } \\
\hline $\mathrm{R}-1$ & \multicolumn{6}{|c|}{ Inside $\mathrm{R}-1$ ports } \\
\hline RT & \multicolumn{6}{|c|}{ Replicating tape samples } \\
\hline
\end{tabular}




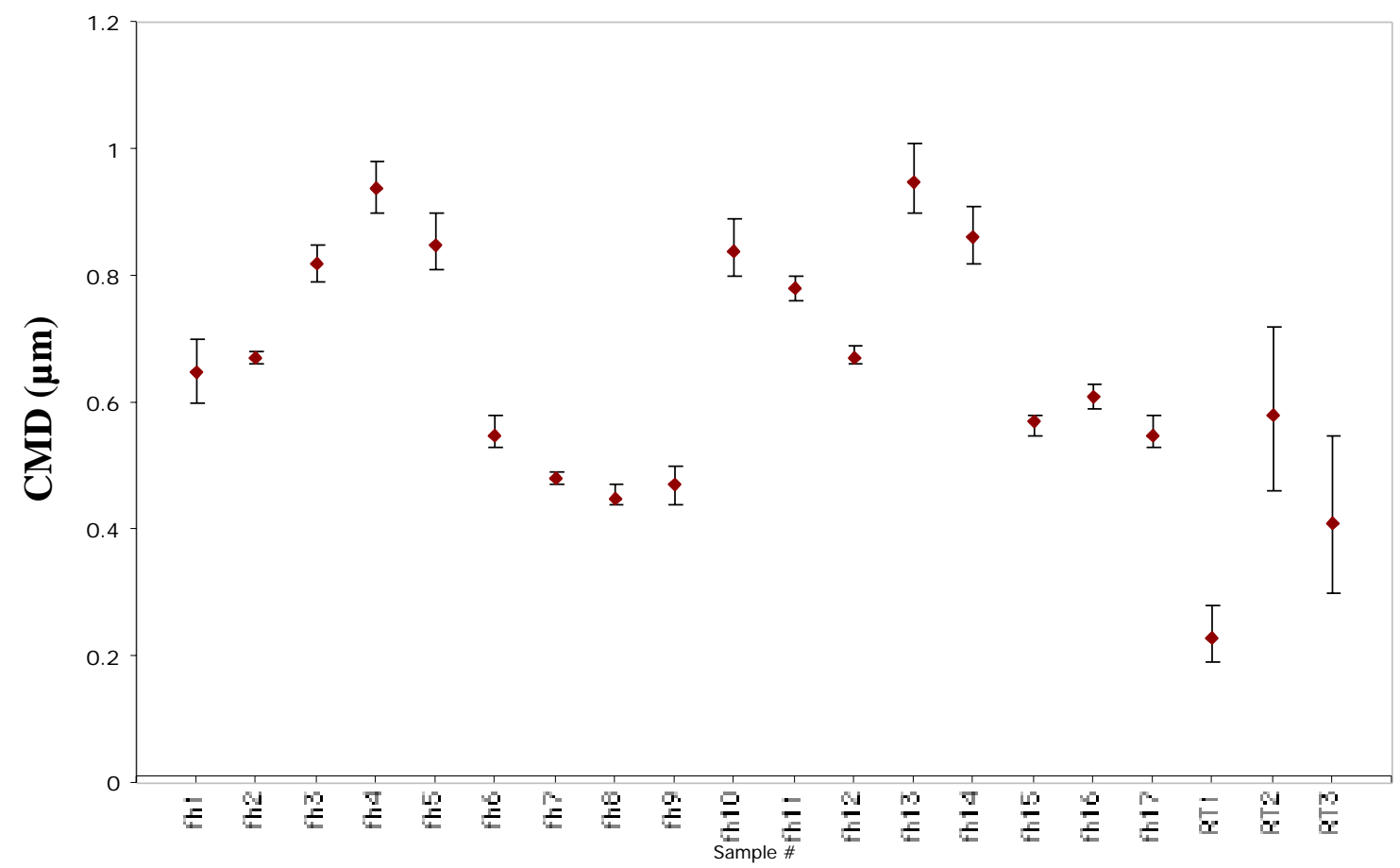

Figure 5.27. Plot of CMD with associated $95 \%$ confidence intervals.

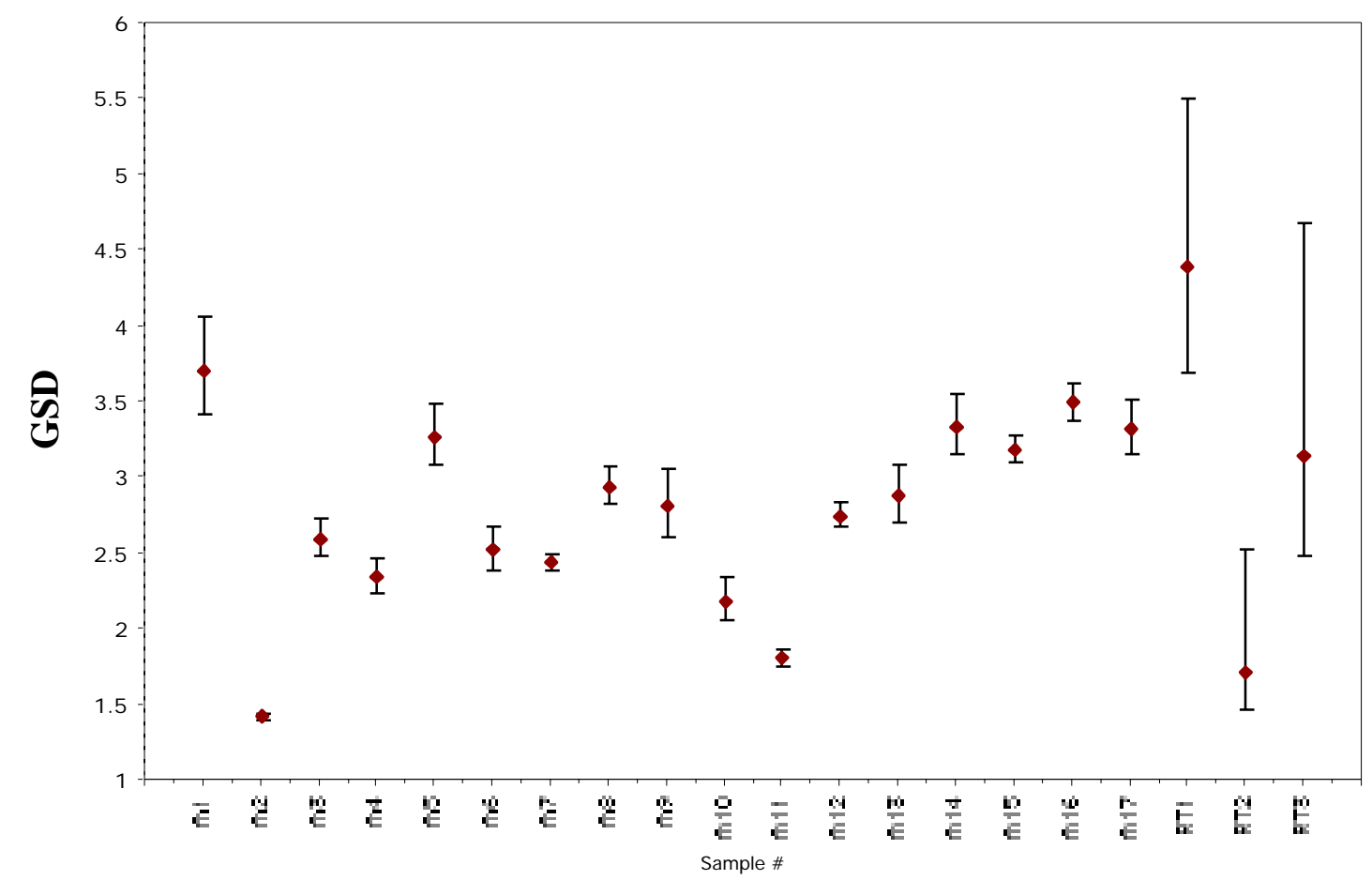

Figure 5.28. Plot of distribution GSD with associated 95\% confidence intervals. 


\subsection{Particle Size Analysis using a Coulter LS130 Laser Particle Sizer}

Sampling particulate from surfaces after the particulate has attached to the surface is difficult due primarily to van Der Waals forces of attraction between the particle and the surface. We use multiple collection and analysis methods to ensure that a representative quantification of the particle characteristics was made. We used lift-off replicating tape samples to collect particulate that might have been missed by the vacuuming technique employed in most locations in the machine. These replicating tape samples were disolved in acetone and the resulting particle suspension analyzed in a Coulter LS130 laser diffraction particle size analyzer. Three samples were taken using this technique employing two separate tapes placed in adjacent sample locations. Section 2.2 presents a detailed description of the sample locations. Three locations were sampled; RT1, the lower $45^{\circ}$ tile at the $30^{\circ}$ toroidal location, RT2, the lower $45^{\circ}$ tiles at the $90^{\circ}$ toroidal location, and RT3, inside the R-1 port located at the $105^{\circ}$ toroidal location.

Figure 5.29 shows a plot of the results of analysis using the Coulter LS130. Since the measurement technique yields a measure of particle diameter based on a volume measurement, the reported results are in volumetric terms. Volumetric determined size analysis is generally dominated by the larger particulate and is more sensitive to larger particulate than a count based measurement. Figure 5.30 shows the same data plotted on as cumulative distributions.

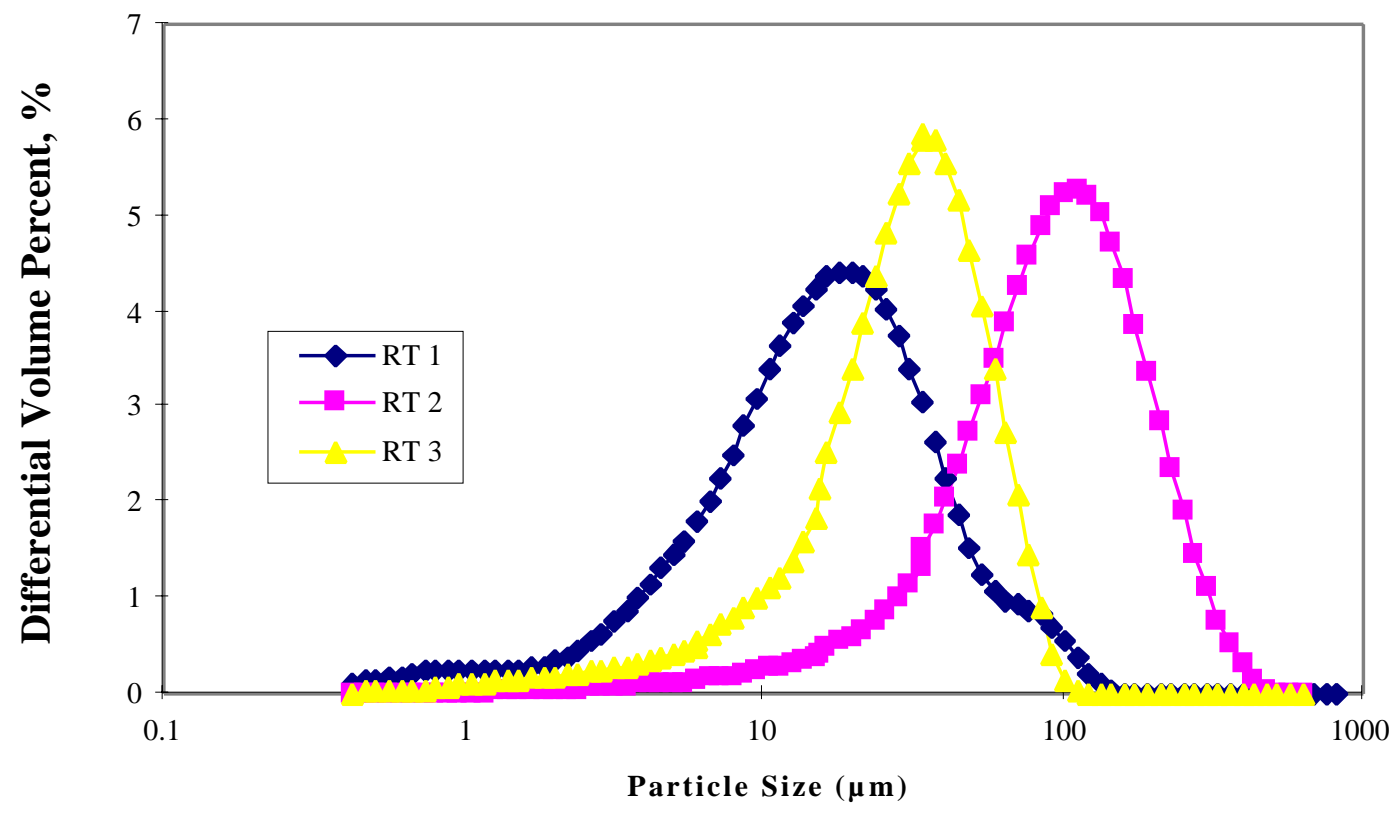

Figure 5.29. Differential volume percent verses particle size as determined by Coulter LS130 analysis. 


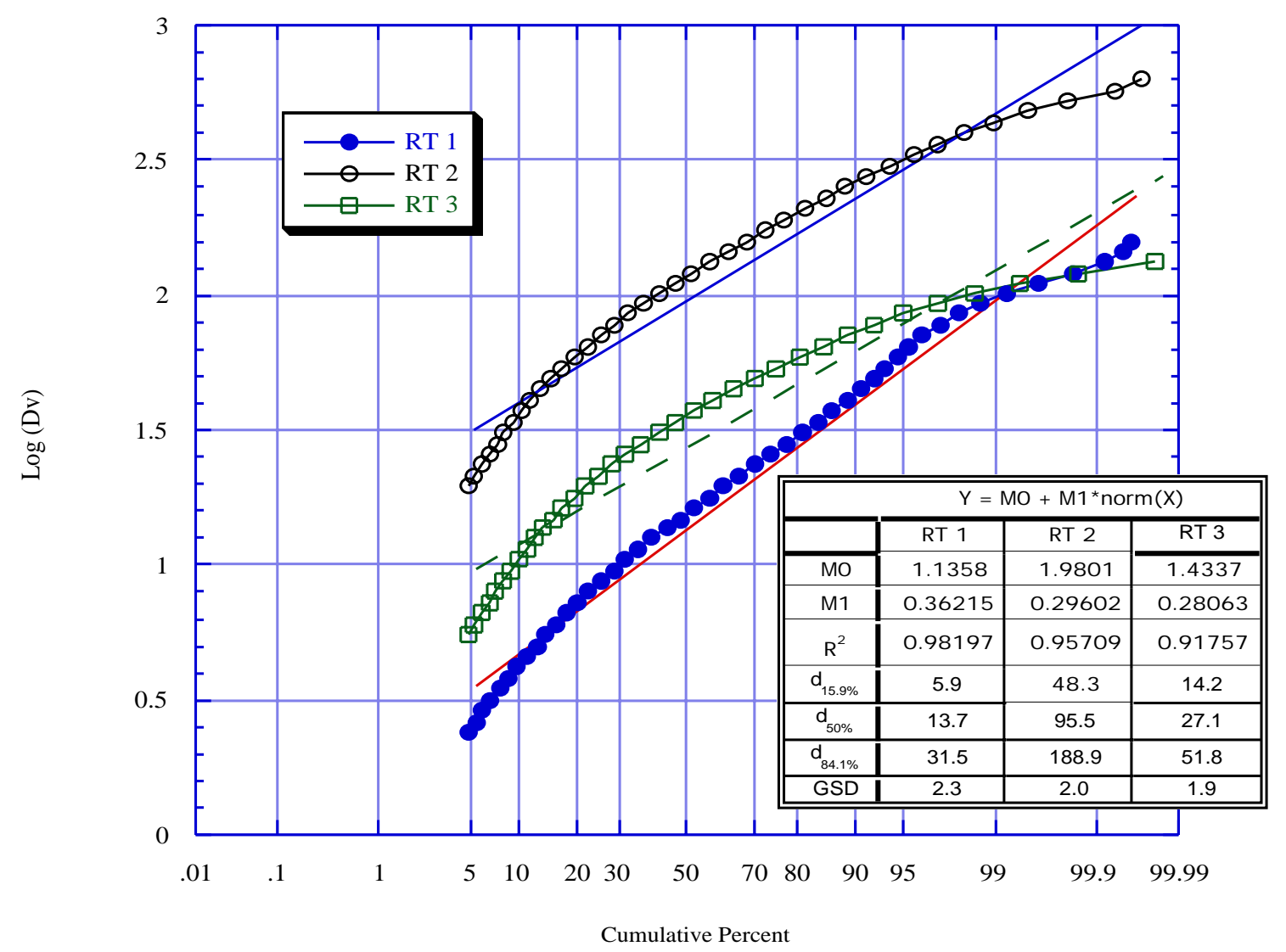

Figure 5.30. Cumulative volume percent verses $\log \left(\mathrm{D}_{v}\right)$ on a log-normal plot for RT1, RT2, and RT3.

The results of this analysis are consistent with the measurements obtained using the count based particle size analysis reported for the optical microscope above. RT2 shows a median diameter that is larger than expected. This is probably due to the presence of large pieces of particulate (i.e. $>100 \mu \mathrm{m}$ diameters) that skews the distribution to higher sizes.

\subsection{Particle Size Distribution Measurement Results from Cascade Impactor Measurements}

Particle size analysis using a cascade impactor results in particle distributions based upon mass. A cascade impactor measures particle size distributions by selecting particles for measurement based on inertial mass. Similar to the Coulter LS130 volumetric measurement a cascade impactor measurement is most sensitive to larger particle diameters. The range of operation is generally between $0.2 \mu \mathrm{m}$ and $15 \mu \mathrm{m}$ aerodynamic or Stoke's diameter. In contrast, the Coulter LS130 range of sensitivity is 1 $\mu \mathrm{m}$ up to approximately $700 \mu \mathrm{m}$. 


\subsubsection{Method of Cascade Impactor Sampling}

Four 20 liter per minute Intox 7-stage cascade impactors were used to measure the mass based particle size distribution of dust collected in various areas of the DIII-D vacuum vessel. The suction line from the sampling pump used for the vacuum filter housings was attached to the exit of the cascade impactors and a flow of 20 liters per minute drawn through the impactors. The sample nozzle from the filter housings was attached to the inlet of the cascade impactors. Four areas of the DIII-D internals were vacuumed with the impactors. Approximately $1900 \mathrm{~cm}^{2}$ behind the Lower $45^{\circ}$ and Row 1 tiles were vacuumed in the $35-45^{\circ}, 135-145^{\circ}, 225-335^{\circ}$, and the $337-345^{\circ}$ toroidal locations. The data are analyzed by calculating the mass of particles collected on each stage of the impactor. Each stage has a characteristic particle size that is collected depending upon the flow rate drawn through the impactor. This characteristic particle size is called the estimated cut diameter (ECD) and represents the particle collected with $50 \%$ efficiency on each stage. The cumulative percent of mass collected on each successive stage is calculated and the diameter corresponding to the $50^{\text {th }}$ percentile in mass determined. This diameter is the MMD. The geometric standard deviation is determined by dividing the diameter corresponding to the $84^{\text {th }}$ percentile $\left(\mathrm{d}_{84 \%}\right)$ by the MMD.

\subsubsection{Results of Cascade Impactor Sampling}

Table 5.6 shows the results of the impactor stage differential weight measurements obtained from behind the $45-55^{\circ}$ Lower $45^{\circ}$ and Row 1 floor tiles (CIMSS-01), from behind the $135-145^{\circ}$ Lower $45^{\circ}$ and Row 1 floor tiles (CI-MSS-03), from behind the $225-235^{\circ}$ Lower $45^{\circ}$ and Row 1 floor tiles (CI-MSS-05), and from behind the $337-345^{\circ}$ Lower $45^{\circ}$ and Row 1,2, and 3 floor tiles (02-250). The MMD for the dust collected behind the $45-55^{\circ}$ Lower $45^{\circ}$ and Row 1 floor tiles is $8.94 \mu \mathrm{m}$ with a GSD of 3.2. The MMD for the dust collected from behind $135-145^{\circ}$ Lower $45^{\circ}$ and Row 1 floor tiles is $7.39 \mu \mathrm{m}$ with a GSD of 2.77. The MMD for the dust collected behind the 225$235^{\circ}$ Lower $45^{\circ}$ and Row 1 floor tiles is $5.64 \mu \mathrm{m}$ with a GSD of 1.98. The MMD, for the dust collected behind $337-345^{\circ}$ Lower $45^{\circ}$ and Row 1,2 , and 3 floor tiles is $5.26 \mu \mathrm{m}$ with a GSD of 3.11.

Most of the particulate mass found in the DIII-D vacuum vessel has diameter greater than $10 \mu \mathrm{m}$ in aerodynamic size. This result is in agreement with the count based particle size distributions determined from optical microscopy analysis and from the Coulter LS130 analysis. 
CI-MSS-01

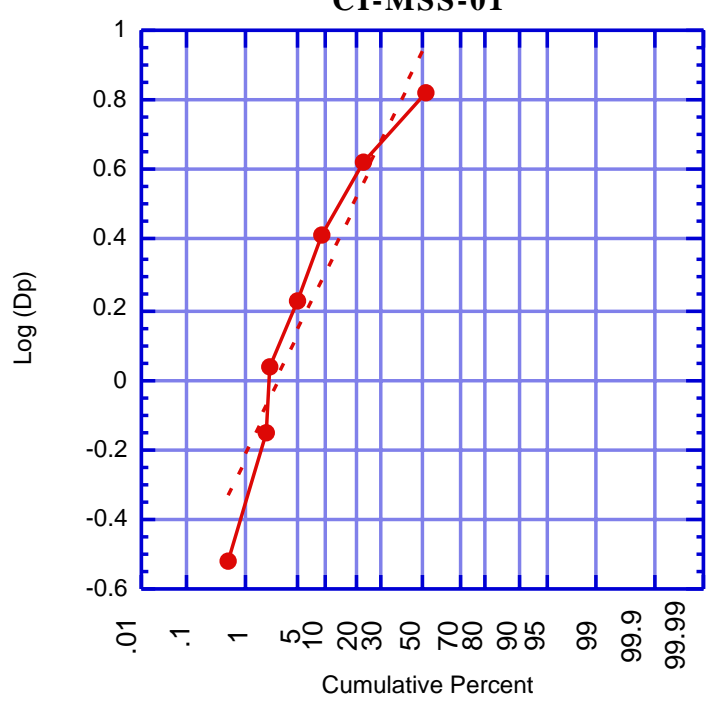

CI-MSS-05

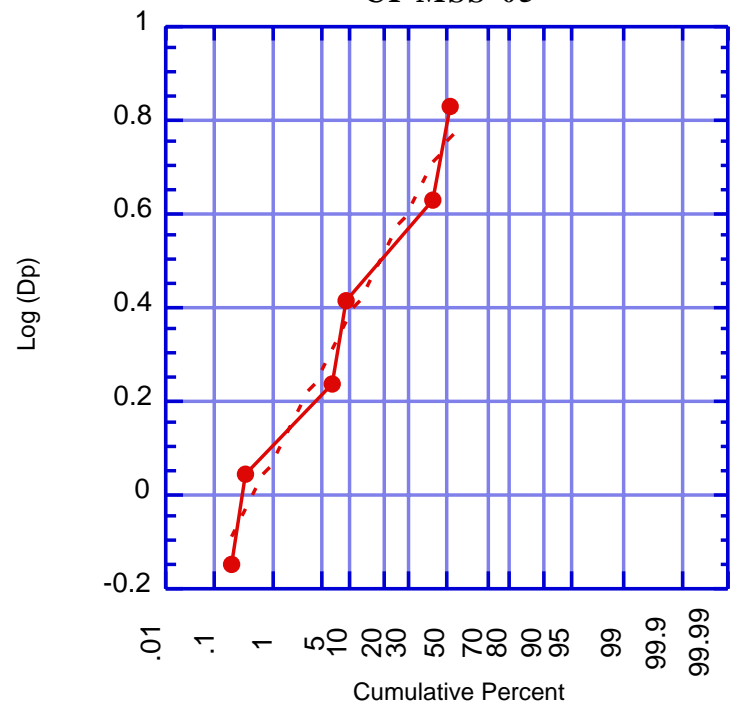

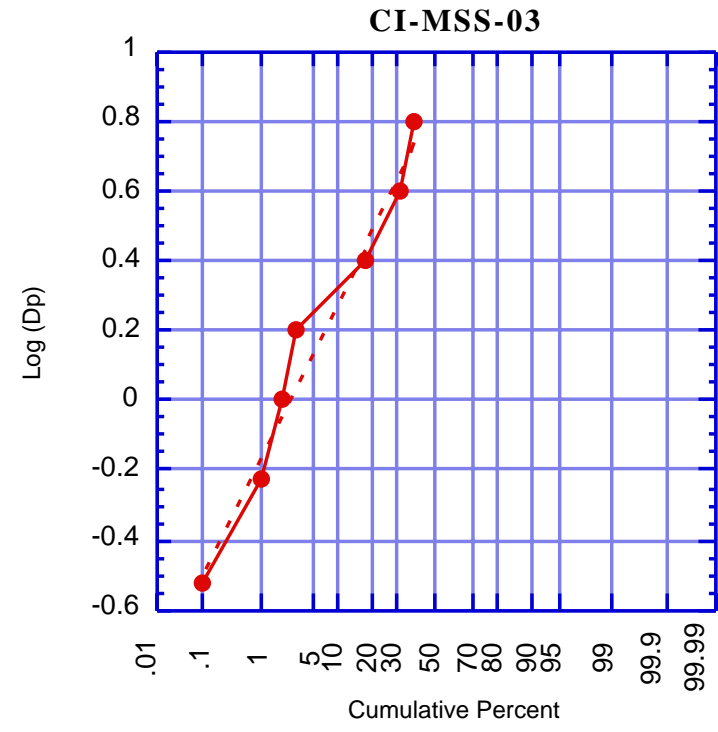

02-250 SS

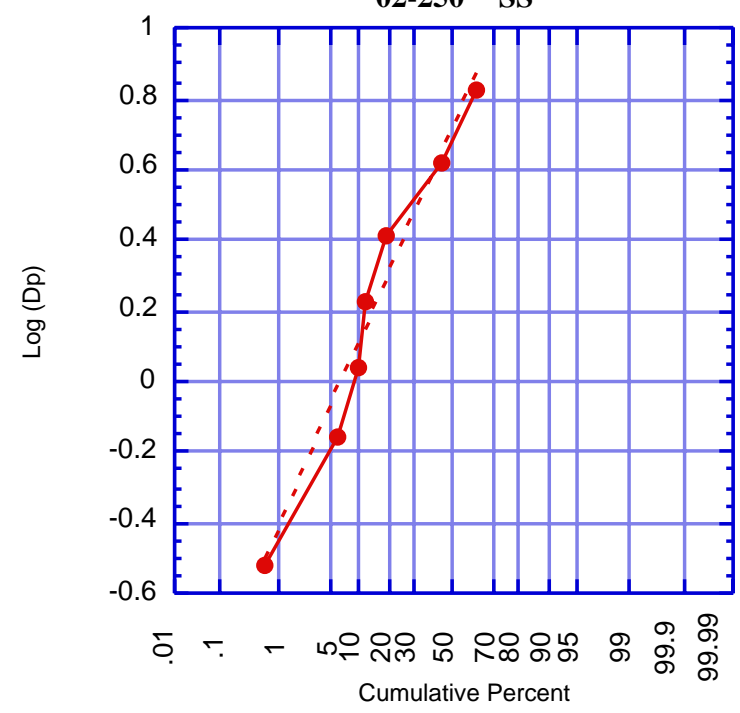

Figure 5.31. Cumulative percent distribution for the four cascade impactor samples. 
Table 5.6. Summary table of cascade impactor measurements.

\begin{tabular}{|c|c|c|c|c|c|c|c|c|}
\hline \multicolumn{9}{|c|}{ CI-MSS-01 } \\
\hline $\begin{array}{c}\text { Stage } \\
\text { Number }\end{array}$ & $\begin{array}{l}\text { Flow } \\
\text { Rate } \\
1 / \mathrm{min}\end{array}$ & $\begin{array}{c}\text { Cut } \\
\text { Diameter } \\
(\mu \mathrm{m})\end{array}$ & $\begin{array}{c}\text { Initial } \\
\text { Weight } \\
\mathrm{g}\end{array}$ & $\begin{array}{c}\text { Final } \\
\text { Weight } \\
\mathrm{g}\end{array}$ & $\begin{array}{c}\text { Differential } \\
\text { Weight } \\
\text { g }\end{array}$ & Fraction & $\begin{array}{c}\text { Cumulative } \\
\text { Fraction }\end{array}$ & $\begin{array}{c}\text { Cumulative } \\
\text { Percent } \\
\%\end{array}$ \\
\hline 1.00 & 22.00 & 10.72 & 0.6634 & 0.7458 & 0.0824 & 0.48 & 1.00 & 100 \\
\hline 2.00 & 22.00 & 6.70 & 0.6653 & 0.7148 & 0.0495 & 0.29 & 0.52 & 51.6 \\
\hline 3.00 & 22.00 & 4.22 & 0.6601 & 0.6829 & 0.0228 & 0.13 & 0.22 & 22.5 \\
\hline 4.00 & 22.00 & 2.62 & 0.6622 & 0.6692 & 0.0070 & 0.04 & 0.09 & 9.0 \\
\hline 5.00 & 22.00 & 1.65 & 0.6600 & 0.6647 & 0.0047 & 0.03 & 0.05 & 4.9 \\
\hline 6.00 & 22.00 & 1.06 & 0.6645 & 0.6648 & 0.0003 & 0.00 & 0.02 & 2.2 \\
\hline 7.00 & 22.00 & 0.67 & 0.6623 & 0.6649 & 0.0026 & 0.02 & 0.02 & 2.0 \\
\hline Final Filter & 22.00 & 0.33 & 0.0153 & 0.0161 & 0.0008 & 0.00 & 0.00 & 0.5 \\
\hline & & & & Total & 0.1701 & & & \\
\hline \multicolumn{9}{|c|}{ CI-MSS-03 } \\
\hline 1.00 & 24.50 & 10.21 & 0.6557 & 0.8321 & 0.1764 & 0.61 & 1.00 & 100 \\
\hline 2.00 & 24.50 & 6.34 & 0.6625 & 0.6813 & 0.0188 & 0.07 & 0.39 & 38.8 \\
\hline 3.00 & 24.50 & 4.03 & 0.6587 & 0.7007 & 0.0420 & 0.15 & 0.32 & 32.3 \\
\hline 4.00 & 24.50 & 2.47 & 0.6834 & 0.6610 & 0.0418 & 0.14 & 0.18 & 17.8 \\
\hline 5.00 & 24.50 & 1.61 & 0.6588 & 0.6619 & 0.0031 & 0.01 & 0.03 & 3.3 \\
\hline 6.00 & 24.50 & 1.00 & 0.6547 & 0.6579 & 0.0032 & 0.01 & 0.02 & 2.2 \\
\hline 7.00 & 24.50 & 0.63 & 0.6646 & 0.6674 & 0.0028 & 0.01 & 0.01 & 1.1 \\
\hline Final Filter & 24.50 & 0.32 & 0.0152 & 0.0155 & 0.0003 & 0.00 & 0.00 & 0.10 \\
\hline & & & & Total & 0.2884 & & & \\
\hline \multicolumn{9}{|c|}{ CI-MSS-05 } \\
\hline 1.00 & 22.00 & 10.72 & 0.6397 & 0.8603 & 0.2206 & 0.48 & 1.00 & 100 \\
\hline 2.00 & 22.00 & 6.70 & 0.6659 & 0.7121 & 0.0462 & 0.10 & 0.52 & 52.1 \\
\hline 3.00 & 22.00 & 4.22 & 0.6661 & 0.8197 & 0.1536 & 0.33 & 0.42 & 42.0 \\
\hline 4.00 & 22.00 & 2.62 & 0.6658 & 0.6754 & 0.0096 & 0.02 & 0.09 & 8.7 \\
\hline 5.00 & 22.00 & 1.65 & 0.6766 & 0.6607 & 0.0285 & 0.06 & 0.07 & 6.6 \\
\hline 6.00 & 22.00 & 1.06 & 0.6602 & 0.6613 & 0.0011 & 0.00 & 0.00 & 0.39 \\
\hline 7.00 & 22.00 & 0.67 & 0.6640 & 0.6645 & 0.0005 & 0.00 & 0.00 & 0.15 \\
\hline Final Filter & 22.00 & 0.33 & 0.0151 & 0.0153 & 0.0002 & 0.00 & 0.00 & 0.04 \\
\hline & & & & Total & 0.4603 & & & \\
\hline \multicolumn{9}{|c|}{$02-250 \mathrm{SS}$} \\
\hline 1.00 & 22.00 & 10.72 & 0.6719 & 0.7268 & 0.0549 & 0.38 & 1.00 & 100 \\
\hline 2.00 & 22.00 & 6.70 & 0.6832 & 0.6773 & 0.0251 & 0.17 & 0.62 & 61.7 \\
\hline 3.00 & 22.00 & 4.22 & 0.6844 & 0.6670 & 0.0378 & 0.26 & 0.44 & 44.3 \\
\hline 4.00 & 22.00 & 2.62 & 0.6660 & 0.6744 & 0.0084 & 0.06 & 0.18 & 17.9 \\
\hline 5.00 & 22.00 & 1.65 & 0.6554 & 0.6442 & 0.0026 & 0.02 & 0.12 & 12.1 \\
\hline 6.00 & 22.00 & 1.06 & 0.6700 & 0.6763 & 0.0063 & 0.04 & 0.10 & 10.2 \\
\hline 7.00 & 22.00 & 0.67 & 0.6652 & 0.6727 & 0.0075 & 0.05 & 0.06 & 5.9 \\
\hline Final Filter & 22.00 & 0.33 & 0.0154 & 0.0163 & 0.0009 & 0.01 & 0.01 & 0.63 \\
\hline & & & & Total & 0.1435 & & & \\
\hline
\end{tabular}

* ECD - Estimated Cut Diameter (Dependent upon flowrate maintained through impactor). 


\subsection{Spherical Particle Size Distribution Analysis Results}

Image and SEM analysis of the particles found in DIII-D clearly indicates numerous spherical particles formed from either melt atomization or vapor transport processes during operation of the DIII-D experiment. The SEM/EDS analysis discussed in Section 4.2 shows that the spherical particles are composed of either carbon, steel, or aluminum and oxygen. Analysis of the spherical particles was completed to determine the particle size of the spheres found in the samples. Figure 5.32 shows the cumulative size distribution of spherical. Overall, the distribution shown in Figure 5.32 is represented by 48 spherical particles having a CMD of $1.15 \mu \mathrm{m}$ and a GSD of 1.94. The smallest spherical particle observed had a diameter of $0.48 \mu \mathrm{m}$ and the largest spherical particle observed had a diameter of $10.9 \mu \mathrm{m}$. Spherical particles having compositions of iron alloys, carbon, and aluminum oxide were observed.

Due to the relatively small number of total particles used in this analysis and the difficulty of relating locational dependencies in the samples, no statistical tests have been performed for this analysis. Therefore, these data should only be used for informational purposes. The purpose of this data analysis is to provide preliminary information into possible formation mechanisms related to spherical particulate in carbon first wall fusion machines. We believe that the spherical particulate is generally formed during plasmawall interactions yielding either melt atomization of material into droplets or by vapor to particle conversion of material following a plasma-wall interaction.

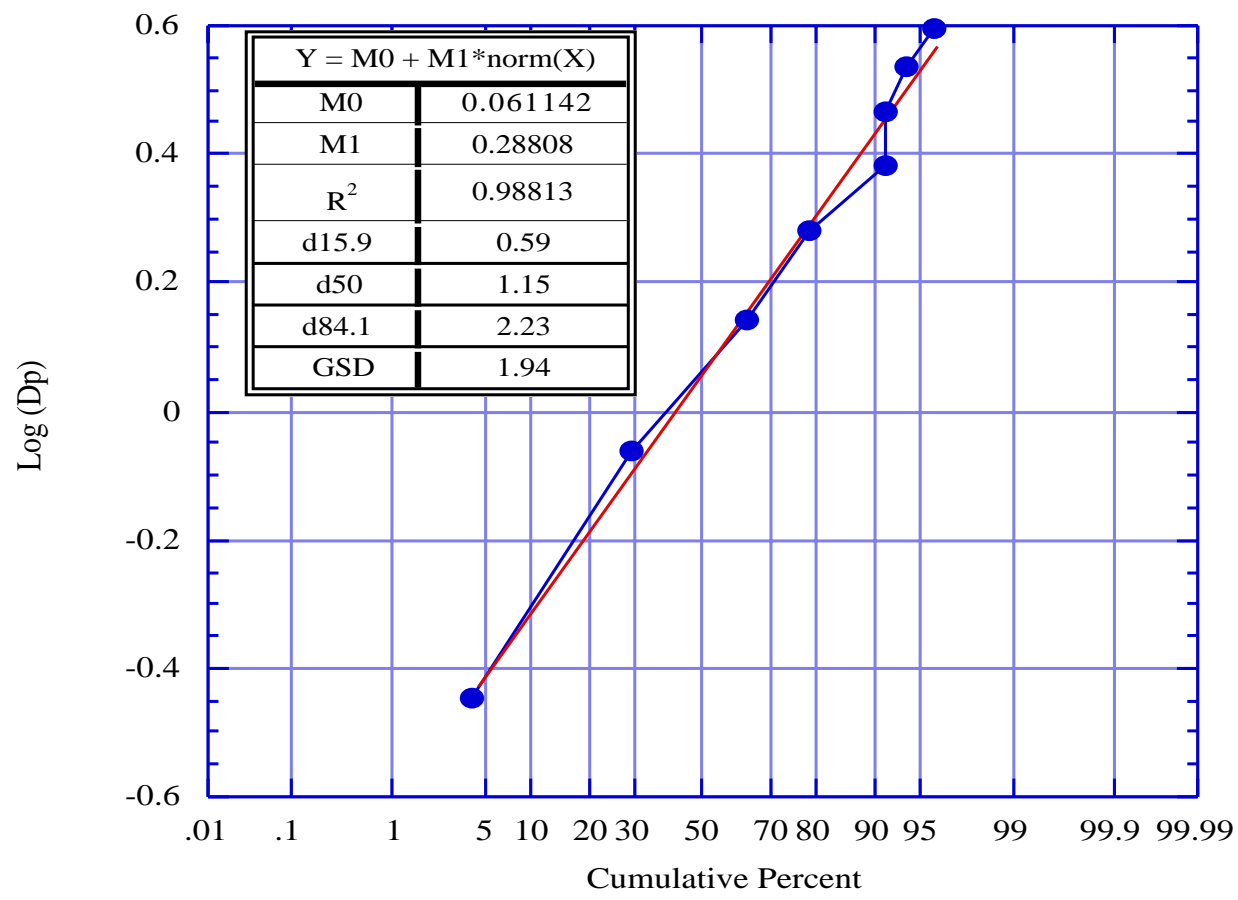

Figure 5.32. Cumulative percent size distribution for spherical particles. 


\subsection{Discussion}

\subsection{Comparison with Previous DIII-D Collection (1996 Vent)}

The samples analyzed for this report represent a detailed sampling of the DIII-D vessel. The sample that we collected in 1996 represented a selective sampling of surfaces. At the time we did not know that the bulk of the particulate resided in lower horizontal locations protected from direct plasma exposure. We did not keep good track of the sampled locations nor the sampled surface area. The samples collected in 1998 were collected in multiple areas of the machine on separate substrates keeping detailed track of both the sample location and the sampled surface area. Additional analysis for the 1998 vent included specific surface area and detailed ICP-MS chemical analysis. These analyses were not completed during 1996 because we did not plan the sampling to facilitate the preparation of samples for elemental and surface area analysis. The only quantitative analysis for composition was completed using the EDS detector on the SEM. The EDS indicated carbon, silicon dioxide, aluminum dioxide, and Inconel were present in the samples.

The samples presented in this report contained an average of $45 \mathrm{wt} \%$ total metal and an average of $30 \mathrm{wt} \%$ carbon. We also observed significant higher quantities of spherical particles as opposed to the predominately flake material found in 1996. This is probably due to the large quantity of metal dust found on the cold wall surfaces of DIII-D during this vent. The particle size distributions measured during the 1996 vent of DIII-D compare well with the analysis completed for this effort. Count median diameters from the 1996 vent ranged from $0.5 \mu \mathrm{m}$ to $0.86 \mu \mathrm{m}$ with geometric standard deviations ranging from 2.03 to 3.05 . Count median diameters determined during this analysis ranged from $0.46 \mu \mathrm{m}$ to $1.0 \mu \mathrm{m}$ with geometric standard deviations ranging from 1.42 to 4.39 . Mean surface-volume diameters ranged from 7.20 to $33.3 \mu \mathrm{m}$. A variety of particle shapes were observed including flakes and spheres of carbon, iron alloys, and other exotic material. More spherical particles were observed during this analysis than were observed in the 1996 vent. This is most likely due to the careful sampling used during the 1998 vent.

\subsection{Comparison with other Tokamak Dusts}

The size distribution and specific surface area of the particulate found in the 1998 DIII-D samples compare well with other those of dust found in DIII-D and TFTR. Figure 6.1 shows a plot of the specific surface area verses the particle mean surface-volume diameter for a variety of materials, previous tokamak dust measurements, and the current DIII-D measurement. The specific surface area of dust obtained in the 1998 DIII-D vent is higher than theoretical carbon spheres but compares extremely well with the previous DIII-D measurement completed in 1996. This is expected since the bulk of the sample is flake material sometimes composed of agglomerates of smaller particles and not spherical. The bulk of the dust collected from both DIII-D and TFTR has had flake structures. 


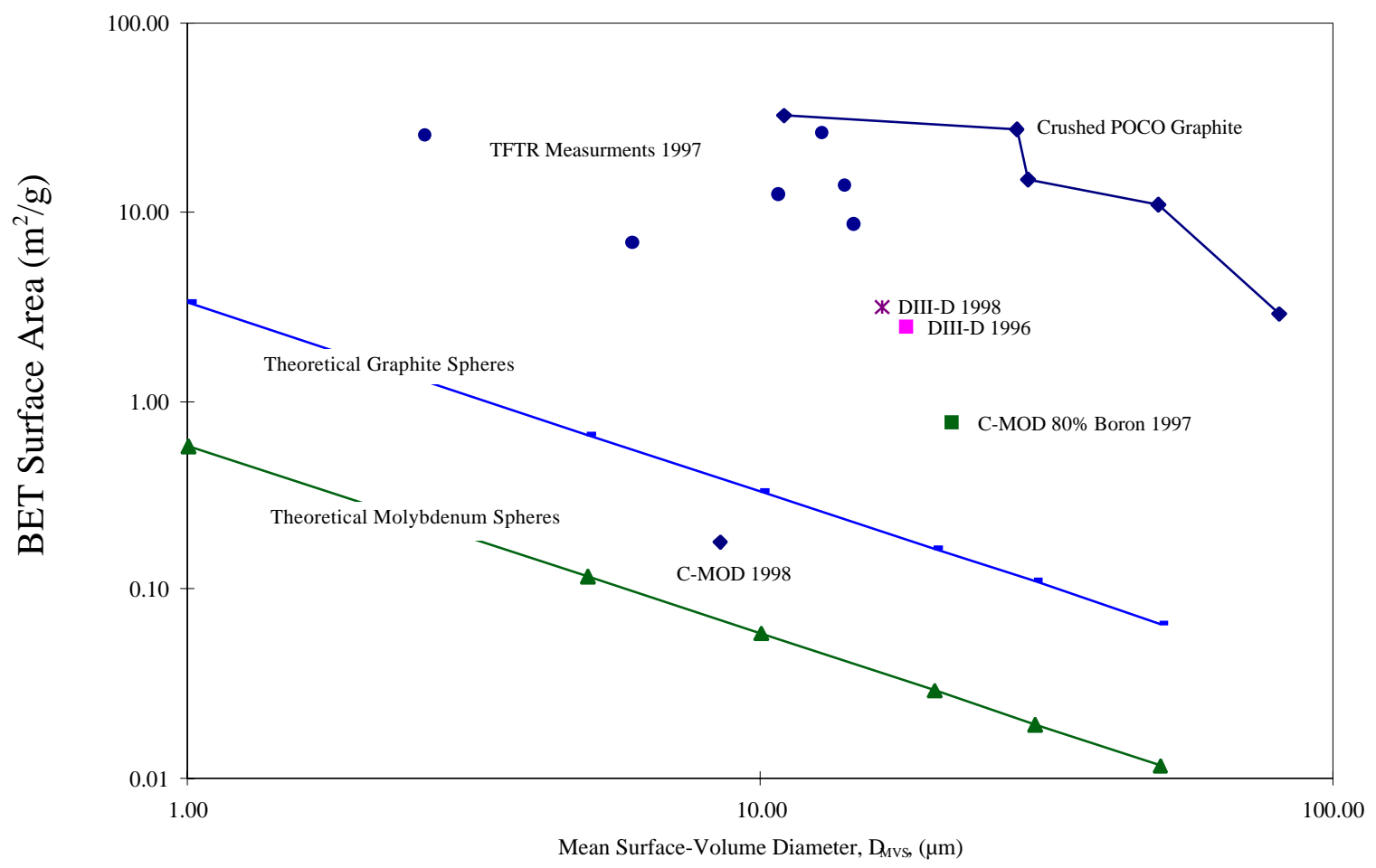

Figure 6.1. Graph of the BET Specific Surface area plotted verses the mean surfacevolume diameter for a variety of materials, previous measurements, and the current C-MOD measurement.

\subsection{Comparison with Simulated Disruption Dust (SIRENS)}

The SIRENS disruption simulation facility has completed testing the interaction of plasma disruptions with carbon materials ${ }^{8}$. Three pure carbon interaction tests were completed using UTR-22 graphite, ATJ graphite and lexan. Additional tests conducted by the SIRENS facility included testing mixed material interactions such as carbon/aluminum, carbon/stainless steel, carbon/copper, and carbon/tungsten. CMD values from the pure carbon tests ranged from 0.07 to $0.54 \mu \mathrm{m}$ with GSDs ranging from 1.96 to 3.57. Figure 6.2 shows a $5000 \mathrm{X}$ magnification photomicrograph of dust collected on Button 3 of the ATJ graphite test. The photomicrograph shows both flake material as well as small spherical particles of graphite.

Similar to the SIRENS tests, spherical particles having compositions of carbon, iron alloys, and other materials have been found during analysis of the DIII-D dust. Figure 6.3 shows a graph of CMD and GSD results from various dust collection analyses and tests in the SIRENS facility. Also shown is the NSSR-2 dust specification'. The analysis results of DIII-D dust collected in 1996 is labeled "DIII-D 96" and is shown on the left side of the graph. The current, 1998, collection analysis is labeled "DIII-D 98" and is shown on the right side of the graph. 


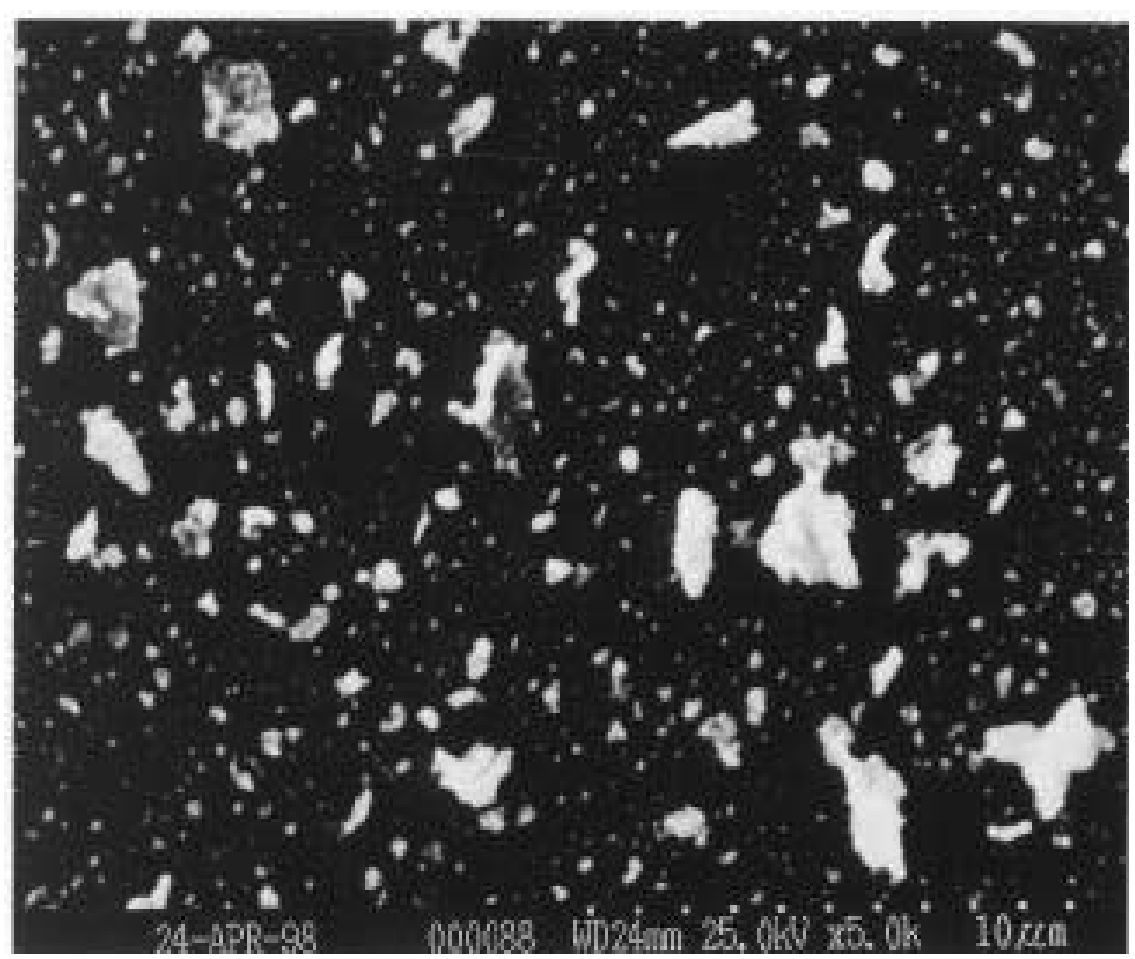

Figure 6.2. Photomicrograph of SIRENS ATJ graphite test (S764, button 3) (5000 X magnification).

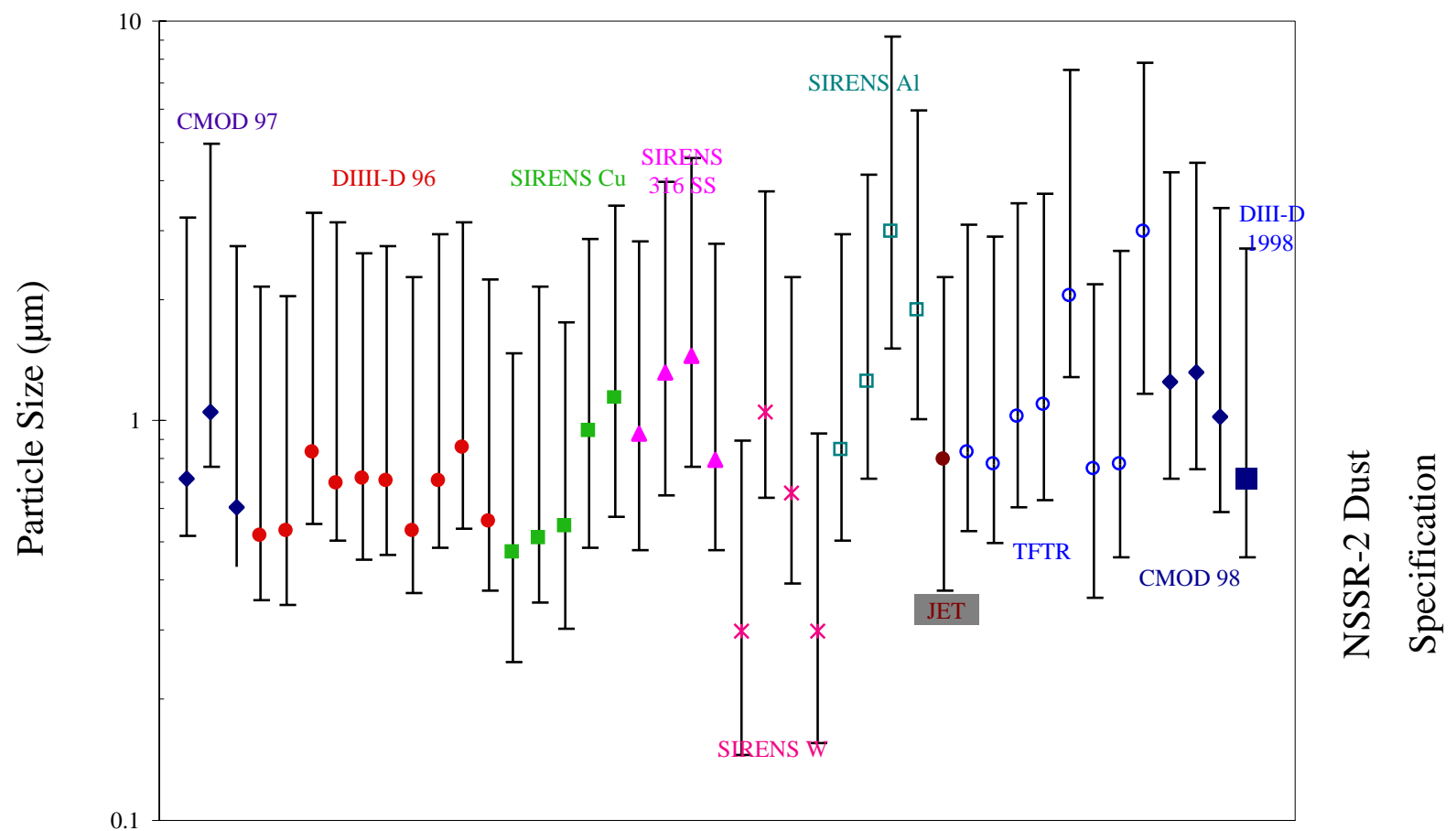

Figure 6.3. Plot of various dust characterization analyses and SIRENS tests results. 


\subsection{Estimate of Total Dust Content of the DIII-D Vacuum Vessel}

A primary objective of the dust collection activity during the 1998 vent period was to sample a significant portion of the available surface area within the vacuum vessel. Protection tiles were removed from the floor, ceiling, and outer divertor with the specific purpose of sampling for dust underneath plasma facing components. An attempt was made to sample for dust on top of and underneath the 337 to $345^{\circ}$ tiles on the floor, on the outer divertor, and on the ceiling. Sampling in this radial location at different poloidal locations gave an estimate of the relative distribution of dust in the poloidal direction both on the surface of tiles and also underneath the same tiles. We also sampled from the surface and from underneath three additional sets of floor tiles with all of this data we were able to determine the distribution of dust in and around the DIII-D vacuum vessel (see Figure 2.19). We then took average values of dust concentrations on and underneath the baffle surfaces, the upper vertical surfaces, and the floor surfaces and multiplied by the appropriate surface area to obtain an estimate of the total mass of dust in DIII-D. The results are shown in Table 6.1. There is uncertainty in this estimate associated with the following:

a) surface area of components. Values are approximate due to variations of tile size in the machine. (Estimated error: $\pm 10 \%$ )

b) Penetrations. Penetrations are assumed to represent a small portion of the surface area of the DIII-D vacuum vessel and thus are not accounted for. (Estimated error: $+5 \%)$.

c) Particulate collection efficiency. The collection efficiency is assumed to be $100 \%$ in the analysis. Limited controlled lab tests indicate sampling efficiencies for total mass filter housings are on the order of $80-90 \%$. For cascade impactor measurements, efficiencies may be as low as 30-40\%. (Estimated error: 300 $400 \%)$

d) Ex-vessel dust locations. Dust located in penetrations and locations removed from the first wall and immediately behind the first wall are not considered. Dust in these locations generally are not applicable to accident source terms because it is not readily mobilized nor is it subjected to high heat fluxes during accidents. (Estimated error: 0\%).

Based upon these errors we feel that the estimate of 33 grams could be a significant underestimate because of the low sampling efficiency of the cascade impactor and the large amount of mass collected by the impactor underneath the floor tiles. The total dust could actually be as high as 90 to 120 grams.

Table 6.1. Summary of total dust estimate.

\begin{tabular}{|c|c|c|c|c|c|c|c|}
\hline & $\mu \mathrm{g} / \mathrm{cm} 2$ & cm2 & mg & & $\mu \mathrm{g} / \mathrm{cm} 2$ & cm2 & mg \\
\hline Baffle Surfaces & 0.15 & 252696 & 38 & $\begin{array}{l}\text { Underneath } \\
\text { Baffle Surfaces }\end{array}$ & 19.6 & 252696 & 4952 \\
\hline $\begin{array}{l}\text { Upper/Vertical } \\
\text { Surfaces }\end{array}$ & 0.10 & 254657 & 25.5 & $\begin{array}{l}\text { Underneath } \\
\text { Upper/Vertical } \\
\text { Surfaces }\end{array}$ & 0.81 & 254657 & 56.4 \\
\hline Floor Surfaces & 0.132 & 290322 & 100 & $\begin{array}{l}\text { Underneath } \\
\text { Floor Surfaces }\end{array}$ & 82 & 290322 & 28000 \\
\hline \multicolumn{2}{|c|}{ Total Surfaces } & \multicolumn{2}{|c|}{$163.5 \mathrm{mg}$} & \multicolumn{2}{|c|}{ Total Underneath Surfaces } & \multicolumn{2}{|c|}{$33000 \mathrm{mg}$} \\
\hline \multicolumn{4}{|c|}{ Total } & \multicolumn{4}{|c|}{33 grams } \\
\hline
\end{tabular}




\subsection{Conclusion}

General Atomics and INEEL scientists collected dust samples from the DIII-D vacuum during the first days of a vent. Seventeen samples vacuumed onto filters, four samples vacuumed through cascade impactors, and three replicating tape samples were collected from the vacuum vessel. The samples were collected using the same procedures used in the previous sampling of DIII-D, Alcator C-MOD, and TFTR. All of the samples collected at DIII-D were sealed and returned to the INEEL for analysis. Three types of analyses were performed on the samples at the INEEL: BET specific surface area, ICP-MS and SEM/EDS composition, and particle size distribution analysis. Surface area measurements give information important to predicting the chemical reactivity of tokamak dust. Particle size measurements are needed to provide information on the transportation of particulate. We report particle size data as the CMD and GSD when presenting general particle size distribution information and as the $\mathrm{D}_{\mathrm{Mvs}}$ when relating a distribution's specific surface area and particle size. Our compositional analysis helps identify the source of dust and the particle formation mechanisms. Based on our analysis, the following conclusions can be drawn:

- Our BET analysis reported results are based upon three measurements of a sample combined from approximately $75 \%$ of the filter housing samples. The samples were combined to yield a detectable surface area of dust. The combined sample had an average specific surface area of $3.18 \mathrm{~m}^{2} /$ gram from a total sample weight of 0.11 grams. This value is very similar to the value obtained in the 1996 DIII-D dust campaign and is a factor of 2 greater than that for theoretically dense graphite spheres. This indicates that as previously observed, the particulate is not spherical and is composed of agglomerates of smaller particles.

- The particle size distribution analysis results of dust taken from inside the vacuum vessel show a range of CMD values ranging between $0.81 \mu \mathrm{m}$ and $2.89 \mu \mathrm{m}$ with a range of GSD values between 1.33 and 3.43 . $\mathrm{D}_{\mathrm{Mvs}}$ values ranged between 1.1 and $13.3 \mu \mathrm{m}$. The MMD of the particulate was determined from the cascade impactor data. The MMD's were 7.25 $\mu \mathrm{m}$ with a GSD of 1.4 and $5.44 \mu \mathrm{m}$ with a GSD of 2.2. The observed particles appeared in the form of both flakes and spheres. Compositional analysis by SEM/EDS showed individual dust composed of molybdenum, iron, boron, and aluminum. Overall chemical analysis by ICP-MS of the cascade impactor samples and the combined filter housing sample used for BET analysis resulted in a wide variety of material.

- Elemental analysis of the dust indicates that the dust is primarily carbon (30 wt\%) with significant quantities of metal (45 wt $\%$, primarily iron/nickel based alloys). Insulator materials were found in the dust throughout the machine as well as smaller quantities of various elements that are contained in instrumentation and diagnostic components.

- The bulk of the material analyzed was found in lower protected regions of the vacuum vessel. Most of the dust was found under the floor tiles and inside the access ports. Dust concentrations in these locations were between 10 and $100 \mu \mathrm{g} / \mathrm{cm}^{2}$. The smallest quantities of dust were found in the upper vertical locations of the vacuum vessel and on plasma facing surfaces. Dust concentrations in these locations were between 0.01 to $1 \mu \mathrm{g} / \mathrm{cm}^{2}$. Using these dust concentrations and integrating around the vacuum vessel in the general areas sampled, the total quantity of dust that may be 
present in the vacuum vessel could be as low as 30 grams and as high as 90 to 120 grams. 


\section{References}

1 Carmack, W.J., Englehardt, M.E., Hembree, P.B., McCarthy, K.A., and Petti, D.A., "DIII-D Dust Particulate Characterization," INEEL External Report INEEL/EXT-9700702, November 1997.

2 Brunauer, S., Emmett, P.H., and Teller, E., "Journal of the American Chemical Society,"60, 1938, p. 309.

3 Anderl, R.A., Smolik, G.R., Carmack, W.J., Hembree, P.B., Oates, M.A., and Pawelko, R.J. "BET Surface Area Measurements of Materials for Fusion Safety Studies," ITER Engineering Design File ITER/US/97/TE/SA-20, January, 1998.

4 Smolik, G.R., Anderl, R.A., Pawelko, R.J., Carmack, W.J., Hembree, P.B., and Oates, M.A., "BET Surface Area Measurements of Materials for Fusion Safety Studies," 17th IEEE/NPSS Symposium on Fusion Engineering. San Diego, CA, October 6-7, 1997.

5 NIH-Image. Image Processing Software. National Institute of Health. USA (available on the Internet at http://www.rsb.info.nih.gov/nih-image/).

6 Hollander, M. and Wolfe, D.A., "Non-parametric Statistical Methods," John Wiley and Sons, New York, 1973.

7 Hinds, W.C. "Aerosol Technology, Properties, Behavior, and Measurement of Airborne Particles," John Wiley and Sons, New York, NY, 1982, p. 80.

8 Sharpe, J.P., Bourham, M., and Gilligan, J.G., "Generation and Characterization of Carbon Particulate in Disruption Simulations," Presented at the $13^{\text {th }}$ Topical Meeting on the Technology of Fusion Energy, June 7-11, 1998, Nashville, TN, To be published in Fusion Engineering and Design, 1999.

9 ITER Non-Site Specific Safety Report (NSSR-2), December 17, 1997. 